\title{
INNOVATION SNOWBALLING AND CLIMATE LAW
}

\section{ZACHARY LISCOW \& QUENTIN KARPILOW*}

\begin{abstract}
Findings at the frontier of economics suggest startling implications of an under-appreciated fact about technological development: innovation builds on itself, developing path dependencies in which past innovations attract similar, but more advanced, innovations. Innovation snowballs. The world economy needs to undergo a dramatic transformation to avoid the risk of catastrophic effects from climate change. Policy to encourage this transformation should be sensitive to innovation snowballing.

The conventional policy view has long been that, to address a social harm like pollution, the right response is simply to tax the behavior causing the harm, leading to a variety of responses including induced technological change. The Article shows that this view is incomplete. Rather, the most efficient response to climate change-and likely other social harms-requires a combination of taxes and a big push of government support to specifically redirect innovation toward technologies that alleviate social harm. Without a big push in cleantech innovation to change the trajectory of innovation, energy technology will tend to stay trapped in its high-pollution path.

For climate policy and likely other pressing policy issues, the Article suggests a paradigm shift in the role of innovation policy: from broad to targeted. Otherwise, the transition to clean energy will be longer, more expensive, and riskier for the global climate. The Article shows how to efficiently deploy innovation policy to meet this challenge.
\end{abstract}

* Associate Professor, Yale Law School; zachary.liscow@yale.edu. Yale Law School, Class of 2018; quentin.karpilow@yale.edu. We thank Michael Abramowicz, Ian Ayres, Dan Esty, Daniel Hemel, Amy Kapczynski, Doug Kysar, Mark Lemley, David Liscow, Michael Livermore, Jacob Nussim, Lisa Larrimore Ouellette, Ricky Revesz, David Schleicher, Gui Woolston, and participants at the University of Toronto Tax Policy Workshop for helpful comments. Michael Loughlin and Paul Rink provided excellent research assistance. 


\section{TABLE OF CONTENTS}

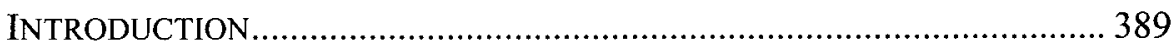

I. INNOVATION AND SOCIAL HARMS: THE CONVENTIONAL

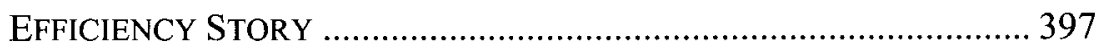

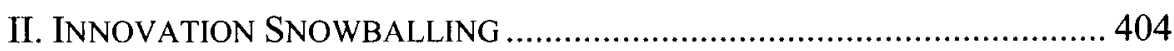

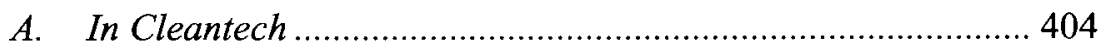

B. When Does Innovation Snowballing Matter? .......................... 414

III. DOMESTIC POLICY ...................................................................... 421

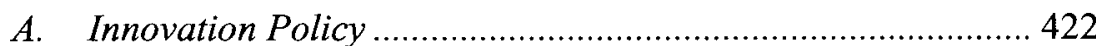

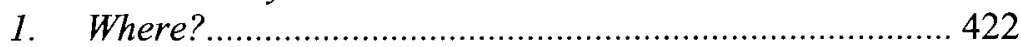

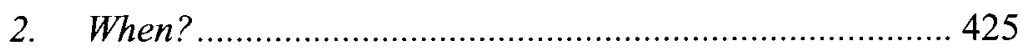

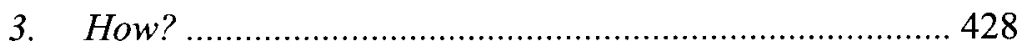

B. Non-Innovation Policy .......................................................... 440

1. Performance Standards ................................................ 440

2. Deployment Subsidies...................................................... 443

3. Government Procurement ............................................... 445

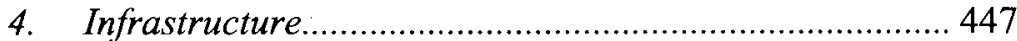

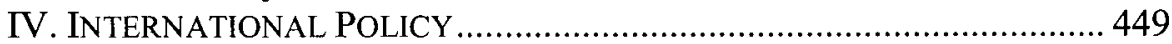

A. Innovation in the International Regime ................................... 449

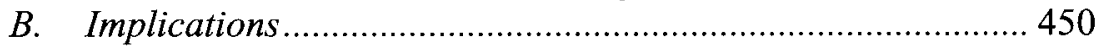

1. The Paris Agreement ..................................................... 451

2. Knowledge Sharing Platforms........................................ 454

3. International Intellectual Property Regime ...................... 456

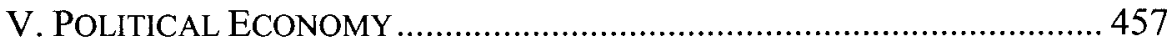

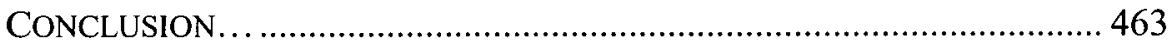




\section{INTRODUCTION}

To address social harms like climate change, government policy should encourage innovation in targeted areas. That's the simple point of this Article. The claim may seem obviously true-for example, that innovation policy should encourage innovations that reduce the risk of climate change over those that exacerbate the problem. But conventional law-andeconomics efficiency analysis opposes policies that seek to specifically incentivize innovation in certain areas, and argues instead that, if a party causes a social problem, the party should be taxed to discourage the activity but should not receive subsidies to develop innovations that would help reduce the social harm. ${ }^{1}$ New economics research overturns this view, based on what we call "innovation snowballing:" innovation builds on itself over time, developing path dependencies in which past innovations make present ones more valuable, with past innovations attracting similar, more advanced innovations. ${ }^{2}$ Thus, to maximize efficiency in the presence of innovation snowballing, innovation policy should target certain areas to address social problems, so that future innovation will follow the path toward reducing those social harms. This Article explains: (1) how conventional efficiency analysis disapproves of targeting innovation to address social problems, (2) why new economics research on innovation snowballing overturns that view, and (3) how policy should respond in the context of climate law - an area where innovation snowballing is particularly significant.

Economic analysts agree that, for innovations that could exacerbate or mitigate a social harm, there are two potential reasons for government intervention. First, since society benefits from innovation to a greater extent than innovators themselves capture (partly because not all ideas can

1. See William Nordhaus, Designing a Friendly Space for Technological Change to Slow Global Warming, 33 ENERGY ECON. 665, 665 (2011) (conducting a traditional efficiency analysis of innovation subsidies in the context of climate change). See, e.g., Jacob Kavkewitz, Jamming the Square Peg Through the Round Hole: EPA's Options for Implementing Efficient Climate Change Regulation Under the Clean Air Act, 4 ARIZ. J. ENVTL. L. \& POL'Y 1001, 1006 (2013) (calling a global cap-and-trade system for carbon the "ideal solution"); Robert N. Stavins, A Meaningful U.S. Cap-andTrade System to Address Climate Change, 32 HARV. ENVTL. L. REV. 293 (2008); Yoram Margalioth, Tax Policy Analysis of Climate Change, 64 TAX L. REV. 63, 63-64 (2010) (framing climate change as an "efficiency problem" that can be solved by equating the private and social costs of greenhouse gases).

2. Daron Acemoglu has pioneered the economics research on innovation snowballing. See, e.g., Daron Acemoglu et al., Transition to Clean Technology, 124 J. POL. ECON. 52, 52 (2016) [hereinafter, Acemoglu et al., Transition]. 
be patented), ${ }^{3}$ innovators produce positive "externalities" for society. ${ }^{4}$ Externalities can be positive (beneficial for society) or negative (harmful for society), and occur when the activities of one party makes another party better or worse off, but the first party does not bear those gains or losses. ${ }^{5}$ Because of these positive innovation externalities, innovation should be subsidized, to encourage the socially optimal amount of innovation. ${ }^{6}$ Technologies that produce social harms like greenhouse gas emissions also produce a second externality: a negative one, since these emissions increase climate risks. ${ }^{7}$ Because of these negative pollution externalities, the government should adopt some form of a carbon tax to discourage pollution.

Though some have argued otherwise, ${ }^{8}$ the conventional view is that these twin externalities-positive for innovation and negative for pollution-are separable, rather than intertwined. In particular, government innovation policy should be equally supportive of privatesector innovation in "cleantech" (technologies with low or no greenhouse gas emissions, like wind and solar) and "dirtytech" (fossil fuel technologies with significant greenhouse gas emissions and associated technologies, like fracking or deep sea oil drilling). ${ }^{9}$ In other words, the

3. See generally Bronwyn H. Hall, Jacques Mairesse \& Pierre Mohnen, Measuring the Returns to $R \& D$, in 2 HAND BOOK OF THE ECONOMICS OF INNOVATION 1033-82 (Bronwyn H. Hall \& Nathan Rosenberg eds., 2010) (reviewing the theoretical and empirical literature on research and development spillovers).

4. Brett M. Frischmann \& Mark A. Lemley, Spillovers, 107 COLUM. L. REV. 257, 257-58 (2007) (discussing intellectual property law and innovation spillovers).

5. Jonathan Gruber, PUblic FinanCe And PUblic POlicy 122 (4th ed. 2013).

6. Daniel J. Hemel \& Lisa Larrimore Ouellette, Beyond the Patents-Prizes Debate, 92 TEX. L. REV. 303, 327 (2013) (explaining the advantages and disadvantages of different innovation instruments in addressing standard innovation spillovers).

7. Intergovernmental Panel on Climate Change, Climate Change 2014 Synthesis REPORT: SUMMARY FOR POLICYMAKERS 6-13 (describing the negative impacts of climate change on ecosystems and societies across the globe); Tamma A. Carleton \& Solomon M. Hsiang, Social and Economic Impacts of Climate, 353 SCI. aad9837-1, aad9837-9-aad9837-10 (2016) (summarizing the empirical literature on the agricultural, economic, health, and social impacts of climate change); COMM. ON ASSESSING APPROACHES TO UPDATING THE SOC. COST OF CARBON ET AL., ASSESSMENT of Approaches to Updating the Social Cost of Carbon: Phase 1 Report on a Near-Term UPDATE 1-2 (discussing estimates of the social cost of carbon, which measures the discounted economic costs of emitting greenhouse gases into the atmosphere).

8. Reuven S. Avi-Yonah \& David M. Uhlmann, Combating Global Climate Change: Why a Carbon Tax Is a Better Response to Global Warming than Cap and Trade, 28 STAN. ENVTL. L.J. 3, 41 (2009) (calling for cleantech tax credits to address the positive externalities associated with research and development); Margalioth, supra note 1, at 88 (arguing that cleantech innovation spillovers justify "subsidies or government grants for research in the area of alternative clean energy sources"); David E. Adelman \& Kirsten H. Engel, Reorienting State Climate Change Policies To Induce Technological Change, 50 ARIZ. L. REV. 835, 847-57 (2008) (justifying the adoption of cleantech innovation policies by states on the existence of positive innovation spillovers).

9. Indeed, legal scholars have long expressed skepticism toward the government "picking winners" to encourage innovation in some technologies over others. See, e.g., Adam B. Jaffe, Richard 
government should not attempt to directly influence the direction of technological development. Rather, it should tax pollution, provide technology-neutral innovation support, and then let the cards lay where they fall, trusting the private sector to respond in the cheapest, most efficient way. By this logic, for example, new wind technologies and new fracking technologies should receive the same government support. The reasoning is simple: the innovation subsidy corrects for the innovation externality, which is produced by both wind and fracking innovation, and the pollution tax corrects for the pollution externality. So there is no need for additional subsidies for cleantech innovation.

This traditional argument is reflected in a wide swath of economic analysis on climate change, as well as an international climate regime that encourages reductions in greenhouse gas emissions, but does not try to do so through targeted innovation. ${ }^{10}$ However, new research shows that this view is misguided and that, as a result, policymakers are failing to use the most efficient, cheapest, quickest, and most effective tools to reduce the

G. Newell \& Robert N. Stavins, A Tale of Two Market Failures: Technology and Environmental Policy, 54 ECOLOGICAL ECON. 164, 169 (2005) ("There is a strong strain in the economic analysis of technology policy of avoiding choosing particular technical areas for support, that is 'picking winners." () (emphasis omitted); RICHARD A. POSNER, CATASTROPHE: RISK AND RESPONSE 160 (2004) (expressing "well known" skepticism about the government picking technological winners); Jonathan H. Adler, Eyes on a Climate Prize: Rewarding Energy Innovation to Achieve Climate Stabilization, 35 HARV. ENVTL. L. REV. 1, 37 (2011) (arguing that the government is ill-equipped to identify and efficiently subsidize promising new technologies); David Weisbach, Designing Subsidies for LowCarbon Energy, 20 J. ENVTL. \& SUSTAINABILITY L. 1, 15 (2013). In the environmental law context, the question of picking winners often comes up implicitly or explicitly in analyses comparing the efficiency of command-and-control regulations and pollution taxes. See, e.g., Bruce A. Ackerman \& Richard B. Stewart, Reforming Environmental Law, 37 STAN. L. REV. 1333, 1342-43 (1985); Richard B. Stewart, Regulation, Innovation, and Administrative Law: A Conceptual Framework, 69 CALIF. L. REV. 1256, 1262-64 (1981); Cass R. Sunstein, Paradoxes of the Regulatory State, 57 U. CHI. L. REV. 407, 420 (1990); Nathaniel O. Keohane, Richard L. Revesz \& Robert N. Stavins, The Choice of Regulatory Instruments in Environmental Policy, 22 HARV. ENVTL. L. REV. 313, 313-14 (1998).

10. See, e.g., Richard J. Pierce, Jr. The Past, Present, and Future of Energy Regulation, 31 UTAH ENVTL. L. Rev. 291, 299-300 (2011); Ann E. Carlson, Designing Effective Climate Policy: Cap-and-Trade and Complementary Policies, 49 HARV. J. Legis. 207, 240 (2012); Richard B. Stewart, A New Generation of Environmental Regulation?, 29 CAP. U. L. REV. 21, 173 (2001); Margalioth, supra note 1, at 63-64; Daniel C. Esty \& Steve Charnovitz, Green Rules to Drive Innovation, HARV. BUS. REV., Mar. 2012, at 121. This conventional view also permeates media portrayals of the global warming problem. See, e.g., David Kestenbaum, Economists Have a One-Page Solution to Climate Change, NPR, (June 28, 2013, 3:46 AM http:/www.npr.org/sections/money/2013/06/28/196355493/ economists-have-a-one-page-solution-to-climate-change; Henry M. Paulson Jr., Opinion, The Coming Climate Crash, N.Y. TIMES, June 22, 2014, at SR1, available at https://www.nytimes.com/2014/06 /22/opinion/sunday/lessons-for-climate-change-in-the-2008-recession.html?_r=0; Paul Krugman, Building a Green Economy, N.Y. TIMES (Apr. 7, 2010), http://www.nytimes.com/2010/04/11/magaz ine/11Economy-t.html; Alan S. Blinder, Commentary, The Carbon Tax Miracle Cure, WALL ST. J. (Jan. 31, 201 1), https://www.wsj.com/articles/SB10001424052748703893104576108610681576914. 
risk of a climate catastrophe. ${ }^{11}$

Specifically, the conventional view misses the dynamics of innovation. ${ }^{12}$ Its understanding of how innovation occurs over time is too simple. In short, it misses innovation snowballing. Suppose that an innovator comes up with a blockbuster technology making solar energy cheaper than energy from fossil fuels. In this scenario, conventional economic analysis assumes that innovation rates in cleantech and dirtytech will remain unchanged. Thus, more solar cells will be produced after the blockbuster innovation, but the breakthrough solar technology does not fundamentally alter the processes underlying innovation in cleantech and dirtytech. As a result, under the conventional framework, innovation in cleantech and dirtytech will chug along at the same pace as if the breakthrough had never occurred.

This conventional assumed response of innovation is likely incorrect. Instead, if there is a blockbuster solar innovation, innovators will flock to solar and away from dirtytech because solar is now the cheapest technology, meaning new solar innovations can be immediately commercialized for a larger number of users. Follow-up solar innovations will only further reduce the costs of solar and attract even more innovators from dirtytech to cleantech, accelerating cleantech innovation even more. Innovation in solar will, in other words, snowball, gathering speed, mass, and momentum as more innovations and innovators gravitate toward the technology with the largest stock of knowledge. ${ }^{13}$ Building upon a few decades of work on the dynamics of innovation, ${ }^{14}$ new research shows

11. Daron Acemoglu et al., The Environment and Directed Technical Change, 102 AM. ECON. REV. 131, 132-33 (2012) [hereinafter Acemoglu et al., Environment and Technical Change]; Acemoglu et al., Transition, supra note 2, at 54-56.

12. This Article can be viewed as a specific application of David Driesen's general critique that economic analysis of environmental law, as well as law more generally, ignores dynamics. See generally DAVID M. DRIESEN, THE ECONOMIC DYNAMICS OF LAW (2012); DAVID M. DRIESEN, THE ECONOMIC DYNAMICS OF ENVIRONMENTAL LAW (2003).

13. This point on path dependence in innovation has parallel observations that some in environmental law and policy have made about technological path dependence resulting from the lockin of dirtytech capital. RICHARD L. REVESZ \& JACK LIENKE, STRUGGLING FOR AIR: POWER PLANTS AND THE "WAR ON COAL" 24-29 (2016) (describing how exemptions of existing power plants from many Clean Air Act emission standards delayed the retirement of dirtytech capital); Emily Hammond \& Jim Rossi, Stranded Costs and Grid Decarbonization, BROOK. L. REV. (forthcoming), available at $\mathrm{http}: / /$ ssrn.com/abstract $=2833870$ (observing that investments in natural gas threaten to lock society into fossil fuels in the mid-term due to the longevity of natural gas infrastructure); Patrick Parenteau \& Abigail Barnes, A Bridge Too Far: Building Off-Ramps on the Shale Gas Superhighway, 49 IDAHO L. REV. 325, 328 (2013) (expressing similar concerns about the path-dependent nature of investing in natural gas production). But the mechanisms for innovation are different than those for capital lock-in, and the implications of the cleantech innovation stock are global in scope and therefore potentially much more significant.

14. For key economics articles see, Paul M. Romer, Endogenous Technological Change, $98 \mathrm{~J}$ POL. ECON. S71, S71 (1990) (linking endogenous growth rates to changes in the stock of human 
how innovation exhibits this path dependence-namely, how a blockbuster innovation in solar can change the course of innovation because innovation builds on itself. ${ }^{15}$ Innovators "stand on the shoulders of giants"-and, under circumstances that this Article explains, they prefer to stand on the tallest shoulders in order to get the quickest, largest financial returns. ${ }^{16}$

This new research has transformational implications for the law, which this Article works out. Most basically, innovation policy should be at the core of environmental policy - and likely other areas of policy as well. In particular, environmental policy should include innovation policy that specifically encourages cleantech, since cleantech innovation needs a big push so that its innovation will snowball beyond that of dirtytech. Due to society's failure to tax greenhouse gas emission for over a century, the accumulation of dirtytech knowledge has far outpaced that of cleantech. ${ }^{17}$ As a result, innovators are in a rut: they gravitate toward dirty technology because it has the largest knowledge stock, having benefitted from dirtytech subsidies as well as the longstanding absence of a carbon tax, and therefore promises the quickest profits. But a big push of government support for innovation in clean energy will catapult innovators out of their dirty energy rut and onto a cleantech path that the planet needs to avoid massive climate disruption.

How policymakers should implement this big push is the topic of the second half of the Article. We explain the implications for three areas of climate policy: domestic innovation policy, domestic non-innovation policy, and international policy.

First, innovation snowballing has several implications for domestic innovation policy in areas touching on climate policy. One key implication is that innovation snowballing reduces the appeal of using intellectual property (IP) to promote cleantech relative to subsidies like prizes,

capital), and Philippe Aghion \& Peter Howitt, A Model of Growth Through Creative Destruction, 60 ECONOMETRICA 323 (1992) (developing of a model of endogenous growth generated by a competitive research sector). See also Suzanne Scotchmer, Standing on the Shoulders of Giants: Cumulative Research and the Patent Law, 5 J. ECON. PERSP. 29 (1991) (applying this line of research to patent law).

15. See Daron Acemoglu, Directed Technical Change, 69 REV. ECON. STUD. 781, 781 (2002) (outlining a theoretical framework for innovation path dependency). For empirical estimates of innovation snowballing, see, for example, Philippe Aghion et al., Carbon Taxes, Path Dependency, and Directed Technical Change: Evidence from the Auto Industry, 124 J. POL. ECON. 1, 1 (2016); W. Walker Hanlon, Necessity is the Mother of Invention: Input Supplies and Directed Technical Change, 83 ECONOMETRICA 67, 67 (2015).

16. Acemoglu, supra note 15 , at 793 .

17. See Acemoglu et al., Transition, supra note 2, at 79-80 (finding empirical evidence of a large gap between cleantech and dirtytech knowledge stocks). 
research grants, and research and development (R\&D) tax credits. Patents and other forms of intellectual property have a main purported advantage of using markets to provide guidance on the value of innovations and main disadvantages of transaction costs and monopoly pricing, making it more difficult to use others' innovations. ${ }^{18}$ Innovation snowballing undercuts the benefits of patents by reducing the utility of market valuation, since markets reflect an uneven playing field created by a century of untaxed greenhouse gas externalities. Additionally, because patents hinder the use of others' innovations, they slow the snowballing process. As a result, innovation snowballing makes patents a less compelling tool for spurring cleantech innovation. We suggest a cleantech $R \& D$ tax credit as a possibly useful tool in this context.

Innovation snowballing also undercuts some long-held views about the structure of domestic innovation subsidies. For example, conventional wisdom calls for subsidizing research on basic science over $R \& D$ on products closer to commercialization because research on basic science is least likely to be provided by the private sector. ${ }^{19}$ However, a compelling reason to subsidize late-stage $R \& D$ is that its contribution to path dependence can be more easily discerned, unsettling the conventional preference for basic science. Path dependence also emphasizes the value of prioritizing increases in $R \& D$ spending over reductions in emissions in the short term, as the sooner society closes the innovation gap between cleantech and dirtytech, the sooner private-sector innovation will flow to cleantech without government support. In other words, in the short term, innovation snowballing argues for prioritizing technological development alongside (and to some extent instead of emissions reductions to achieve a long-term goal of greater emissions reductions.

Innovation snowballing also offers guidance on what types of innovations should be prioritized: in particular, those that build up the cleantech innovation stock. Innovation snowballing makes two types of innovations less appealing than they would otherwise seem: first, innovations that make dirtytech cleaner, like improvements in the

18. Steven Shavell \& Tanguy van Ypersele, Rewards Versus Intellectual Property Rights, 44 J.L. \& ECON. 525, 525-27 (2001) (describing the debate between patents and rewards); Benjamin N. Roin, Intellectual Property Versus Prizes: Reframing the Debate, 81 U. CHI. L. REV. 999, 999 (2014); Amy Kapczynski, The Cost of Price: Why and How to Get Beyond Intellectual Property Internalism, 59 UCLA L. REV. 970, 974-75 (2012) (discussing both the dominant view of intellectual property and the "long and important tradition of dissent").

19. David Popp, Induced Innovation and Energy Prices, 92 AM. ECON. REv. 160, 177 (2002); Richard R. Nelson, The Simple Economics of Basic Scientific Research, 67 J. POL. ECON. 297, 302 (1959); Hall, Mairesse \& Mohnen, supra note 3, at 1051 (summarizing several empirical studies showing that the social returns to research are higher for basic than for applied or development research). 
efficiency of the internal combustion engine or carbon capture and sequestration; and second, innovations that produce low-emissions cleantech but help build up the stock of dirtytech innovations, such as biomass energy, which builds on and contributes to combustion technologies. Both types involve innovations that may further entrench dirty fossil fuel energy sources. ${ }^{20}$ Innovation snowballing offers a reason to focus on technologies, like wind and solar, that especially build up cleantech and not dirtytech - though, of course, the Article cannot solve the difficult technical questions about what role various technologies should play in the future energy mix.

Second, innovation snowballing draws into question long-held views about the value of domestic non-innovation policies - or policies that are not necessarily designed specifically to spur innovation, but may nonetheless produce innovation effects. For example, some performance standards, such as those for fuel economy, induce technological development, but in ways that may make dirtytech cleaner rather than cleantech cheaper. ${ }^{21}$ By contributing to the dirtytech knowledge stock, these regulations run the risk of being counter-productive, as they can perversely entrench dirtytech. Innovation snowballing likewise unsettles conventional views about deployment subsidies, such as those for installing solar panels or buying electric vehicles, which are generally regarded as bad policies by economists. ${ }^{22}$ This Article does not take a stand on whether such subsidies should be adopted; however, the existence of innovation snowballing makes them more valuable than generally recognized because they induce innovation and can thus have longstanding impacts in shifting the innovation equilibrium. ${ }^{23}$ Conversely, subsidies for fossil fuels are even worse than generally recognized because they widen the innovation gap between cleantech and dirtytech. Similarly, infrastructure spending is even more consequential than is generally

20. See infra Section III.B.1.

21. For a review of the technology forcing nature of these fuel economy standards, see Ian Ayres \& Amy Kapczynski, Innovation Sticks: The Limited Case for Penalizing Failures to Innovate, 82 U. CHI. L. REV. 1781, 1815-17 (2015). In 2010, EPA and the National Highway Traffic Safety Administration (NHSTA) finalized a joint rule setting fuel economy and greenhouse gas emission standards for model year 2012 through 2016. See Light-Duty Vehicle Greenhouse Gas Emission Standards and Corporate Average Fuel Economy Standards, 75 Fed. Reg. 25,324, 25,324 (May 7, 2010 ).

22. Robert W. Hahn, Climate Policy: Separating Fact from Fantasy, 33 HARV. ENVTL. L. REV. 557,580 (2009) (arguing that subsidies are not well-suited for incentivizing cleantech innovation); Lawrence H. Goulder \& Ian W. H. Parry, Instrument Choice in Environmental Policy, REV. ENVTL. ECON.\& POL'Y 152, 155-157 (2008) (observing that subsidies can induce excessive output).

23. Popp, supra note 19 , at 160 (providing empirical evidence of induced innovation in the context of energy technologies). 
regarded. For example, while we do not take a stand on whether building Keystone XL and fracking infrastructure are good ideas, ${ }^{24}$ they are likely worse than conventional law and economics analysis suggests, since they will not only lock in dirtytech infrastructure but also induce more dirtytech innovation.

Third, the Article draws out a parallel set of implications in the international arena. The current international climate regime fails to sufficiently encourage the switch to cleantech. It encourages reductions, but-beyond what is provided by patents-does not give countries "credit" for reductions in ways that will redirect technological development toward cleantech to benefit the whole world. ${ }^{25}$ It leaves proverbial low-hanging fruit on the table, failing to seize one of the cheapest means to achieve climate stabilization: innovations that help make the shoulders of cleantech giants taller (i.e., more profitable) than those of their dirtytech competitors. We suggest that the next round of international negotiations could disproportionately incentivize reductions through innovation rather than through production cutbacks or the adoption of existing technology, since innovation doubly benefits the world-through innovation snowballing and reduced pollution.

While this Article primarily argues for increased use of innovation tools to combat climate change as a matter of economics, political economy considerations reinforce this recommendation. First, innovation commits future and foreign governments to emissions reductions in a way that carbon taxes or agreements to reduce emissions in the short-term do not. Cleantech innovation cannot be repealed while a carbon tax can. Also, cleantech innovation policy helps build a political constituency for a carbon tax and reduces the cost of adopting one, suggesting-with some historical support-that innovation policy can help lead to the adoption of a carbon tax..$^{26}$

This Article proceeds as follows. Part I explains the reasoning behind the conventional view that a carbon tax would induce an efficient amount of innovation. Part II introduces innovation snowballing, explaining how it upends the conventional view. Parts III and IV examine how innovation

24. See generally Parenteau \& Barnes, supra note 13, at 326-29 (outlining the pros and cons of natural gas infrastructure).

25. U.N. Conference of the Parties, Adoption of the Paris Agreement, U.N. Doc. FCCC/CP/2015/L.9/Rev.1 (Art. 10) (Dec. 12, 2015); Annalisa Savaresi, The Paris Agreement: A New Beginning?, 34 J. ENERGY \& NAT. RESOURCES L. 16, 16 (2016) (providing an overview of the Agreement).

26. See Jonas Meckling et al., Winning Coalitions for Climate Policy, 349 SCl. 1170,1170 (2015) (finding that nearly two-thirds of climate pricing regimes were preceded by either a renewable portfolio standard or a feed-in tariff for cleantech). 
snowballing affect the merits of policy options at the domestic and international level. Part V discusses political economy considerations.

\section{INNOVATION AND SOCIAL HARMS: THE CONVENTIONAL EFFICIENCY STORY}

In conventional economics, the story of innovation and social harms like climate change is rarely laid out in a clear manner, but is implicit nonetheless in much of the existing legal and economic scholarship. It is a story of two externalities - one from the production of innovation, the other from the production of a social harm like pollution. ${ }^{27}$ Within the conventional framework, each externality operates on a separate, parallel track: there is no interaction between the two issues and each externality is solved independently.

The first externality results from "innovation spillovers." Without any government intervention to promote innovation, society will produce an inefficiently small amount of innovation, as a result of innovators' inability to capture the full value of their investments in research and development, which results in innovation spillovers benefitting other innovators. ${ }^{28}$ While creating new ideas can be quite costly, appropriating new ideas that others have produced can be relatively cheap. So, in the absence of intellectual property, there are strong incentives to free ride: non-innovators may just use innovators' ideas without compensating the original innovator. As a result, many innovators will not put forth the effort to create new inventions, even when they create great social value. ${ }^{29}$

Intellectual property solves part of this problem, but not all of it. ${ }^{30}$

27. Jaffe, Newell \& Stavins, supra note 9, at 164 (describing the conventional economic analysis of cleantech innovation).

28. For the classic article on the welfare implications of innovation spillovers, see Kenneth $J$. Arrow, Economic Welfare and the Allocation of Resources for Invention, in THE RATE AND DIRECTION OF INVENTIVE ACTIVITY; ECONOMIC AND SOCIAL FACTORS 609 (Nat'l Bureau of Econ. Research ed., 1962).

29. Adam B. Jaffe, Richard G. Newell \& Robert N. Stavins, Technological Changes and the Environment, in HANDBOOK OF ENVIRONMENTAL ECONOMICS 461, 471 (K.G. Mäler \& J.R. Vincent eds., 2003) (noting that knowledge spillovers to freeriding firms and consumers can lead to "significant underinvestment by private firms in R\&D, relative to the social optimum")

30. Empirical evidence on whether strong patent protection boosts innovation is mixed. For a brief review of this work, see Keishun Suzuki, Economic Growth Under Two Forms of Intellectual Property Rights Protection: Patents and Trade Secrets, 115 J. ECON. 49, $50-51$ (2015). In addition, it is also worth noting that nearly all IP rights are time limited, meaning that non-innovating firms can benefit from a new invention twenty years down the line. Kenneth Gillingham \& James Sweeney, Market Failure and the Structure of Externalities, in HARNESSING RENEWABLE ENERGY IN ELECTRIC Power Systems: Theory, Practice, Policy 69, 78 (Boaz Moselle, Jorge Padilla \& Richard Schmalensee eds., 2010). 
Intellectual property creates incentives for innovators to produce new ideas by forcing users of those ideas to pay the creators. ${ }^{31}$ However, not all new knowledge is patentable. ${ }^{32}$ As a result, economists estimate that there are large spillovers of value from innovation activity-with the innovators themselves only capturing at most half of the benefits of their innovation. ${ }^{33}$ These innovation spillovers take a variety of forms. At the R\&D stage of innovation, for example, knowledge can "leak" to competitors as scientists switch firms. ${ }^{34}$ Reverse engineering, technical conferences, and publications in academic journals have also been identified as conduits for innovation spillovers. ${ }^{35}$ And as a new technology moves toward commercialization, non-innovators may benefit from a variety of learningby-doing effects-that is, efficiency improvements that arise when a firm accrues experience in producing a technology. ${ }^{36}$ To the extent that noninnovators can appropriate this experiential knowledge, innovation leaders will see their returns to innovation siphoned off by their competitors (free of charge) ${ }^{37}$ The result of these spillovers is that, even with intellectual

31. See e.g., Joseph E. Stiglitz, Economic Foundations of Intellectual Property Rights, 57 DUKE L.J. 1693, 1699-1700 (2008); Hemel \& Ouellette, supra note 6, at 327-28.

32. For example, tacit knowledge is difficult to patent because, by definition, it is difficult to capture in writing. See David B. Audretsch \& Maryann P. Feldman, Knowledge Spillovers and the Geography of Innovation, in 4 HANDBOOK OF REGIONAL AND URBAN ECONOMICS 2713, 2718-19 (J.V. Henderson \& J.F. Thisse, eds., 2004).

33. Careful surveys of the empirical literature find that the social rates of return to research and development (which tend to cluster between thirty percent and seventy percent) are two to five times greater than corresponding private rates (which often range between six percent and fifteen percent). See Gillingham \& Sweeney, supra note 30, at 78; Hall, Mairesse \& Mohnen, supra note 3, at 1050-51. If social rates of return are at least twice the corresponding private rate, then private innovators capture at most half of the benefits from innovation. See also Charles I. Jones \& John C. Williams, Measuring the Social Rate of Return to R\&D, 113 Q. J. ECON. 1119, 1119-21 (1998) (using a macroeconomic growth model to conclude that the true social rates of return from R\&D are at least two to four times greater than private returns).

34. See Amar Bhide, How Entrepreneurs Craft Strategies that Work, 72 HARV. BUS. REV. 150, 151 (1994) (finding that seventy-one percent of founders of fast-growing start-up companies reported replicating or modifying "an idea encountered through previous employment"). Econometric analyses similarly identify interfirm mobility as an important conduit for knowledge diffusion. See, e.g., Mika Maliranta et al., Is Inter-Firm Labor Mobility a Channel of Knowledge Spillovers? Evidence from a Linked Employer-Employee Panel, 18 INDUS. \& CORP. CHANGE 1 161, 1161-62 (2009); Paul Almeida \& Bruce Kogut, Localization of Knowledge and the Mobility of Engineers in Regional Networks, 45 MGMT. SCI. 905, 905-07 (1999).

35. See Nordhaus, supra note 1, at 666 (discussing the role of conferences and journals in diffusing new ideas); Hall, Mairesse \& Mohnen, supra note 3 (same).

36. Economists have shown that learning processes play a key role in reducing the production costs of new technologies. See, e.g., Richard McDowell, Learning by Doing and Spillovers in Renewable Energy: Evidence from U.S. Wind and Solar Farms 2 (Mass. Inst. of Tech., Working Paper, 2015) (noting that learning-by-doing has yielded productivity gains in "numerous industries, including shipbuilding, vehicle and airplane manufacturing, and the production of semi-conductors").

37. While there are strong theoretical reasons for thinking that learning-by-doing externalities exist, economists have struggled to develop precise estimates of them. See Gillingham \& Sweeney, supra note 30 (discussing the econometric difficulties in empirically identifying learning-by-doing 
property protections, innovators will not produce the socially efficient amount of innovation. For innovations that would benefit society but are relatively costly to produce, many innovators will not be compensated enough by the private returns to their intellectual property alone to justify the investment.

To address those spillovers, additional subsidies are needed to encourage innovators to produce new ideas up to the efficient amount. For example, if a new idea produces benefits of $\$ 100$ to society, but the innovator only captures $\$ 50$ of value (through patents, for example), then basic economic theory calls for a government subsidy of $\$ 50$. These subsidies could take various forms, including research and development tax credits ${ }^{38}$ prizes, grants, and direct government funding of research. ${ }^{39}$ With the subsidies and the private returns, innovators will have the proper incentives to develop socially beneficial innovations.

Innovation externalities may occur with or without a second externality: a social harm, like pollution, that results from consuming and producing a product. Since the classic negative externality is pollution, we will call this the "pollution externality." In the context of climate change, a factory produces greenhouse gas emissions, increasing the risk of climate change, but does not pay for the social harm caused to others. There are also many externalities in public health, for examle: if someone spreads a disease to others, he has imposed a negative externality on them. Even income inequality can be viewed as an externality: if an employer pays her impoverished workers more, and society generally wishes to reduce poverty or income inequality, then the employer has imposed a positive externality on the general population, making them better-off without receiving any compensation from them.

In areas with pollution externalities, there is a standard response that parallels the response to innovation externalities: a tax corresponding to the size of the externality. So, for example, if a polluter causes a harm of $\$ 50$, then it should pay a fee of $\$ 50$. That way, the polluter will have the proper incentive to reduce pollution, since - with the fee - the polluter will pay the full social cost of polluting. ${ }^{40}$

The central question of this Article is: if innovation in general is

externalities).

38. I.R.C. $\S 174$ (2015) (expensing of research and experimental expenditures); I.R.C. $\S 41$ (2015) (credit for increasing research activities).

39. See SUZANNE SCOTCHMER, INNOVATION AND INCENTIVES 32 (2006).

40. See, for example, ChaRLES D. KOLSTAD, ENVIRONMENTAL ECONOMICS (2009), for a discussion of this so-called "Pigouvian taxation." 
properly incentivized through intellectual property and technology-neutral subsidies, and if those causing social harms are fined by the amount of harm that they are causing, is there any reason to additionally encourage innovation to address the social harm? That is, should innovation policy treat innovations that mitigate social harms (e.g., cleantech or a vaccine) differently from those that do not (e.g., dirtytech or a new computer gaming app for smartphones)? So, taking the example of pollution, if the government already (1) provides $\$ 1$ in innovation subsidies for every $\$ 1$ of positive innovation spillovers, and (2) taxes polluters $\$ 1$ for every $\$ 1$ of social harm from their greenhouse gas emissions, is there any additional reason to subsidize innovation in cleantech?

It may seem intuitive that subsidies to innovate should be higher where the innovations will help mitigate a social harm. Increasing subsidies for cleantech innovation might seem appealing because it results in two benefits: promoting innovation spillovers as well as reducing pollution. ${ }^{41}$ But conventional efficiency analysis rejects this line of thinking. (The Online Appendix ${ }^{42}$ shows these results mathematically.) Under the conventional approach, to address pollution or other social harms, it is most efficient to encourage those causing the harm to take the most costeffective means of reducing it. A polluter may have many means of reducing pollution in response to a newly imposed pollution fee. It could shut down, reduce production, or switch to an existing, lower-pollution technology. Or it could innovate new cleantech: and, indeed, innovation (called "induced innovation") does result from taxing social harms like pollution. ${ }^{43}$ Assuming that the government provides technology-neutral innovation subsidies that account for innovation externalities in general, the polluter is already properly incentivized to produce efficient levels of cleantech. Any increases in the subsidy for cleantech innovation would result in too much innovation, because it would induce some polluters to produce expensive cleantech innovations when they could have achieved the same emissions reductions at a lower cost through other means. Thus, the conventional view is that, to solve the social problem of climate change, the necessary and sufficient condition is to tax the activity causing the social harm, so long as innovation overall is properly incentivized

41. Margalioth, supra note 1 , at 88 (justifying "subsidies or government grants for research in the area of alternative clean energy sources" on the existence of standard innovation spillovers); Joshua D. Sarnoff, Government Choices in Innovation Funding (With Reference to Climate Change), 62 EMORY L.J. 1087-94 (2013) (motivating an analysis of cleantech innovation funding with a discussion of standard innovation spillovers).

42. The Online Appendix to this Article is available at https://sites.google.com/site/liscow/

43. David Popp, Innovation and Climate Policy, 2 ANN. REv. ResourCe ECON. 275, 280-83 (2010) (summarizing the empirical literature on environmental policy and induced innovation). 
through a technology-neutral innovation subsidy.

The conventional efficiency story identifies a parallel risk where the government seeks to spur cleantech innovation by increasing its pollution tax beyond the level equal to the social harm caused by the pollution. Again, it may seem that this policy would result in two benefits: less pollution and more innovation spillovers because of the induced innovation. But this policy will cause some polluters to inefficiently adopt expensive existing technologies or cut back on production when innovating new cleantech is actually the cheapest way to reduce emissions, yielding inefficiently expensive increases in innovation. ${ }^{44}$

Thus, according to conventional analysis, the most efficient way to reduce pollution is to tax pollution in accordance with the uncaptured harm it causes. And the most efficient way to encourage innovation is to subsidize innovation in accordance with the uncaptured spillover benefits it produces. The two policies operate on parallel, non-interacting paths. And no further government intervention would be efficient.

In practice, the subsidy for innovation spillovers or the tax on the social harm may be suboptimal (the Online Appendix develops results under these circumstances). In that case, the conventional analysis does not hold, and a variety of "second-best" policies (i.e., policies that are good to adopt when the "first-best"-i.e., optimally efficient-option is not available) would be desirable. ${ }^{45}$ For example, if there is an insufficiently high pollution fee, then increasing cleantech innovation subsidies will help pick up the slack by encouraging innovation that would have been induced by the ideal pollution fee. Similarly, if there are insufficiently high innovation subsidies in general, then increasing the pollution fee also helps pick up the slack by inducing some innovation that would have been incentivized by the ideal innovation subsidy. But these are just second-best policies. This Article focuses on first-best policies, asking: in the best of all worlds, what policies should be adopted to maximize efficiency? For that, the conventional efficiency argument remains: reduce pollution by taxing pollution and encourage innovation by subsidizing innovation.

Many reasons beyond efficiency may justify addressing social harms by encouraging innovation. For example, implementation difficulties could drive increased subsidization. Consider the case of vaccines. Fining people for spreading disease would cause people to demand vaccines, inducing innovation. But imposing such a fine would be very difficult. So,

44. See Online Appendix, supra note 42 .

45. R. G. Lipsey \& Kelvin Lancaster, The General Theory of Second Best, 24 REV. ECON. STUD. 11,11 (1956) (introducing the theory of second-best). 
directly subsidizing innovation in vaccines may very well be the best feasible policy. Alternatively, one might believe that people have a right to a vaccine, justifying government spending on vaccines for reasons beyond economic efficiency.

But this Article focuses on an economic efficiency justification for targeting innovation to solve social problems. ${ }^{46}$ And currently the views of efficiency-oriented scholars on how to address climate change-the focus of this paper-reflect the views implied by conventional economic thinking. For example, environmental law casebooks barely mention innovation policy. ${ }^{47}$ The policy discussion addressing climate change overwhelmingly focuses on a carbon tax or a cap-and-trade scheme, rather than on subsidizing innovation in cleantech. ${ }^{48}$ Implicit or explicit in these analyses is the belief that pollution pricing alone will induce optimal amounts of cleantech innovation, assuming a backdrop of optimal general innovation policy. ${ }^{49}$ In other words, innovation problems are seen as

46. Of course, there are important differences between well-being and efficiency, especially in contexts involving individuals of different income levels. See Zachary Liscow, Is Efficiency Biased?, Yale Law and Economics Research Paper No. 581 (2017), available at https://ssm.com/abstract=3018 796 (explaining the differences between efficiency and well-being).

47. We checked eight of the most prominent environmental law casebooks by searching for the term "innovation" in the table of contents and for the terms "innovation," "invention," and "technology" in the index. Although all mention technology-forcing regulations (though generally in a cursory way), none has a substantial discussion of innovation policy. For example, only HUNTER ET AL. infra, even mentions intellectual property directly. See ZYGMUNT PLATER ET AL., ENVIRONMENTAL LAW \& POLICY: NATURE, LAW, AND SOCIETY 178-79, 507-12 (5th ed. 2016); David hunter et al., INTERnational EnVIRONMENTAl LaW \& POLICY 80-83, 1296-99 (5th ed. 2015); Richard Revesz, ENVIRONMENTAL LAW AND POLICY 176, 547 (3rd ed. 2015); RoberT Percival et al., EnVironmental Regulation: Law, Science and Policy 161-64, 555 (7th ed. 2013); Holly DOREMUS ET AL., ENVIRONMENTAL POLICY LAW 35, 698, 705-09 (6th ed. 2012); ROBERT GLICKSMAN ET AL., ENVIRONMENTAL PROTECTION: LAW AND POLICY (6th ed. 2011); LINDA Malone \& William TaBB, Environmental LaW, Policy, And Practice 362, 373, 378, 381,482, 829 (2nd ed. 2011); J. B. Ruhl et al., The Practice and Policy of Environmental LaW 195-98, 211,229 (2nd ed. 2010).

48. See, e.g., Kestenbaum, supra note 10 (quoting economist Henry Jacoby of MIT as claiming that climate change can be solved by taxing carbon emissions); Paulson Jr., supra note 10 (arguing that the solution to climate change is putting a price on carbon dioxide emissions); Krugman, supra note 10 (framing climate change as "a classic negative externality"). See also Louis Kaplow \& Steven Shavell, On the Superiority of Corrective Taxes to Quantity Regulation, 4 AM. L. \& ECON. REV. 1, 1 (2002).

49. Alex Rice Kerr, Why We Need a Carbon Tax, 34 EnVIRONS ENVTL. L. \& POL'Y J. 69, 75 (2010) (explaining why a carbon tax is better than other policy instruments at bringing about "a clean tech revolution"); Pierce, supra note 10, at 307 (recognizing that "[o]ur only hope of mitigating global warming lies in major technological breakthroughs," but focusing solely on a carbon tax as the mechanism for bringing about these needed technology advancements); Jonathan $M$. Gilligan \& Michael P. Vandenbergh, Accounting for Political Feasibility in Climate Instrument Choice, 32 VA. ENVTL. L.J. 1, 23 (2014) (observing that "[c]ap and trade programs and carbon taxes emerge as the optimal remedy in the economics and legal literatures" for addressing climate change); Roberta Mann, How to Love the One You're With: Changing Tax Policy To Fit Cap-and-Trade, 2 SAN DIEGo J. Climate \& ENERGY L. 145, 156, 161-62 (2010) (characterizing a carbon tax as the optimal policy response and concluding that pricing carbon is more efficient than subsidizing particular sources of 
derivative of the unaddressed pollution problem. As a result, addressing the negative externalities associated with greenhouse gas emissions is assumed to also address the cleantech innovation problem.

Of course, we are not the first to suggest that policy should specifically encourage cleantech innovation. ${ }^{50}$ Many of the early modern environmental regulations were "technology-forcing," designed specifically to encourage innovation..$^{51}$ For example, in the Clean Air Act and the Clean Water Act, Congress mandated that regulated entities adopt the "Best Available Technology" (BAT) for pollution control. ${ }^{52}$ Because such technologies do not need to be commercially available (or even in existence) at the time of promulgation, ${ }^{53}$ they were expected to push the boundaries of technological progress by requiring industry to invent and install increasingly effective pollution-control equipment. ${ }^{54}$ More recently, some policy groups have proposed a "moonshot" 55 in clean energy. ${ }^{56} \mathrm{But}$ a

energy, without acknowledging separate innovation justifications for innovation subsidies).

50. Bruce A. Ackerman \& Richard B. Stewart, Reforming Environmental Law: The Democratic Case for Market Incentives, 13 COLUMBIA J. OF ENVTL. L. 171, 174 (1988). Others have made similar critiques on the basis of integrated assessment models failing to allow for endogenous technological change, instead of assuming a constant rate that does not allow for transformative technological change. See Douglas A. Kysar, Commentary, Politics by Other Meanings: A Comment on "Retaking Rationality Two Years Later," 48 Hous. L. REV. 43, 57-66 (2011) (noting, among other things, that the social cost of carbon used in climate assessment models is built around marginal changes that assume away transformative technological change). However, we are the first to walk through the new economics framework of path dependent innovation and apply them to the spectrum of environmental policy options.

51. See D. Bruce La Pierre, Technology-Forcing and Federal Environmental Protection Statutes, 62 IOWA L. REV. 771, 771 (1977) (documenting how the environmental statutes of the 1970 s sought to protect public health, spur technological advancements in pollution control technologies, and induce industry to accept the costs of pollution control equipment).

52. See, e.g., 42 U.S.C. $\$ 7411(\mathrm{a})(1)(\mathrm{C})(2012)$ (Clean Air Act); 33 U.S.C. $\S 1316(\mathrm{a})(1)$ (Clean Water Act).

53. See Portland Cement Ass'n v. Ruckelshaus, 486 F.2d 375, 391 (D.C. Cir. 1973). See also Sierra Club v. Costle, 657 F.2d 298, 364 (D.C. Cir. 1981) (holding that pollution standards promulgated under section 111 of the Clean Air Act can still be lawful even if industry cannot meet them using existing technology).

54. See Sunstein, supra note 9, at 420 (observing that the "BAT strategy is motivated by a desire to produce technological innovation"). For defenses of technology-based regulation, see Sidney A. Shapiro \& Thomas O. McGarity, Not So Paradoxical: The Rationale for Technology-Based Regulation, 1991 DUKE L.J. 729, 751 (1991) (arguing for technology standards primarily on the basis of a non-efficiency based normative goal - in particular, "that society should do the best it can to protect workers, even when" traditional efficiency analysis would reject the measure), and Howard Latin, Ideal Versus Real Regulatory Efficiency: Implementation of Uniform Standards and "FineTuning" Regulatory Reforms, 37 STAN. L. REV. 1267, 1270-73 (1985) (arguing that the efficiency benefits of market-oriented reforms may be more theoretical than realized).

55. A "moonshot" refers to a big, government-supported push in innovation like sending a human to the moon.

56. See Alisha Fowler, Gore Issues 'Moon Shot' Call, BrEAKTHRough InST. (July 17, 2008), https://thebreakthrough.org/archive/gore_issues_moon_shot_call; Andrew C. Revkin, Opinion, Bill 
cleantech moonshot has lacked an efficiency argument for its adoptionuntil now.

\section{INNOVATION SNOWBALLING}

\section{A. In Cleantech}

The problem with the conventional story is that, in the presence of a carbon tax or other tax on a social harm, it treats all current innovations as if they will have the same impact on future innovations. As this Part explains, that is probably a poor prediction. In the conventional story, innovation spillovers benefit the rest of society by helping them innovate. But there is no account of what future innovators will produce in response to earlier innovations. This Part explains "innovation snowballing," the process by which earlier innovations can lead to similar but more advanced innovations, causing a snowballing of innovation in a particular technology area, like cleantech.

With the innovation spillovers that innovation policy scholars are used to considering, innovators benefit one another because each individual innovator is unable to reap the full rewards from her innovations. This feature captures an important part of the innovation process, but not the whole story. Another feature of innovation is path dependence, in which the innovation choices of past innovators influence the types of innovation pursued by future innovators. Path dependence does not necessarily directly benefit innovators. Rather, it redirects innovators toward the types of technologies with the larger stock of knowledge by changing the relative profitability of different types of technologies. Redirecting technological development toward cleantech may not increase the profitability of innovating or producing in the energy sector (and thus may not lead to innovation spillovers), but it does reduce pollution externalities. Thus, with innovation snowballing the population at largenot the innovators themselves-gain from technological development with social benefits like lower pollution externalities. And unlike spillovers,

Gates's Clean-Energy Moon Shot, N.Y. TimEs (Feb. 23, 2016), https://www.nytimes.com/2016/02/23/ opinion/bill-gatess-clean-energy-moon-shot.html. And, of course, many academics recognize the importance of innovation to solving climate change. See, e.g., Daniel C. Esty, Rethinking Global Environmental Governance to Deal with Climate Change: The Multiple Logics of Global Collective Action, 98 AM. ECON. REV, 116, 119 (2008); NICHOLAS STERN, STERN REVIEW: THE ECONOMICS OF Climate CHANGE (2007); Adelman \& Engel, supra note 8, at 835 (arguing that state policymakers should focus primarily on innovation-related market failures while the federal government should be primarily responsible for addressing the negative externalities of greenhouse gas emissions); Felix Mormann, Requirements for a Renewables Revolution, 38 ECOLOGY L.Q. 903, 903 (2011) (explaining why carbon pricing will not induce optimal cleantech innovation levels). 
innovation snowballing does justify encouraging cleantech innovation even in the presence of an optimal carbon tax and optimal general innovation policy. In particular, new economic research suggests that there are substantial social welfare gains to encouraging clean technology innovation specifically, along with a carbon tax. ${ }^{57}$ Innovation snowballing resuscitates early environmental law's goals (though not its means) of using policy to encourage the development of certain pollution-reducing technologies.

Today's innovators "stand on the shoulders" of yesterday's innovators. ${ }^{58}$ Pick almost any technology, and it will be the combination of a myriad of innovations developed across many years. There would be no Uber, for example, without the invention of GPS. There would be no electric car without the invention of the battery. Innovation is a cumulative process whereby past innovations create new opportunities for future innovations. All else equal, innovating in technologies with small knowledge stocks (e.g., cleantech) will tend to be less productive and less profitable than innovating in technologies with large knowledge stocks (e.g., dirtytech). As a result, profit-seeking innovators naturally gravitate towards technologies with the most productive knowledge base-and therefore the greatest expected returns to research and development investments. ${ }^{59}$ Innovation therefore begets more innovation, creating path dependencies and inertia in the direction of technological change. A corollary to this insight is that society will sometimes continue to innovate in certain technologies, even after it becomes clear that superior alternatives exist. Economists have been working with the "standing-onshoulders" idea for a few decades now. ${ }^{60}$ What's new is working out the implications of the path dependence where the dominant existing technology produces big negative externalities, like greenhouse gas emissions. The result of innovation snowballing is that the innovation system has multiple possible technology equilibria - and that major interventions can shift the system to a different equilibrium by altering the relative productivity of different lines of research. ${ }^{61}$

57. Acemoglu et al., Environment and Technical Change, supra note 11, at 313 .

58. Acemoglu, supra note 15, at 793; Romer, supra note 14; Aghion \& Howitt, supra note 14; JOHN R. HICKS, THE THEORY OF WAGES 124-25 (1932) (discussing how changes in the relative prices of production factors directs innovation flows).

59. Acemoglu et al., Transition, supra note 2, at 53; Popp, supra note 43, at 280-81; Jaffe, Newell \& Stavins, supra note 29 , at 469-71.

60. Romer, supra note 14; Aghion \& Howitt, supra note 14; Scotchmer, supra note 14.

61. See, e.g., John J. Donohue III \& James Heckman, Continuous Versus Episodic Change: The Impact of Civil Rights Policy on the Economic Status of Blacks, 29 J. ECON. LiTERATURE 1603, 1639 
The concept can perhaps be best understood through the example of VHS and Betamax, two competing video format technologies in the 1970s and 1980s. ${ }^{62}$ For what many think were largely idiosyncratic reasons, VHS won out over Betamax, despite there being little inherent advantage of one over the other ${ }^{63}$ As a result, VHS technology kept on advancing, while Betamax did not. But imagine that society later discovered that VHS, but not Betamax, produced a big negative externality. This is essentially the story of energy technology: fossil fuels have benefited from decades of innovation, which largely explains why they are cheaper than clean energy. ${ }^{64}$ Unless the VHS externality posed an immediate threat, the best way to switch from VHS to Betamax would not be to suddenly apply a large tax on VHS - that would inefficiently lead to a surge in consumer prices for VHS. Rather, as we show below, the solution would be to subsidize innovation (in concert with a modest tax) so that the stock of Betamax innovation could catch up with the stock of VHS innovationresulting in companies eventually choosing to invest in the Betamax technology by virtue of both the price signal and the stock of innovation that enables it to be made cheaply and with high quality.

Figure 1 depicts in a simplistic fashion the decision-making tendencies of private innovators in a world of path dependence, contrasting the outcomes with and without government intervention in cleantech innovation. To distill innovation snowballing to its conceptual core, the Figure ignores a host of complexities, including unpredictability and varying productivity of innovations, to just name two simplifications. ${ }^{65}$ Figure 1 portrays innovations as blocks that build on each other, either dirtytech (depicted with dashed black lines) or cleantech (depicted with diagonal solid green lines). For simplicity, suppose that there exist two types of production, clean and dirty, and both produce essentially the same thing: ${ }^{66}$ electrons flowing through wires. Each innovation reduces the cost

(1991) (describing multiple equilibria in the case of race relations).

62. Michael A. Cusumano et al., Strategic Manewvering and Mass-Market Dynamics: The Triumph of VHS over Beta, 66 BUS. HIST. REV. 51, 51 (1992) (providing a detailed description of this competition).

63. W. Brian Arthur, Positive Feedbacks in the Economy, 262 SCI. AM. 92, 92 (1990).

64. Acemoglu et al., Transition, supra note 2, at 79-80 (finding empirical evidence of a large gap between cleantech and dirtytech knowledge stocks).

65. Furthermore, the relevant comparison is often between the cost of producing energy with existing installations of dirtytech versus with new installations of cleantech. It is typically cheaper to produce energy with existing installations because the cost of installation has already been borne. But, to achieve large reductions in greenhouse gas emissions, there will likely need to be large shutdowns of existing dirtytech installations, requiring that cleantech installation is cheaper not only than new installations of dirtytech but also than existing installations.

66. In reality, they are not literally the same; for example, the timing of electricity production can vary, with solar producing little electricity at night. 
of electricity generation by some amount. The higher the stack of innovation blocks, the more advanced, the cheaper, and the more profitable electricity is to produce with the technology. The cost of developing electricity with the technology is depicted on the vertical axis, with lower costs at the top and higher costs at the bottom, reflecting how costs of production go down as innovation blocks go up. The private innovator, whose block is located at the top of the panels, has to decide whether to invest in cleantech or dirtytech.

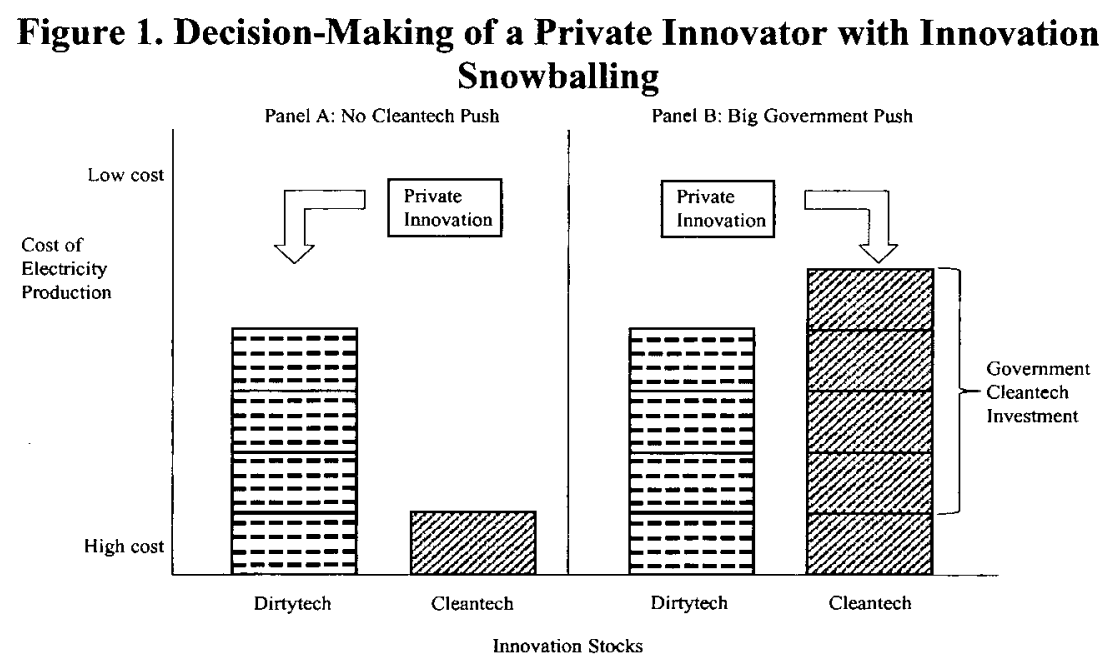

Panel A depicts the decision-making of a private innovator with no cleantech subsidy from the government. Under these circumstances, there are four dirtytech blocks (with dashed black lines) and only one cleantech block (with diagonal solid green lines), reflecting the reality that dirtytech has a century head start on cleantech. As a result of this disparity in knowledge stocks, dirtytech produces electricity at a much lower cost than cleantech, even in the presence of a carbon tax. Consider the incentives facing the profit-maximizing innovator. She knows that she can immediately commercialize an innovation in dirtytech because it would reduce the cost of the already-cheapest form of electricity-producing technology. Thus, she can profit in the near term. In contrast, if she innovates in cleantech, profiting in the near term is less likely. A single innovation-i.e., a single innovation block-will not be enough for cleantech to overtake dirtytech as the cheapest form of energy production in the short run. Instead, energy producers will continue to rely on dirtytech-and the cleantech innovator will receive little for her efforts. 
Faced with such incentives, then, the profit-maximizing innovator will likely invest in dirtytech, thereby further increasing its profitability and entrenching its dominance. Of course, in a more complex model, some innovators will have such brilliant cleantech innovations that they will invest in cleantech even if the product would be far from commercialization, but the overall tendency will be for innovators to invest in the cutting-edge dirtytech technology, where they can earn profits now.

Panel B shows the results when there is a "big push" of governmentencouraged cleantech innovation. Under this scenario, the government adds a large stock of cleantech innovation (four additional innovation blocks), thereby making cleantech cheaper than dirtytech. The whole reasoning then reverses: it becomes more profitable to invest in cleantech innovation than dirtytech innovation, meaning that subsequent innovations will flow without government support to cleantech. This government intervention pushes the innovation market over its "tipping point," after which the self-perpetuating nature of innovation will drive cleantech growth. ${ }^{67}$

While Figure 1 shows the decision-making of a single innovator at a point in time, Figure 2 shows the results of aggregating many innovators across time, contrasting how the stock of cleantech and dirtytech innovation evolve over time under the same two scenarios of no government intervention and a big cleantech push. The stocks are plotted on the vertical axis and time is plotted on the horizontal axis. As in Figure 1 , the dirtytech stock is depicted in dashed black lines and the cleantech stock is depicted in solid green lines.

In Panel A, again with no government intervention, the stock of dirtytech innovation initially exceeds that of cleantech innovation. In the absence of a government intervention, the stock of dirtytech innovation grows more quickly than the stock of cleantech innovation, since private innovators will tend to innovate in the more profitable cutting-edge technology. The cleantech innovation stock still grows because there are still some very good investments worth pursuing, but since only the very best innovations are pursued, the stock grows slowly. As a result of the slower innovation rate for cleantech, the two innovation stocks diverge, with dirtytech's stock pulling ever further ahead of cleantech.

67. Aghion et al., supra note 15 , at $37 \mathrm{n} .38$ (describing this tipping point as the "point at which the market starts innovating more in clean technologies than in dirty technologies without policy intervention [because] the clean technology is more productive than the dirty technology"). 
Figure 2. Innovation Stock Over Time with Innovation Snowballing

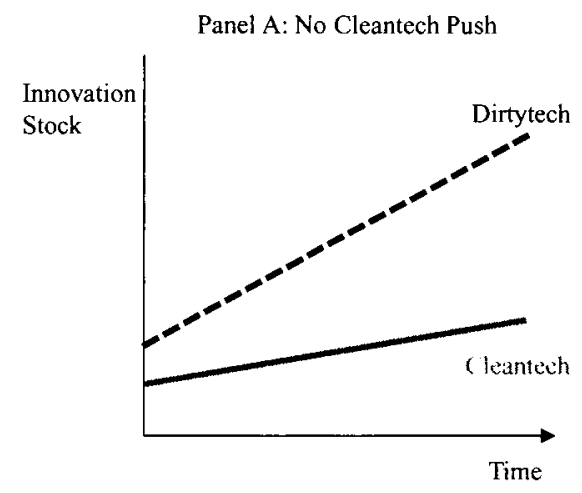

Panel B: Big Government Push

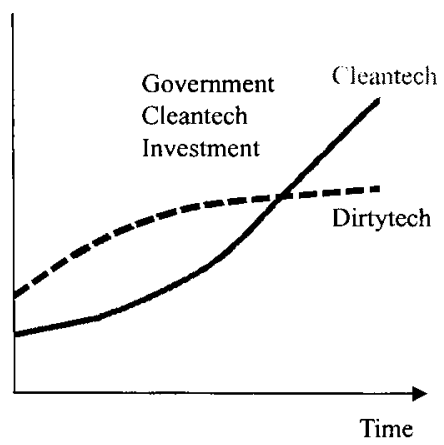

Reaching the tipping point is key for the long-term impact of the intervention. If the government cleantech investment only leads to the point at which cleantech has eighty percent of the stock of dirtytech, cleantech will grow at a faster rate than it would have otherwise; however, with time, the dirtytech stock will still diverge from the cleantech stock because innovators will still tend to gravitate toward the cutting-edge technology of dirtytech. A modest intervention helps but does not achieve the key benefit, which is that after passing the tipping point, the private sector will gravitate toward cleantech and the cleantech stock will diverge from the dirtytech stock without additional government intervention.

Reality differs in many ways from these stylized diagrams. First, and perhaps most importantly, we depicted innovation as a deterministic process, when it is, in fact, highly stochastic. Even without a big government push (Panel $\mathrm{A}$ in both figures), random shocks of genius may make a particular clean technology the lowest-cost option for some period of time. Alternatively, unforeseen external factors, such as the 1970s oil crisis, may dramatically alter the innovation investment calculus. The figures also do not capture real world variation across geographies and sectors. Without a big government push, cleantech innovators may find profitable market segments for their inventions, such as electricityconstrained Hawaii. ${ }^{68}$ Thus, just because dirtytech has a head start up the

68. Island economics favor the deployment of rooftop solar. See Davide Savenije, Hawaii Provides U.S. Utilities a Glimpse of the Future, UTILITY DIVE (Jun. 11, 2014), http://www.utilitydive.com/news/hawaii-provides-us-utilities-a-glimpse-of-the-future/272824. See also Gregory C. Unruh, Escaping Carbon Lock-In, 30 ENERGY POL'Y 317, 321-22 (2002) (discussing how inventors have used specialized niche markets to develop and grow new technologies). 
innovation ladder does not imply zero innovation in cleantech. However, notwithstanding the stochastic nature of innovation, the figures still capture the general tendency for innovators to flow towards technologies with the greatest knowledge stock - and thus the highest average returns on R\&D-when choosing between cleantech and dirtytech. In other words, there is some small chance that a blockbuster clean energy technology will arise by chance, obviating any value in government intervention - but that is unlikely to happen, leaving the expected general tendencies in the future as the basis for government policymaking.

Of course, innovators will pursue more profitable innovations before they engage in less profitable ones, likely leading to declining marginal returns to innovation. ${ }^{69}$ However, declining returns do not undo the impact of innovation snowballing, which works by shifting up the returns of the range of possible innovations available to innovators. That is, even if there are declining returns among the innovations available, those returns are higher with a bigger stock of existing knowledge. As a result, there is still a suboptimal "bias" towards investing in dirtytech innovation. Thanks in part to the absence of a carbon tax over the past century, the historical stock of innovation in dirtytech has made commercialization easier for dirtytech than cleantech. Put differently, dirtytech entrepreneurs benefit from a century's worth of intertemporal knowledge spillovers, while cleantech innovators only benefit from a few decades of past innovation. Importantly, this bias remains even after policymakers implement a carbon $\operatorname{tax}$.

A general subsidy for innovation would also fail to correct this problem. Under a policy aimed at addressing innovation spillovers (Section I), both dirtytech and cleantech would receive some support, since neither industry fully captures the social value of their R\&D. But such a policy would be suboptimal because it does not account for the historical advantage that dirty innovation has over clean innovation. Nor would increasing the size of a carbon tax be as good of a policy as specifically encouraging cleantech innovation through subsidies, for the reasons described in Section I. Increasing the carbon tax encourages more cleantech innovation, but also reduces output and causes a shift to loweremission but more expensive dirty technologies, which harms consumers and fails to produce the innovation needed to reach the innovation tipping point and redirect private innovators toward cleantech.

69. Popp, supra note 19 , at 163 (finding empirical evidence of declining marginal returns to energy research); David Popp, ENTICE: Endogenous Technological Change in the DICE Model of Global Warming, 48 J. ENVTL. ECON. \& MGMT. 742, 749 (2004) ("Empirical work suggests that there are diminishing returns to energy research over time."). 
Innovation snowballing is more than just a theory. Recent quantitative work suggests it is an empirical reality. Economist David Popp, for instance, finds that the propensity to innovate in a given energy-efficient technology increases with the number of prior patents filed for each technology, indicating that energy innovators do, in fact, stand on the shoulders of past entrepreneurs, leading to innovation snowballing. ${ }^{70}$ Other research shows that oil shocks increase innovation in energy-saving technology like air conditioners and that the switch toward more innovation in energy-saving technology persists after the end of the oil shock. ${ }^{71}$ Path dependency also characterizes the trajectory of clean automobile innovations. In particular, a team of researchers led by Harvard economist Philippe Aghion shows that, when fuel prices increase, innovation rates in cleantech (e.g., hybrid and electric vehicles) increase and that these increased rates are self-perpetuating, while innovation rates in dirtytech (the internal combustion engine) decrease. ${ }^{72}$ Firms with a history in clean auto innovation are much more likely to channel their future research efforts towards clean technologies. ${ }^{73}$ The same is true for firms with histories in dirty car technologies. A firm's future research agenda depends not only on its own innovation history, but also on those of its neighbors: a company's propensity to innovate in clean (dirty) technologies increases if they are situated in countries where other firms focus more on clean (dirty) automobile innovation. Put differently, firms that are exposed to clean (dirty) innovation spillovers are more likely to engage in clean (dirty) innovation in the future. ${ }^{74}$

Nor is path dependency unique to energy innovation. Empirical work, for example, has demonstrated that innovation snowballing affects the direction of pharmaceutical inventions. ${ }^{75}$ And one carefully conducted

70. Popp, supra note 19 , at 161 .

71. Richard G. Newell, Adam B. Jaffe \& Robert N. Stavins, The Induced Innovation Hypothesis and Energy-Saving Technological Change, 114 Q.J. ECON. 941, 971 (1999) (showing that oil price spikes biased innovation in air conditioning towards producing more energy efficient units); Popp, supra note 19 , at 160 (demonstrating that higher energy prices directed innovation towards energysaving inventions).

72. Aghion et al., supra note 15 , at 1 .

73. Id. at 63 .

74. Research suggests that standard innovation spillovers and innovation snowballing interact with each other. Some evidence suggests that cleantech tends to have significantly larger standard spillovers than dirtytech, since larger standard spillovers imply more innovation snowballing. See Antoine Dechezleprêtre, Ralf Martin \& Myra Mohnen, Knowledge Spillovers from Clean and Dirty Technologies 3 (Ctr. for Econ. Performance, Discussion Paper No. 1300, 2014) ("We find consistent evidence that clean patents generate larger knowledge spillovers than their dirty counterparts.").

75. Daron Acemoglu \& Joshua Linn, Market Size in Innovation: Theory and Evidence from the Pharmaceutical Industry, 119 Q.J. ECON. 1049, 1084 (2004). 
study by economist Walker Hanlon provides strong empirical evidence that path dependency shaped the historical evolution of textile technologies. ${ }^{76}$ In particular, the American Civil War cut off the supply of American cotton, leading demand to temporarily shift to lower-quality Indian cotton. That temporary shock caused a jump in innovations for processing Indian cotton, which, in turn, made the quality of Indian cotton as good or better than American cotton. As a result, the impacts of the temporary innovation shock lasted past the end of the Civil War. Innovations in the technologies for processing Indian cotton continued to increase, alongside demand for Indian cotton, even after American cotton became available again. ${ }^{77}$

Scholars have also mapped out the innovation stocks of a wide array of different technologies in an analysis of 1.8 million U.S. patents and their citations. ${ }^{78}$ Consistent with the theory of innovation snowballing, they find that technology classes with more past innovations tend to innovate more. ${ }^{79}$ Indeed, variation in technologies' previous patenting activity (i.e., patent rates among "upstream" technologies) explains more than half of the aggregate variation in present patenting activity across different technology classes. This result suggests that the size of a technology's knowledge stock is highly determinative of that technology's future innovation trajectory. ${ }^{80}$

To some, the implications of innovation snowballing may seem unintuitive and to others, obvious. Whatever one's reaction, the structure of the analysis is profoundly different from conventional economics. In the conventional story, a new technology can reduce the cost of producing cleantech. But the key piece that the conventional story misses is the dynamics: how that new technology not only lowers cleantech production costs today but draws in future cleantech innovators, progressively shifting production toward cleantech, creating a snowball effect. Those new innovators are drawn in because, as cleantech becomes cheaper to produce, future innovations are closer to commercialization and profitability. Furthermore, as cleantech becomes cheaper and closer to becoming the cutting-edge technology, more people will use the technology, increasing the scale over which cleantech innovators can deploy their innovation and make a profit. Once cleantech surpasses the

76. Hanlon, supra note 15 .

77. Id.

78. Daron Acemoglu et al., Innovation Network 1 (Nat'l Bureau of Econ. Research, Working Paper No. 22783, 2016), http://www.nber.org/papers/w22783.

79. $I d$.

80. Id. 
tipping point of being the cheapest energy technology, cleantech innovation will snowball at a greater rate than dirtytech-thereby ensuring a virtuous cycle. The conventional story entirely misses these dynamics. Rather, it treats technological progress as if - once there is a breakthrough technology in solar that makes it cheaper to produce energy from the sun than from fossil fuels-technological progress will continue as if no such breakthrough had occurred and entrepreneurs would continue innovating in dirtytech at the same rate, even once it has been overtaken by solar. If policy is driven by this conventional economic view, the government loses the opportunity to push toward the tipping point and thereby efficiently and cheaply deploy the private sector to achieve greater gains for environmental quality at lower cost.

Recently, MIT economist Daron Acemoglu and his coauthors have explored the implications of innovation snowballing for climate policy. Based on empirical estimates of recent innovation activity, they find that the cost of relying on a carbon tax alone, and not encouraging cleantech through subsidies, is very large, amounting to costs equal to 1.9 percent of consumption globally. This loss translates to approximately $\$ 1.42$ trillion a year - or roughly a tenth of total U.S. GDP ${ }^{81}$ Notably, this welfare loss arises from addressing innovation snowballing with a second-best policy (carbon taxes) instead of an optimal instrument (research subsidies). If policymakers ignored innovation snowballing altogether, and devised a climate plan that solely focused on the negative externality of carbon pollution, the efficiency loss would be substantially greater. ${ }^{82}$

The best estimates suggest that global government R\&D spending on cleantech is far from optimal. Acemoglu and coauthors estimate that government spending should account for roughly ninety percent of cleantech $R \& D$ funding ${ }^{83}$ - a far cry from the current state where only forty-three percent of spending comes from the public sector. ${ }^{84}$ And,

81. To arrive at this number, we take 1.9 percent of world GDP, which is approximately $\$ 75$ trillion. See Acemoglu et al., Transition, supra note 2, at 56.

82. Moreover, while Acemoglu's framework accounts for the path dependency of innovation, it does not model the standard innovation spillovers described in Section II.A. Indeed, R\&D subsidization in Acemoglu's model is motivated entirely by (1) the global costs of carbon, and (2) the path dependency of innovation. Id. at 55 . As a result, the cost estimates only reflect the efficiency gains that come from addressing the historical bias in cleantech and dirtytech knowledge stocks. Correcting for standard innovation spillovers-and suboptimal subsidies to address them-would therefore further add to this $\$ 1.42$ trillion in efficiency gains.

83. Id. at 63,86 fig.6. Figure 6 shows the optimal research subsidy starting at ninety percent today.

84. Angus MCCrone et aL., U.N. Environment Programme, Global Trends in RENEWABLE ENERGY INVESTMENT 2015, 73 fig.55 (2015) (reporting government spending on renewable energy technologies). 
according to a number of studies, government spending on cleantech R\&D - which currently totals about $\$ 18$ billion per year worldwide ${ }^{85}$ falls far short of needed levels. A recent report by the International Energy Agency, for example, estimated that global public expenditures on clean energy innovation would need to increase between two- and five-fold in order to maintain global warming below two degrees Celsius. ${ }^{86}$ Other researchers have reached similar conclusions using different models and alternative assumptions. ${ }^{87}$ Thus, the scope for addressing innovation snowballing in cleantech through increased public R\&D spending appears significant.

\section{B. When Does Innovation Snowballing Matter?}

This application of innovation snowballing to climate change begs the question: when does innovation snowballing justify government intervention? Nearly any line of technology can, in theory, experience innovation snowballing, since the accumulation of knowledge could increase the productivity and profitability of most technologies. ${ }^{88}$ However, government intervention is not necessarily efficient whenever one technology's knowledge stock is bigger than another's. Instead, government should only direct innovation away from one technology and towards another if two specific requirements are satisfied: there is a policy

85. Estimates vary depending on the data source, year, and definition of clean technology R\&D. According to a 2016 report published by Mission Innovation (see below for more details), the twentyone participating countries spent a total of $\$ 14.69$ billion per year on clean energy $R \& D$. The report claimed that this amount represented at least eighty percent of all related spending, which would put total global public expenditures on clean energy R\&D at roughly $\$ 18.4$ billion. MISSION INNOVATION SECRETARIAT, BASELINE, DOUBLING, AND NARRATIVE INFORMATION SUBMITTED BY MISSION INNOVATION COUNTRIES AND THE EUROPEAN UNION 2, 109 (2016). Another estimate suggests that Organisation for Economic Cooperation and Development (OECD) countries spent about $€ 14$ billion (\$19 billion US) on climate mitigation research and development in 2011. See ANTOINE Dechezleprêtre et al., Climate Change Policy, Innovation and Growth 17 (Grantham Research Inst., London Sch. of Econ. 2016). However, OECD countries increased their spending on cleantech R\&D in response to the worldwide financial crisis. Id.

86. See TOM KerR \& JoAna Chiavari, InT'L Energy Agency, Global GaPS in Clean ENERGY RESEARCH, DEVELOPMENT, AND DEMONSTRATION 14 (2009).

87. Most analyses suggest that optimal government investments in clean energy R\&D are between two and ten times current public spending levels. See id. at 52 tbl.28 (Table 28 synthesizes estimates of the cleantech R\&D investments needed to address climate change from a number of prominent studies). To be clear, these estimates represent the additional R\&D spending that must either be induced from the private sector (e.g., through a carbon tax) or supplied directly by the government (i.e., to address knowledge spillovers). As such, they do not identify how much of the needed R\&D investment would be induced by an optimal carbon tax, and how much must come from government coffers.

88. And indeed, Acemoglu and company's careful analyses of 1.8 million U.S patents find strong evidence of path dependence across a wide range of different technologies. See Acemoglu et al., Transition, supra note 2, at 1. 
reason to redirect investment (the "ends condition"), and the government has the ability to redirect innovation efficiently (the "means condition"). In developing these criteria, we are the first to digest this economic theory into implications for broader innovation policy.

First, there must be a policy rationale for switching the innovation ladder from one set of technologies to another, typically a historically untaxed externality that both leads to underinvestment in innovation in one area and constitutes a reason to encourage innovation in that area. ${ }^{89}$ This is the "ends condition." In the case of climate change, untaxed pollution externalities have yielded a huge amount of induced innovation in dirtytech that places it far ahead of cleantech in the innovation race. ${ }^{90}$ Innovation can build in one particular direction for many reasons. In the case of Betamax, for example, innovation arguably gravitated towards VHS for largely idiosyncratic reasons. ${ }^{91}$ However, in the absence of an externality, society as a whole has little reason to redirect innovation back toward Betamax. ${ }^{92}$ In contrast, the same pollution externalities that gave dirtytech an advantage over cleantech also provide a clear policy rationale for directing future innovation towards cleantech and away from dirtytech, even once a carbon tax is in place. ${ }^{93}$

Second, for the most effective interventions, the government must have the ability to redirect technological development through a limited intervention, after which the private sector will continue in the desired direction. This is the "means condition." The key feature here is the degree

89. There need not be an externality involved. Idiosyncratically, innovation could take a direction that turns out to be inefficient. But making a compelling argument along those lines would be very difficult, as it would require arguing that a set of technologies that has not yet been developed would be more efficient than the direction that the free market took-without a reason like externalities to point to. See S.J. Liebowitz \& Stephen E. Margolis, Path Dependence, Lock-In, and History, 11 J.L. ECON. \& ORG. 205, 205-206 (1995) (discussing the difficulties in identifying instances where historical contingencies working in tandem with path dependency lead to inefficient market equilibria).

90. Acemoglu et al., Transition, supra note 2, at 79-80 (estimating a significant gap in cleantech and dirtytech knowledge stocks).

91. Arthur, supra note 63 , at 92 .

92. Notably, society's failure to tax carbon is the sole justification for the efficiency of an innovation subsidy in Acemoglu's model. See Acemoglu et al., Transition, supra note 2.

93. The technology trees between the two (or more) different technologies also need to be distinct, as it is not possible to direct technology in one particular direction if the technologies build on the same innovation stock. In the context of cleantech and dirtytech, however, evidence suggests that they are largely distinct. JOELLE NOAILLY \& VICTORIA SHESTALOVA, CPB NETH. BUREAU FOR ECON. POL'Y ANALYSIS, ON WHICH TECHNOLOGIES DO RENEWABLE ENERGY INNOVATIONS BUILD ON? 1 (2013) (finding few spillovers between renewable and fossil-fuel technologies in a patent citation analysis); Rob Aalbers et al., Innovation Policy for Directing Technical Change in the Power Sector, 63 ENERGY POL'Y 1240, 1243 (2013) (reviewing empirical studies that indicate that cleantech builds largely on prior cleantech inventions). 
of substitutability between the current technology (e.g., dirtytech) and the desired technology (e.g., cleantech). By substitutability, we mean the degree to which two goods are interchangeable. ${ }^{94}$ Substitutability allows technological development to be highly skewed in one particular direction. If two products are effectively identical in terms of services provided, then consumers can easily flock to the cheapest one. A high degree of substitutability therefore creates vastly greater potential for a one-time intervention to push a new technology over a tipping point. Once the costs of the emergent technology fall below those of the dominant technology, consumers will quickly switch to the new technology, bringing with them new private-sector innovation that will spur even greater cost declines, even after the public-sector push has abated. Equivalently, one can think of high substitutability as moving innovation closer to a zero-sum game. If two technologies are perfect substitutes, then one technology's gain (in terms of new adoptees) is the other's loss, since both are competing for the same pool of customers. In contrast, if the two technologies provide entirely unrelated services, then one technology's gain has no bearing on the other technology's market share. ${ }^{95}$ In the former instance, a government push can redirect customers from one technology to another; in the latter case, government subsidization of one technology will not attract customers from the other.

Table 1 provides examples of technology pairs that satisfy or fail to satisfy the means and ends conditions. The top right box represents the case where the ends condition but not the means condition is met. Consider the competition between innovation in malaria medication and hair loss medication. Suppose that the government wants to correct a strong unwarranted bias in the innovation system in favor of hair loss pills (a medication of the rich) instead of malaria pills (a medication of the poor). ${ }^{96}$ The "externality" in this case could be conceptualized as the

94. Acemoglu et al,, Environment and Technical Change, supra note 11, at 133 (explaining substitutability in this context).

95. Acemoglu describes substitutability as the key factor that trades off competing factors: the price effect vs. the market size effect. See Acemoglu, supra note 15, at 783. See also Acemoglu et al, Environment and Technical Change, supra note 11 , at 132 . The price effect directs innovation to areas where the price of the output good is high. That is, if it costs a lot to make something, the correspondingly high prices drive innovators to work in that area to reduce costs and thereby reap profits. On the other hand, large market sizes-and therefore a large number of customers -also attract more innovation, since the innovators can benefit from selling to more people. It is the substitutability of the targeted innovation sector that determines which of the two effects will dominate. When there is relatively high substitutability, as between cleantech and dirtytech technology, the price effect matters relatively little, since there is little reason to invest in an expensive technology when there is a close substitute for it; instead, the market size effect dominates. Id.

96. This hypothetical set-up has roots in the real world. Bill Gates and others have criticized the marketplace for skewing research funding towards male baldness research and away from malaria 
public's preference for innovation that is broadly equitable across the income distribution. So, the ends condition is satisfied.

\section{Table 1. When Innovation Snowballing Justifies Government Intervention}

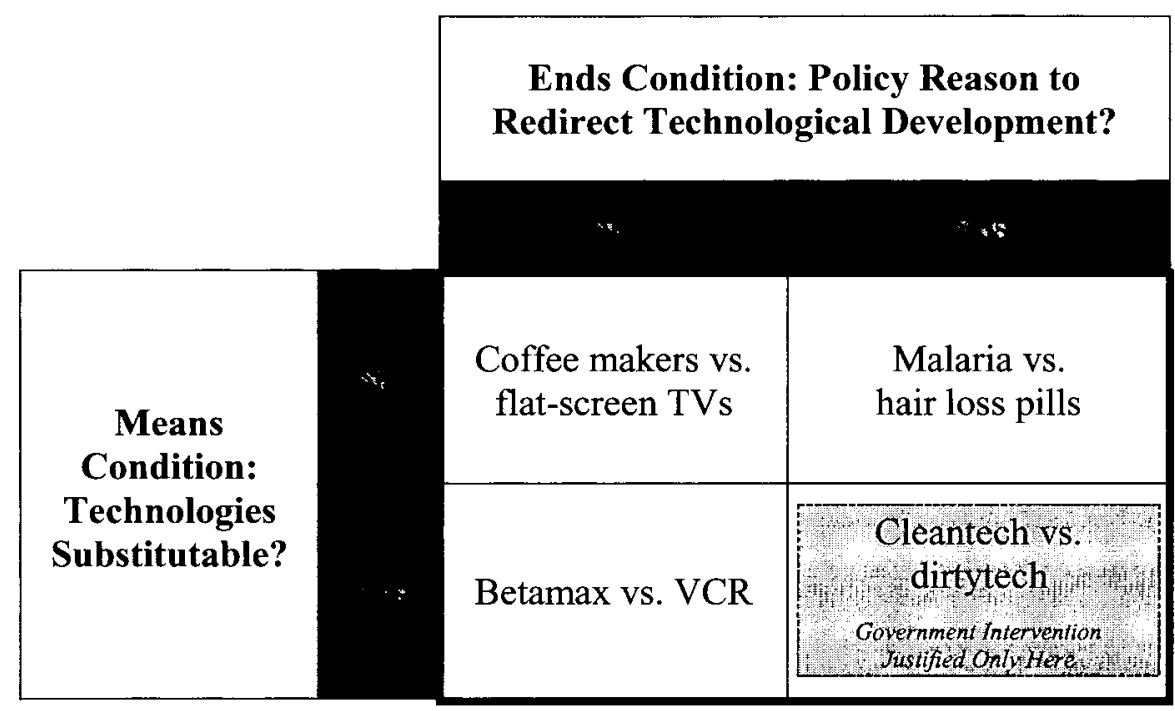

But the means condition is not satisfied. In the case of cleantech, once the government has a big push, the grid can largely switch over to cleantech because both cleantech and dirtytech produce a nearly identical final good: energy. Of course, cleantech and dirtytech are not perfectly substitutable. There are, for example, intermittency problems with solar and wind, which, in turn, makes battery technology an important part of the cleantech technology ladder. ${ }^{97}$ Irrespective of this imperfect substitutability, cleantech is far more substitutable for dirtytech than malaria pills are for hair loss pills. If there were a big push in malaria medication, malaria medication would not "overtake" hair loss pills; rather, both would continue being produced even after the big push, since

vaccine studies. See Olivia Solon, Bill Gates: Capitalism Means Male Baldness Research Gets More Funding Than Malaria, WIRED (Mar. 14, 2013), http:/www.wired.co.uk/article/bill-gates-capitalism.

97. Steven Chu \& Arun Majumdar, Opportunities and Challenges for a Sustainable Energy Future, 488 NATURE 294, 300 (2012) (underscoring the need to develop storage technologies to address the intermittency problems of renewable energy technologies like solar). 
a reduction in the cost of malaria pills will only marginally affect the demand for hair loss pills. In other words, the value of the government's trying to redirect technological development is quite small in this scenario because the means condition is not satisfied.

Now consider the bottom left corner, where the means but not the ends condition is satisfied. The competition between Betamax and VCR is a good example of this square. Betamax and VCR are quite substitutable, so a government intervention making Betamax the better, cheaper technology would redirect innovation away from VCRs and toward Betamax (though Betamax would need to become good enough and cheap enough to also overcome the issue that people already had large supplies of VCR tapes, an issue not relevant for electricity production, since cleantech and dirtytech produce the same electrons). However, the ends condition is not satisfied, since most people believe that there is no societal justification for the government to intervene in favor of Betamax. Owning a VCR does not harm others. Nor are the benefits of Betamax innovation more equitably distributed across the income distribution than those associated with VHS. The choice between DVDs and VCRs, or between LCDs and cathode ray tubes for TVs, may also belong in this box: they are substitutable, but there is little reason to redirect research.

The top left corner represents those cases where neither the means nor the ends condition is satisfied. One can imagine a host of fanciful combinations of goods and services that are not substitutes and do not provide a policy rationale for switching from one to another: coffeemakers and flat-screen TVs, diapers and laser jet printers, sunscreen and impotence drugs, umbrellas and dog leashes (indeed, these last two are probably complements rather than substitutes).

It is only the bottom right corner, which includes the race between cleantech and dirtytech, that has the means and ends conditions satisfied: there is a reason to redirect because of the pollution externality and the means to do so because cleantech and dirtytech are substitutable. Determining where else innovation snowballing justifies government intervention will require more work. No other area has the breadth of documentation on the environmental externalities or the amount of path dependence. ${ }^{99}$ That said, one tentative area for consideration might be the

99. The field of climate change science has been growing at an exponential rate. For example, according to one careful analysis of more than 220,000 research publications on global warming, the total number of peer-reviewed climate papers doubles every 5-6 years. See Robin Haunschild et al., Climate Change Research in View of Bibliometrics, 11 PLOS ONE 1, 1 (2016). On the other hand, only a few studies have empirically documented innovation snowballing outside of the climate-energy context. See, e.g., Acemoglu \& Linn, supra note 75 (providing empirical evidence of directed technical change in pharmaceutical research); Hanlon, supra note 15 (providing empirical evidence of 
choice between innovation that makes labor more productive versus innovation that makes capital (i.e., machines) more productive. Similar to the hair loss-malaria example, the "externality" in this case can be considered a preference that the public has for relative income equality. Capital and labor are fairly substitutable ${ }^{100}$ _at least robotic drivers can more easily replace human drivers than malaria medication can replace hair loss medication. So, there is an externality and moderately high substitutability. Furthermore, some believe that, as capital has become more abundant in recent decades, ${ }^{101}$ the benefits to investing in making capital more productive may have expanded accordingly. In other words, path dependency seems to characterize the development of labor- and capital-augmenting technologies. Taken together, these considerations would suggest that innovation policy might consider favoring laboraugmenting policies (e.g., apps to call human drivers or rooftop solar, which involve lots of relatively low-income laborers) over capitalaugmenting policies (e.g., robotic drivers or improvements in nuclear energy, which largely increase returns to capital). Of course, this example is highly speculative. Knowing the ultimate economic incidence of innovation is very difficult. And, it is not even clear that the technology ladders of "labor-tech" and "capital-tech" are distinct, which is of course also a prerequisite. ${ }^{102}$ After all, if labor-tech and capital-tech build on the same innovation stock, the government cannot possibly redirect innovation from one to the other. But we offer this example to illustrate the other kinds of innovation policy that might be implicated, without making any concrete recommendations.

In cleantech and perhaps in other areas where these two conditions are satisfied, there is a strong case for government intervention to redirect technological intervention on the basis of innovation snowballing. Of course, our argument does not eliminate many of the traditional critiques of government policies encouraging the development of certain

path dependent innovation in textile technologies).

100. Daron Acemoglu, Why Do New Technologies Complement Skills? Directed Technical Change and Wage Inequality, 113 Q.J. ECON. 1055 (1998); Acemoglu, supra note 15, at 804.

101. Thomas PIKeTty, Capital IN THE TwENTy-First CENTURy 25-26 (Arthur Goldhammer trans., 2014).

102. For example, it is unclear whether robots are labor-augmenting, capital-augmenting, or both. See, e.g., Mark Muro \& Scott Andes, Robots Seem to Be Improving Productivity, Not Costing Jobs, HARV. BUS. REV. (Jun. 16, 2015), https://hbr.org/2015/06/robots-seem-to-be-improving-productivitynot-costing-jobs (surveying some empirical evidence suggesting that innovation in robotics may increase labor productivity); The Growth of Industrial Robots, THE ECONOMIST: GRAPHIC DETAIL (Mar. 27, 2017), https:/www.economist.com/blogs/graphicdetail/2017/03/daily-chart-19 (arguing that "the relationship between automation and employment is not always straightforward"). 
technologies over others, even in a way as circumscribed as encouraging cleantech over dirtytech. For example, how is the government to know which technologies will be most effective at achieving emissions reductions? What role should nuclear energy play? What about rooftop solar versus solar farms? Indeed, innovation snowballing in some ways increases the risks of misprediction, by creating the possibility that government intervention could start snowballing in an area that turns out to be inefficient. The debate over using government expertise to intervene in the economy is an old one, and this Article will not resolve it. ${ }^{103}$

On the one hand, the government makes predictive judgments in many areas where there are good reasons to think that the free market on its own will yield inefficient outcomes. The Federal Reserve predicts economic conditions. The Department of Defense, Department of State, and intelligence agencies make predictions about geopolitical conditions. And, indeed, even a carbon tax would necessarily involve significant predictive and normative judgments, including guesses about the future impacts of greenhouse gas emissions on sea levels and value choices about the appropriate discount rate. ${ }^{104}$ The likelihood of misprediction may be greater for government programs that encourage cleantech over dirtytech, but they do not go away for a carbon tax, which has the support of many free-market proponents. ${ }^{105}$ Rather, for all these policy decisions, the government uses market signals and the knowledge of experts-scientists, economists, diplomats, military experts, and businesspeople-to make its best guesses. Where there are sound reasons to think that government intervention can do some good, many would not hesitate to use government intervention, while remaining vigilant to its weaknesses.

On the other hand, many are more concerned about mispredictions, government capture, and other perversities of government intervention. They argue for caution in using government expertise to intervene in the economy. And some suggest a much more limited role for government than currently exists. One can debate whether the cure of government intervention is worse than the disease of an inefficient market outcome.

103. See generally F.A. Hayek, The Use of Knowledge in Society, 35 AM. ECON. REV. 519 (1945); FrIEDriCh HAYEK, THE ROAD TO SERFDOM (1944); MILTON FRIEDMAN \& Rose FRIEDMAN, FREE TO CHOOSE (1980)

104. See William Pizer et al., Using and Improving the Social Cost of Carbon, $346 \mathrm{SCl} .1189$, 1189-90 (2014); Richard L. Revesz \& Matthew R. Shahabian, Climate Change and Future Generations, 84 S. CAL. L. REv. 1097, 1163 (2011); Douglas A. Kysar, Discounting . . On Stilts, 74 U. CHI. L. REV. 119, 136 (2007); Michael Greenstone, Elizabeth Kopits \& Ann Wolverton, Developing a Social Cost of Carbon for US Regulatory Analysis: A Methodology and Interpretation, 7 REV. ENVTL. ECON. \& POL'Y 23, 31-32 (2013).

105. See, e.g., Martin S. Feldstein, Ted Halstead \& N. Gregory Mankiw, Opinion, A Conservative Case for Climate Action, N.Y. TIMES, Feb. 8, 2017. 
But innovation snowballing makes clear that the market outcome- even with optimal carbon taxes and general innovation policy-is, indeed, inefficient. Innovation snowballing articulates a clear market failure, while recognizing that there is room for disagreement over the appropriate policy response. Indeed, in advocating for the consideration of innovation snowballing, this Article suggests a return to an early goal of environmental law of pushing environmentally friendly innovation, though not its means of command and control regulations. ${ }^{106}$ In the next two sections, we discuss how innovation snowballing affects policy choices when confronting these and other tradeoffs.

\section{DOMESTIC POLICY}

Countries can deploy a myriad of domestic policies to increase their production of cleantech innovation. On the one hand, governments can directly subsidize innovation through grants, prizes, patents, and $R \& D$ tax credits. On the other hand, they can indirectly impact innovation through pollution performance standards, clean energy deployment subsidies, government procurement programs, and other "non-innovation" policies. Here, we work out for the first time the implications of innovation snowballing for the choice of innovation and non-innovation policies.

Before proceeding, we pause to summarize in Table 2 the implications of spillovers and snowballing for cleantech innovation policy. In particular, this matrix asks when policymakers should encourage technology-neutral development, target cleantech innovation, or support specific types of technologies within cleantech. This table assumes the presence of both an optimal carbon tax and innovation spillovers for cleantech equal in size to those for other technologies. If there are no innovation externalities, as portrayed in column (1), decision-makers have no economic justification for encouraging innovation at all. There is no problem to solve, so the government should not intervene. If there are only innovation spillovers, as in column (2), the government should deploy technology-neutral innovation policy, but should not pick cleantech over dirtytech and certainly should not subsidize some cleantech technologies over others. If there is only innovation snowballing, as in column (3), then there is no reason to encourage technology in general, but there is a reason to target cleantech - and, as the sections below will touch on, a reason to even target within cleantech, to the extent that some cleantech innovations 
involve technologies that disproportionately build up the cleantech innovation tree over the dirtytech innovation tree.

Table 2. Implications of Spillovers and Snowballing for Cleantech Innovation Policy

\begin{tabular}{|c|c|c|c|}
\cline { 2 - 4 } & $\begin{array}{c}\text { (1) Neither } \\
\text { Spillovers no } \\
\text { Snowballing }\end{array}$ & $\begin{array}{c}\text { (2) Only } \\
\text { Innovation } \\
\text { Spillovers }\end{array}$ & $\begin{array}{c}\text { (3) Only } \\
\text { Innovation } \\
\text { Snowballing }\end{array}$ \\
\hline $\begin{array}{c}\text { Encourage all } \\
\text { innovation }\end{array}$ & No & Yes & No \\
\hline $\begin{array}{c}\text { neutrally? } \\
\text { Target } \\
\text { cleantech } \\
\text { innovation? }\end{array}$ & No & No & Yes \\
\hline $\begin{array}{c}\text { Target within } \\
\text { cleantech }\end{array}$ & No & No & Sometimes \\
\hline imnovation?
\end{tabular}

\section{A. Innovation Policy}

For ease of analysis, we distill cleantech innovation policy design into three main questions:

1. Where should government intervene in the innovation process? That is, how should government allocate support between basic research, applied research, and development?

2. When should government intervene? That is, what should the trajectory of innovation subsidies for cleantech look like over the coming years and decades?

3. How should government intervene? That is, which innovation tools-including patents, prizes, R\&D tax credits, and grants-look more attractive in light of innovation snowballing?

In the following subsections, we examine how innovation snowballing informs each of these considerations.

\section{Where?}

Thus far, we have largely refrained from delving into the details of the innovation process. We have, instead, treated innovation as a unitary event for ease of exposition. In reality innovation is better conceptualized as a 
production pipeline that consists of three main stages. ${ }^{107}$ At the beginning, scientists and laboratories engage in basic research, which produces knowledge with little regard to commercialization. ${ }^{108}$ Basic research, in turn, provides the building blocks for applied research, which aims to solve specific real-world problems with commercial value. ${ }^{109}$ Applied research subsequently leads to the development of commercial goods and services - and, eventually, commercialization. ${ }^{110}$

According to conventional economic wisdom, governments should focus support on more basic forms of research because innovation spillovers decrease in size as a technology approaches commercialization. ${ }^{11}$ There are two reasons why the gap between the social and private returns to research may be particularly large for basic research. First, basic research can contribute to a vast array of technologies and industries because it seeks to answer fundamental questions of science and society. ${ }^{112}$ In contrast, the benefits of applied and development research are more narrowly circumscribed because these forms of research seek to solve particular, practical problems. For example, research to improve the efficiency of wind turbines will likely have limited impact on the development of new pharmaceuticals. But research on a new optimization algorithm might find applications in both wind energy and pharmaceutical markets. As a result, the social value of basic research is greater than that of applied or development research because basic research benefits more industries. ${ }^{113}$

107. There are many different taxonomies of the innovation process. For the purposes of this analysis, we opt for the simple and well-established linear model. Benoit Godin, Invention, Diffusion and Linear Models of Innovation: The Contribution of Anthropology to a Conceptual Framework, 15 J. INNOVATION ECON. \& MGMT. 11, 11 (2014).

108. See Federal Funds Glossary, National Science Foundation, Federal Funds Survey, https://www.nsf.gov/statistics/fedfunds/glossary/def.htm (last visited July 28, 2017) ("In basic research the objective of the sponsoring agency is to gain more complete knowledge or understanding of the fundamental aspects of phenomena and of observable facts, without specific applications toward processes or products in mind.").

109. Id. ("In applied research the objective of the sponsoring agency is to gain knowledge or understanding necessary for determining the means by which a recognized need may be met.").

110. Id. ("Development is systematic use of the knowledge or understanding gained from research, directed toward the production of useful materials, devices, systems, or methods, including design and development of prototypes, and processes.").

111. There are, of course, other factors weighing in favor of government support for more basic forms of research. Perhaps most prominently, the risk that government will crowd out private investments in innovation is lowest for basic research. Indeed, economist David Popp provides evidence that government energy $R \& D$ acted as a substitute for private investments in energy $R \& D$ during the $1970 \mathrm{~s}$, but then later as a complement. The author suggests that this change may be due to a shift in the government's focus from applied to basic energy research. See Popp, supra note 19, at 177.

112. For one of the first statements of this argument, see Nelson, supra note 19, at 302.

113. And indeed, several empirical studies show that the social returns to research are higher for 
Second, appropriating the commercial value of basic research is difficult. ${ }^{14}$ It can take decades for basic research to turn into a patentable and commercially valuable product-making such research vulnerable to appropriation by competitors. ${ }^{115}$ In addition, while a firm may recognize the value of a basic scientific breakthrough to its own industry, it is much less equipped to identify applications in other fields. ${ }^{116}$ As a result, a firm will likely only patent a small subset of applications arising from their basic science research. Scholars therefore believe that the appropriability of innovation declines as research becomes more basic, even as the social value of the research increases. ${ }^{117}$ Consequently, the wedge between the social and private returns to $R \& D$ - and thus the need for government invention - tends to be greatest for basic research with standard innovation spillovers.

Innovation snowballing, however, undercuts the traditional emphasis on basic research for two reasons. First, government support for cleantech is most effective in the long run if it ultimately enables the cleantech knowledge stock to overcome the dirtytech knowledge stock. If an intervention reduces, but does not reverse, the cleantech-dirtytech gap in innovation, innovation snowballing will continue to favor dirtytech, ultimately causing the two technologies to diverge once more. The key, then, is reaching the tipping point at which cleantech is the more profitable, cutting edge technology. And the whole R\&D process-from basic research to commercial development-helps achieve that goal, since all stages contribute to the cleantech knowledge stock. Indeed, it is only commercialization that can ultimately push cleantech over the tipping point, since products that are not commercialized are rarely costcompetitive and therefore rarely profitable. Thus, on the basis of innovation snowballing, government should encourage innovation across the research pipeline in order to reach the tipping point.

basic than for applied or development research. See Hall, Mairesse \& Mohnen, supra note 3.

114. For summaries of this argument, see Nelson, supra note 19 , at 302 .

115. See Hall, Mairesse \& Mohnen, supra note 3 (concluding from the empirical literature that "basic R\&D is really long-term R\&D.").

116. See Nelson, supra note 19, at 302; Ufuk Akcigit et al., Back to Basics: Private and Public Investment in Basic R\&D and Macroeconomic Growth 1, 2 (NBER Working Paper No. 19473, 2013) (describing how "firms operating in more industries will be able to utilize more facets of a given basic information").

117. Nathan Rosenberg, Why Do Firms Do Basic Research (With Their Own Money)?, 19 RES. POL'Y 165, 165 (1990) (noting that appropriability decreases because levels of "uninsurable risk and uncertainty" increase as research moves towards "the basic research end of the research spectrum"); Adam B. Jaffe, The Importance of "Spillovers" in the Policy Mission of the Advanced Technology Program, 23 J. TECH. TRANSFER 11, 14 (1998) (observing that the long lag times between discovery and commercialization increases the size of knowledge spillovers for more basic forms of research). 
Second, innovation snowballing raises concerns that more basic research may accidentally end up promoting dirtytech instead of cleantech innovation. Recall that the key point about innovation snowballing is not the extent to which the benefits of research are unpatentable or otherwise not appropriated by innovators. Innovation snowballing exists even with perfect patentability. Rather, innovation snowballing works through changing the productivity of innovating in one line of research versus another: if the stock of knowledge in cleantech increases, future innovations in cleantech become more valuable because they can build on a larger stock of knowledge, infrastructure, and market share. But, as discussed above, predicting how a basic research breakthrough-which, by definition, has potential applications across a variety of fields-will make its way to the market is difficult. As a result, investments in earlier stages of the research pipeline run a greater risk of not benefitting cleantech or of even benefiting dirtytech instead of cleantech-and thereby perversely widening the clean-dirty knowledge gap. In contrast, there is more certainty in later-stage developments about an innovation's contribution to the cleantech innovation tree, which, in turn, lowers the risk of perverse spillovers to dirtytech. ${ }^{118}$ That being said, we stress that we are not arguing for limiting basic research. Quite the opposite. The large innovation spillovers from basic research justify strong technologyneutral government support. We merely suggest that innovation snowballing argues for also subsidizing later stages of the cleantech innovation pipeline.

\section{When?}

Innovation snowballing offers insight into when governments should invest in cleantech R\&D. In particular, innovation snowballing argues for a large, but temporary, government investment in cleantech innovation. ${ }^{119}$ In contrast, conventional analyses based solely on innovation spillovers suggest that innovations should simply be subsidized to the extent of the spillover, ${ }^{120}$ resulting in government support that is roughly constant over time. That is, conventional reasoning suggests that a present-day invention with a spillover of size $X$ should receive the same subsidy as an invention

118. Indeed, as this Article discusses below, there is some empirical evidence suggesting that spillovers from cleantech to dirtytech are rare.

119. Acemoglu et al., Environment and Technical Change, supra note 11; Acemoglu et al., Transition, supra note 2 , at 56.

120. Michael Grubb \& David Ulph, Energy, the Environment, and Innovation, 18 OXFORD REV. ECON. POL'Y 92, 92 (2002). 
fifty years from now with a standard spillover of size X.

In contrast, innovation snowballing does not imply constant subsidies; instead, it suggests more subsidies now because innovation snowballing increases the costs of delaying climate change action. Without government intervention, innovation gravitates toward dirtytech, the most productive and profitable technology in today's energy markets. Thus, each day that policymakers fail to act further widens the cleantech-dirtytech knowledge gap, making it costlier to bridge the gap in the future. Indeed, Acemoglu and coauthors estimate that delaying carbon pricing and cleantech $R \& D$ subsidization by fifty years would reduce global consumption by 1.7 percent, as compared to the optimal policy path. ${ }^{121}$ In dollar terms, this welfare loss is about $\$ 1.27$ trillion per year. ${ }^{122}$

But, governments only need to disproportionately subsidize cleantech innovation until the productivity gap between cleantech and dirtytech knowledge stocks is closed. Once the system reaches this technology tipping point, cleantech innovation will be more productive and more profitable than dirtytech innovation, meaning that innovation blocks will begin flowing to cleantech without additional government support. Thus, in contrast to a tax on carbon or an innovation subsidy for spillovers, which should be maintained in perpetuity, innovation snowballing can be addressed by a large, but temporary, government investment in cleantech R\&D.

Path dependency also has implications for the timing of carbon prices. The social costs of a carbon price are high in the near term when dirtytech is cheaper than cleantech. ${ }^{123}$ But, as cleantech innovation-with the support of government funding-accelerates and surpasses dirtytech innovation, the cost differences between the two will decline and ultimately reverse. Thus, with the right cleantech innovation policy, emission reductions will cost less in the future than they do today, suggesting value in deferring some emissions reductions by deferring some of the carbon tax increase. This logic argues for cleantech subsidies and carbon taxes that fall and rise, respectively, over time. ${ }^{124}$ Under Acemoglu's optimal path, for example, nearly all cleantech subsidization occurs within the next five decades, while carbon prices steadily increase

121. See Acemoglu et al., Transition, supra note 2, at 89.

122. As a point of reference, recall that welfare losses from solely relying on carbon taxes to respond to climate change totaled to about 1.9 percent of global consumption, or about $\$ 1.42$ trillion a year. See supra note 82 and accompanying text.

123. Acemoglu et al., Transition, supra note 2, at 87

124. Technically, Acemoglu's optimal carbon tax follows an inverted-U-shaped path that peaks in roughly 130 years and then steadily declines. See id. at 86 . 
over the next 130 years. ${ }^{125}$

While earlier investments are better for redirecting innovation, an immediate full ramp up would likely be undesirable. Cleantech innovation requires substantial specialized human capital, and empirical work suggests that the short-run labor supply of scientists and engineers is relatively inelastic. ${ }^{126}$ In other words, it will take time for innovators to develop the necessary expertise to enter the cleantech field. ${ }^{127}$ A petroleum engineer, for instance, cannot become a wind turbine mechanic overnight. Likewise, the educational institutions responsible for training the next generation of cleantech minds will not respond instantaneously to changes in the market for energy innovation. As a result, expanding the pool of cleantech human capital-and thus the knowledge stock for cleantech innovation - will likely require decades, not years, of government support. Given the inelastic supply of scientists in the short-run, a rapid increase in spending in innovation might drive up wages instead of increasing innovation. ${ }^{128}$ In contrast, a more gradual increase in cleantech R\&D subsidization would better ensure that taxpayer dollars increase innovation output, rather than the salaries of scientists. In a similar vein, an optimal climate strategy should involve policies designed specifically to augment the number of cleantech entrepreneurs, such as increased funding to graduate students in cleantech disciplines and the development of new cleantech concentrations in STEM programs.

Finally, the optimal length of subsidization will likely vary across individual cleantech technologies. Economists have, for example, found larger within-technology spillovers for wind technologies than for solar or energy storage technologies. ${ }^{129}$ In other words, past knowledge stocks contribute more to future innovations in the context of wind than in the context of solar or storage. As compared to wind then, solar and storage may require longer periods of government support to reach their respective technology tipping points.

125. Id. at 87 fig. 6 .

126. Austan Goolsbee, Does Government R\&D Policy Mainly Benefit Scientists and Engineers?, 88 AM. ECON. REV. 298, 298 (1998) (presenting empirical evidence suggesting that most R\&D spending goes towards increasing scientist salaries in the short run).

127. See Shi-Ling Hsu, Capital Transitioning: A Human Capital Strategy for Climate Innovation, 6 TRANSNAT'L ENVTL. L. 153 (2017) (for ideas on how to promote this human capital transition).

128. Goolsbee, supra note 126 , at 301 (estimating that "a major component of government R\&D spending is windfall gains to R\&D workers.").

129. Joëlle Noailly \& Victoria Shestalova, Knowledge Spillovers from Renewable Energy Technologies: Lessons from Patent Citations 1, 18-19 (Ctr. for Int'l Envtl. Stud., Research Paper No. 22,2013 ) (providing empirical evidence that within-technology spillovers vary in size across energy technology types). 


\section{How?}

Innovation snowballing also influences the relative attractiveness of the various innovation policy tools. In an economics model, social planners only have access to a single, undifferentiated, intellectual property tool: the so-called "innovation subsidy." But in the real world imperfectly informed policymakers rely on patents, ${ }^{130}$ grants, ${ }^{131}$ prizes, ${ }^{132}$ and R\&D tax credits $^{133}$ to stimulate innovation. Here, we show that innovation snowballing has far-reaching implications for innovation policy design, particularly with respect to the debate over whether regulators should subsidize innovation using market-based rewards (i.e., patents and R\&D tax credits) or government-set rewards (i.e., grants and prizes). ${ }^{134}$ First, innovation snowballing tilts the scales against patents and in favor of government-set prizes and research grants. Second, it argues for directing subsidies not only towards cleantech in general, but also towards particular types of cleantech that especially build up the clean technology tree. Third, it increases the value of $R \& D$ tax credits relative to patents as instruments for spurring cleantech innovation. In the following analysis, we adopt the simplifying assumption that policymakers enact a kind of "pure" form of each policy instrument, ${ }^{135}$ meaning that patents produce monopoly rights, while prizes and grants produce innovations for the public domain. ${ }^{136}$

\section{a. Patents vs. Government-Set Tools}

Innovation snowballing substantially undercuts the main benefits of patents - the use of the market to determine the value of innovation, and the fairness of making beneficiaries pay-while exacerbating their main cost - the impacts of intellectual property monopolization. As a result,

130. Patents subsidize innovation by awarding innovators temporary rights to charge monopoly prices for their inventions.

131. Grants fund research projects that have been selected by government experts. Under this model, the innovation subsidy is distributed prior to the invention.

132. Prizes transfer taxpayer dollars to private entrepreneurs who win research competitions. Funds are distributed after the invention.

133. Tax credits reduce the entrepreneur's tax burden in accordance with her expenditures on specified R\&D activities.

134. We use Daniel Hemel and Lisa Ouellette's classification of innovation tools into government-set and market-set rewards. See Hemel \& Ouellette, supra note 6, at 327.

135. We return to R\&D tax credits below. See infra Section III.A.3.c.

136. It need not be the case that recipients of government funds waive patenting rights. For example, under the Bayh-Dole Act, recipients of government grants can patent. Bayh-Dole Act of 1980, 35 U.S.C. $\S 202$ (2012). Similarly, under the recently-passed 21 st Century Cures Act, winners of innovation prize competitions can patent their inventions. 21 st Century Cures Act, 42 U.S.C. $\S \S$ 1001(i)(1), 201 (2016). 
innovation snowballing makes patents less attractive and government-set tools, like prizes and research grants, more appealing in the context of cleantech.

Much of the debate over optimal innovation policy focuses on whether markets or governments are better situated to identify and reward promising new technologies. ${ }^{137}$ On the one hand, market-based instruments rely on price signals-rather than government experts-to allocate innovation subsidies to private entrepreneurs. Under the patent system, for instance, innovation subsidies come in the form of temporary monopolies. ${ }^{138}$ As a result, markets determine remuneration levels for an invention and private actors decide which research projects to undertake. ${ }^{139}$ In contrast, government-set innovation rewards rely on public experts to disburse innovation subsidies. ${ }^{140} \mathrm{Grants}$, for instance, fund specific research proposals that are selected by government specialists, while innovation competitions are designed to produce specific inventions (e.g., a car that can drive 100 miles to the gallon) by rewarding the winners with taxpayer dollars. Under both tools, then, the government determines which technologies to subsidize and the level of remuneration.

The relative strengths and weaknesses of government-set and marketset innovation instruments are well-known - and this Article does not purport to comprehensively survey the literature. ${ }^{141}$ Instead, we simply show here that innovation snowballing undercuts some of the main reasons for preferring market-set tools, in general, and patents, in particular. Specifically, the conventional view among many economists and legal scholars is that markets are better than the government at identifying commercially viable innovations. ${ }^{142}$ Relative to the entrepreneurs themselves, government experts face severe informational constraints in assessing the costs, risks, and value of private $R \& D$ - and therefore in identifying which innovations are worth pursuing and how much to invest in each. ${ }^{143}$ Markets, in contrast, incorporate the preferences

137. Roin, supra note 18 , at 999 (noting that this "debate over which system is preferable has existed for centuries"); Shavell \& van Ypersele, supra note 18, at 525-27 (describing the longstanding debate between patents and rewards).

138. Stiglitz, supra note 31 , at 1700.

139. Hemel \& Ouellette, supra note 6 , at 327-28.

140. Id.

141. For a comprehensive review of this literature, see Hemel \& Ouellette, supra note 6, at 327; and Roin, supra note 18 , at 999.

142. Kapczynski, supra note 18 , at $974-75$ (discussing both the dominant view of intellectual property and the "long and important tradition of dissent").

143. Nancy Gallini \& Suzanne Scotchmer, Intellectual Property: When Is It the Best Incentive System?, 2 INNOVATION POL'Y \& ECON. 51, $54-55$ (2002). 
of billions of people: an innovation that will benefit large segments of the population will yield large expected profits, which, in turn, will induce innovation by private actors through the invisible hand of price signals. As a result, a major purported advantage of the patent system is that the market sets the remuneration for innovation. ${ }^{144}$

Market signals, however, are much less valuable in a regime with innovation snowballing. As discussed above, many initial cleantech innovations will not be very profitable, even though they will be essential to switching society from a dirtytech to a cleantech equilibrium. Indeed, path dependency arises precisely because innovation gravitates towards technologies with the most productive and profitable knowledge stocks. As a result, markets may serve as a poor guide for addressing innovation snowballing because the market itself is not a neutral arbiter in the case of energy technologies. Because dirtytech has benefited from over a century of extra innovation resulting from an untaxed pollution externality, the present innovation playing field is tilted inefficiently towards dirtytech. ${ }^{145}$ Consequently, even with a tax on carbon, market-set instruments that are technology-agnostic cannot efficiently address innovation snowballing by correcting for this market bias. Instead, optimal innovation policy necessitates discrimination between cleantech and dirtytech.

Patents have also been justified on fairness grounds by the "beneficiaries pay" principle, since patents typically require the beneficiaries and users of an innovation to pay for it. ${ }^{146}$ Innovation snowballing, however, undercuts this logic as well. The costs of greater cleantech patent protection are borne disproportionately by large energy users and future cleantech innovators. But closing the cleantech-dirtytech knowledge gap and moving society to a cleantech equilibrium benefits all of humanity by efficiently reducing the risk of climate change and the costs of climate change mitigation. As a result, the beneficiaries pay principle actually argues against cleantech patents and in favor of cleantech grants, prizes, and R\&D tax credits-each of which can spread

144. Hemel \& Ouellette, supra note 6 , at 327-28.

145. Of course, we are not the first to observe that market signals do not always correlate tightly with social value. See, e.g., Amy Kapczynski \& Talha Syed, The Continuum of Excludability and the Limits of Patents, 122 YALE L.J. 1900, 1900 (2013). But we are the first to discuss how innovation snowballing undercuts the value of market-set innovation tools as drivers of socially-beneficial inventions.

146. For a thorough treatment of this argument, see Hemel \& Ouellette, supra note 6, at 345-52; Richard S. Gruner, Why We Need a Strong Patent System and When: Filling the Void Left by the Bilski Case, 28 SANTA Clara COMPUT. \& HIGH TECH. L.J. 499, 506 (2012) (arguing that one of the patent system's advantages is that "the rewards are paid by the specific users of inventions"). 
the costs of innovation subsidization across the populace through, say, a general income tax.

In addition to reducing the benefits of patents, innovation snowballing exacerbates the costs of patents relative to government-set tools that do not place intellectual property in private hands. Patents' major disadvantage is that the monopoly rights granted to innovators under a patent system increase the cost of using the resulting intellectual property above its marginal cost, thereby reducing the technology's use among two important groups: producers who use the innovation to make a product (e.g., electricity) and entrepreneurs who use the innovation to develop future innovations. $^{147}$ Thus patents-especially those on foundational concepts ${ }^{148}$ - can impede innovations from being added to the innovation stock (i.e., make the "shoulders of giants" smaller than they could be). ${ }^{149}$ For example, companies with patents can, in theory, entirely prevent others from using its technology for the duration of the patent; at a minimum, they will likely charge more than the zero marginal cost of the use of the idea. Likewise, patents can create an anti-commons problem: if a new potential innovation requires as inputs a variety of past innovations, each of which is patented by a different company, then the costs of acquiring all those licenses may be prohibitively high. ${ }^{150}$ Innovation snowballing makes the monopoly pricing and transaction costs under the

147. For a thorough discussion of all the ways in which patents can delay or disincentivize innovation, see Jerome Reichman et al., Intellectual Property and Alternatives: Strategies for Green Innovation 10 (Chatham House Energy, Env't and Dev. Programme Paper, No. 08/03, 2008). See also Jay P. Kesan, Economic Rationales for the Patent System in Current Context, 22 GEO. MASON L. REV. 897,900 (2015) (arguing that broad patents can "deter[] other potential inventors from working on the same or similar issues," leading to a decline in innovation activity); David S. Olson, Taking the Utilitarian Basis for Patent Law Seriously: The Case for Restricting Patentable Subject Matter, 82 TEMP. L. REV. 181, 183 (2009) ("It is also well recognized that our patent system's mechanism for incentivizing innovation-granting property rights to inventors-causes deadweight loss to society in the form of higher prices, and some consumers ending up priced out of the market.").

148. Reichman et al., supra note 147, at 10 (describing how "progress in the automobile and aircraft industries was hampered by problems in licensing broad patents on foundational platforms").

149. See id. at 10-12 (reviewing the means by which patents can delay or disincentivize innovation); Suzanne Scotchmer, supra note 14, at 30 (discussing how patents can slow second generation or follow-up inventions).

150. See Michael A. Heller and Rebecca S. Eisenberg, Can Patents Deter Innovation? Anticommons in Biomedical Research, 280 SCI. 698, 698 (1998) (discussing the anti-commons problem in the context of biomedical research); Carl Shapiro, Navigating the Patent Thicket: Cross Licenses, Patent Pools, and Standard Setting, in 1 INNOVATION POLICY AND THE ECONOMY 119, 119 (Adam B. Jaffe et al. eds., 2000) (discussing how a patent thicket-or "overlapping set of patent rights requiring that those seeking to commercialize new technology obtain licenses from multiple patentees" - can slow innovation growth). In the field of energy technologies, there is also a risk that patents will yield anti-innovative effects. See Lisa Larrimore Ouellette, Addressing the Green Patent Global Deadlock Through Bayh-Dole Reform, 119 YALE L.J. 1727 (2010) (offering evidence of the existence of anti-commons problems in the energy technology space). 
patent system all the more perverse. Path dependency follows from innovators "standing on the shoulders of giants," and patents make it even harder to stand on those shoulders, hindering innovation snowballing.

Admittedly, patents' negative impact on the growth of the cleantech knowledge stock may be partially counterbalanced by patents' tendency to incentivize inventors to publicize their inventions. ${ }^{151}$ Without patents, companies would have greater incentives to hide their innovative breakthroughs from the public (e.g., more inventions would be treated as trade secrets). And an innovation that is hidden from the world cannot serve as a building block in the cleantech knowledge stock. However, we suspect that the information-forcing properties of patents do not fully compensate for the innovation tool's clear downsides. Instead, this discussion highlights an important role for publicity requirements in prizes and government funding. ${ }^{152}$

In sum, innovation snowballing increases the value of government-set innovation tools and decrease the value of patents. ${ }^{153}$ Of course, we do not mean to imply that innovation snowballing overturns the well-known risks to government intervention. The government cannot tell the future. It faces severe information constraints-and more discretionary forms of innovation spending, such as prizes ${ }^{154}$ and grants, are also more vulnerable to lobbying and political interference. ${ }^{155}$ These factors remain concerning. This Article simply points out that innovation snowballing undermines the usefulness of patents-and the market more generally-for guiding cleantech innovation.

151. Roberto Mazzoleni \& Richard R. Nelson, The Benefits and Costs of Strong Patent Protection: A Contribution to the Current Debate, 27 RES. POL'Y 273, 278 (1998) (discussing how "patents encourage and provide a vehicle for disclosure and, more generally, generate quick and wide diffusion of the technical information underlying new inventions"); Note, The Disclosure Function of the Patent System (Or Lack Thereof), 118 HARV. L. REV. 2007, 2007 (2005) (showing that the courts "place a great deal of emphasis on the patent system's role in disseminating information").

152. Vincenzo Denicolò \& Luigi Alberto Franzoni, The Contract Theory of Patents, 23 INT'L REV. L. \& ECON. 365, 368 (2004) (arguing that the patent system "induces disclosure of marginal innovations"). There is, of course, a robust and unresolved debate over the empirical extent to which patents induce the disclosure of meaningful information to the public. See Jason Rantanen, Peripheral Disclosure, 74 U. PITT. L. REV. 1, 1 (2012). We do not take a stand on this question. Rather, we simply stress that policy instruments that slow the incorporation of cleantech innovation into the cleantech knowledge stock will likely exacerbate innovation snowballing.

153. And, of course, all this reasoning works in reverse with respect to dirtytech. Patents are an appropriate tool for dirtytech, in that they encourage the next round of innovation today, but make it difficult (relative to prizes) to build on prior developments.

154. For those who fear that a federal climate prize is unlikely to be feasible, perhaps such a prize would be feasible from a consortium of states.

155. See, e.g., MiChael J. Graetz, The End of Energy 188 (2011). Harold Demsetz provides one of the earliest and most influential defenses of the patent system, partly on informational and political economy grounds. See generally Harold Demsetz, Information and Efficiency: Another Viewpoint, 12 J.L. \& ECON. 1 (1969). 


\section{b. Targeting Innovation Support}

This Article makes a case for government policies directing innovation to cleantech over dirtytech. But how should it do so? While the previous subsection discussed the issues involved in picking cleantech over dirtytech, this subsection argues that the government should encourage not only cleantech over dirtytech but also certain kinds of cleantech over others.

Thus far, we have portrayed cleantech (low greenhouse gas energy sources) and dirtytech (high greenhouse gas energy sources) as forming two separate technology trees. The real world is not so neat. In reality, there is a continuum of building blocks of those technology trees, from those contributing solely to low-greenhouse gas technologies to those contributing solely to high-greenhouse gas technologies. The endpoints of the spectrum are clear: innovation snowballing (unlike the conventional efficiency story) implies that a new wind turbine technology should get more government R\&D support than a new deep-sea oil drilling or coal mining technology. But what about the middle of the spectrum, including both cleantech innovations that also contribute to the production of dirty energy and dirtytech innovations that make dirty energy cleaner? Innovation snowballing has a clear implication: focus support on the technology building blocks that particularly benefit the clean energy technology tree.

Evidence suggests that research into some types of clean energy benefits dirtytech as much as cleantech; innovation snowballing suggests disfavoring those types of research. First, cleantech innovations vary in terms of their spillovers to dirtytech. In general, there appears to be very little cross-pollination between the two: cleantech innovation spillovers predominately benefit cleantech technologies and dirtytech innovation spillovers predominately benefit dirtytech technologies. ${ }^{156}$ For example, empirical work suggests that individual clean energy technologies are not built on a common stock of cleantech knowledge, but rather on technology-specific knowledge stocks. ${ }^{157}$ The research finds that more than eighty percent of solar patents reference previous solar patents, but only two percent cite patents in other renewable energy technologies, such

156. NOAilly \& SheStalova, supra note 129, at 23 tbl.Al (showing that, with the exception of waste and biomass, fewer than ten percent of renewable energy patents are cited in fossil fuel patents).

157. NOAilly \& SHeSTAlova, supra note 93, at 1 (showing through an empirical analysis of patent citations that "renewable technology mainly builds on its own technology-specific knowledge stock"). 
as wind, storage, and hydroelectric. ${ }^{158}$ Innovations in wind therefore appear to contribute very little to the development of solar. Or, stated differently, solar innovators stand largely on the shoulders of past solar innovators, rather than on the shoulders of past renewable energy innovators. This is not to say that there are no meaningful innovation synergies between renewable energy technologies. About ten percent of wind patents, for example, cite innovations in other (non-wind) renewables, while a quarter of patents in marine technologies (which include tidal, wave, and underwater power generators) reference innovations in wind and hydropower. ${ }^{159}$ However, for most renewable technologies, intra-technology spillovers dominate inter-technology spillovers from other forms of cleantech. ${ }^{160}$

But other apparently cleantech technologies do as much or more to build up the dirtytech knowledge stock than the cleantech knowledge stock. For example, knowledge from advancements in waste and biomass technologies flows primarily to fossil-fuel technologies, such as coal, engines, and gas turbines. ${ }^{161}$ The technologies are, after all, fundamentally about combusting materials that resemble fossil fuels. At the same time, intra-technology spillovers-as well as spillovers to other renewablesare quite small for both waste and biomass. ${ }^{162}$ As a result, subsidizing these two "clean" technologies may have the perverse effect of widening the knowledge gap between cleantech and dirtytech, and the logic of innovation snowballing suggests disfavoring biomass in favor of wind and solar.

A second category of innovations makes dirtytech cleaner; innovation snowballing again - by the same logic-suggests disfavoring these technologies relative to purely cleantech technologies. For example, many technologies make the internal combustion engine more efficient, reducing greenhouse gas emissions for each unit of energy produced. Similarly, carbon capture and sequestration promises to reduce the greenhouse gas emissions of fossil fuel technologies by storing some of the emissions underground. These technologies build upon the traditional dirtytech infrastructure of burning fossil fuels, thereby potentially delaying the point at which overall clean technologies become cheaper than dirty ones. The logic of innovation snowballing argues against subsidizing such

158. Id. at $12 \mathrm{tbl} .4 .1$.

159. Id.

160. Id.

161. Noailly \& Shestalova, supra note 129 , at 17 (finding that " $\mathrm{f}$ there are many interactions between the waste and biomass and the [fossil fuel] technologies knowledge bases").

162. Id. at 15 tbl.5 (reporting statistically insignificant coefficients on the variables for intratechnology and inter-renewable technologies spillovers for the waste and biomass regressions). 
technologies. While this Article cannot resolve the difficult technical question of which areas are most likely to succeed in achieving a lowgreenhouse-gas future (e.g., rooftop solar versus utility-scale solar versus offshore wind versus onshore wind), it does weigh in favor of technologies that are more similar to other clean technologies.

Just as the market provides relatively little guidance on how to promote cleantech over dirtytech, it also provides little guidance on how to choose within cleantech. For example, market signals would not indicate that biomass innovations spill over to dirtytech, thereby impeding efforts to close the cleantech-dirtytech gap. Similarly, market signals would not indicate which cleantech technology has the greatest intra-technology spillovers-a piece of information that could be useful to budgetconstrained policymakers, since technologies with larger intra-technology spillovers may, as a result, also require less subsidization. These considerations reduce the value of market-based innovation tools, while increasing the usefulness of government-set rewards that can incorporate this non-market information.

Making this limited case for choosing within cleantech is eased somewhat by the practical reality of implementing government grants and prizes. In the case of research grants, the government must pick winners with each project, thereby necessarily choosing one specific technology over another. Of course, the overall portfolio of grants may seek to be technology-neutral, but in practice the decision-making process typically requires choosing particular technologies. For example, according to the recently-passed 21st Century Cures Act, which includes prizes for innovation in healthcare, experts will pick particular projects. ${ }^{163}$ One might try to imagine the most technology-neutral prize possible-e.g., a prize to the first person who produces energy with no more than $\mathrm{x}$ units of carbon at y cost per unit of energy. In practice though, prizes are likely to be technology specific: e.g., competitions for battery, wind, or solar design. Indeed, setting broad targets for climate prizes may perversely increase the subjectivity in judging the winner, something that many supporters of prizes seek to avoid. ${ }^{164}$ And even scholars who have been critical of the government's role in picking winners have proposed climate prizes that target certain technologies and certain sectors. ${ }^{165}$ Notably, in all of these

163. JUdith A. JOHNSON ET AL., CONG. RESEARCH SERv., R44071, H.R. 6: THE 21ST CENTURY CURES ACT (2015) (describing the prize provision).

164. See, e.g., Richard G. Newell \& Nathan E. Wilson, Technology Prizes for Climate Change Mitigation 27 (Res. for the Future, Discussion Paper No. RFF DP 05-33, 2005).

165. Adler, supra note 9 , at 43 (proposing that the federal government creates climate prizes for 
cases, it is experts and not Congress that make the decisions, which could ease concerns about the influence of lobbying. In short, by arguing for the government to pick cleantech over dirtytech and, in some cases, certain cleantech types over others, we are not proposing something that is procedurally different from what is already done. The government already has wide experience in picking winners project-by-project. Of course, the strongest critics of grants and prizes may ultimately decide that the downsides of those tools outweigh the benefits of addressing innovation snowballing. For them, an $\mathrm{R} \& \mathrm{D}$ tax credit targeted at cleantechdiscussed in the next subsection-may be a desirable alternative for addressing innovation snowballing.

\section{c. R\&D Tax Credits vs. Patents}

Thus far, we have focused on the relative merits of patents and government-set rewards, arguing that innovation snowballing increases the relative attractiveness of grants and prizes. But we have also recognized the risks of government-set innovation subsidies - and therefore the value of market-set policy tools. As a result, it is worthwhile to explore the implications of innovation snowballing for the two main types of marketset innovation instruments: patents and R\&D tax credits. ${ }^{166}$ We show in this subsection that innovation snowballing does not favor all market-set innovation rewards equally. Instead, it increases the value of $R \& D$ tax credits relative to patents.

R\&D tax credits do not face the same problems of monopolization that plague the patent system. ${ }^{167}$ Consider, for example, a cleantech $R \& D$ tax credit that subsidizes cleantech research expenditures above and beyond the support provided under the existing general $R \& D$ tax credit. By increasing the expected returns to cleantech $R \& D$, such a credit could

technologies ranging from "vehicle and building design to fuel cell technology, agricultural methods, and carbon sequestration technologies").

166. Others have considered the merits of encouraging innovation through taxes. See generally Jacob Nussim \& Anat Sorek, Theorizing Tax Incentives for Innovation, 36 VA. TAX REV. 25 (2017) (arguing against using taxes and explaining why non-tax incentives are most likely superior, on the basis of organizational theory); Shaun P. Mahaffy, Note, The Case for Tax: A Comparative Approach to Innovation Policy, 123 YALE L.J. 812, 812 (2013) (suggesting that "tax credits could be used to ameliorate a number of inefficiencies that arise from the failures of patent law.").

167. R\&D tax credits as currently constituted in the U.S. face the problem of non-refundability. That is, to receive the credit, innovators generally need to have enough profits from which to deduct the credit. Small entrepreneurs often do not have such profits and are therefore unable to benefit from the credit. See Hemel \& Ouellette, supra note 6, at 337. (But see I.R.C. $\S 41$ (h) (2017) (allowing limited refundability for small businesses).) Of course, for small entrepreneurs, patents cause problems too: if a business is liquidity-constrained, it may not have enough money to survive long enough to be able to patent its invention and reap the rewards. 
induce greater cleantech innovation. In contrast to patents, however, a cleantech R\&D tax credit would not increase the costs of future cleantech innovations because the credit confers a government subsidy, not monopoly rights, to the inventor. As discussed earlier, monopolization hinders innovators' ability to stand on the shoulders of past cleantech entrepreneurs. The advantages of a cleantech $R \& D$ tax credit remain even if the credit is layered on top of the existing patent system. ${ }^{168}$ Holding patent protection levels constant, an increase in R\&D tax credits for cleantech increases the expected returns to cleantech innovation. ${ }^{169}$ So creation of a cleantech credit would unambiguously work to close the cleantech-dirtytech knowledge gap.

Admittedly, a cleantech R\&D tax credit would require the Internal Revenue Service to do a lot of line drawing with respect to which expenses qualify as cleantech R\&D. And businesses would try to game the system. Indeed, some tax scholars argue that rampant gaming already exists in the current system of R\&D tax credits, although many economists believe that these credits are effective at encouraging innovation. ${ }^{170}$ But attempts to use patents to address innovation snowballing would face similar challenges: designing a patent system that provided extra rewards to cleantech would also raise thorny definitional issues and gaming concerns. R\&D tax credits, however, hold clear advantages over patents in the context of innovation snowballing. In addition to avoiding the problems of monopolization that characterize the patent system, a cleantech R\&D tax credit more closely aligns with the beneficiaries pay principle. As discussed above, spurring cleantech innovation and closing the cleantech-dirtytech gap confers global benefits, as they both reduce the

168. Lisa Larrimore Ouellette, Patent Experimentalism, 101 VA. L. REV. 65, 93 (2015) (briefly discussing the interaction between patents and tax credits); Hemel \& Ouellette, supra note 6, at 32728 (for a longer discussion of this overlay).

169. At least in principle, R\&D tax credits can prohibit monopolization. For instance, policymakers could design a cleantech $R \& D$ tax credit such that companies that relied on it would not be allowed to patent the resulting technology. Such a move, of course, would raise a whole host of logistical complications that are beyond the scope of this Article. However, it is worth noting that replacing patent protections with a sufficiently large cleantech $R \& D$ tax credit could, in theory, preserve the incentives for cleantech innovation without slowing the long-term growth of the cleantech knowledge stock. In any case, as noted in the text, such a prohibition is not needed for an R\&D tax credit to encourage innovation.

170. Compare Stephen E. Shay et al., R\&D Tax Incentives: Growth Panacea or Budget Trojan Horse?, 69 TAX L. REV. 419, 419-26 (2016) (expressing strong skepticism regarding the effectiveness of the current R\&D tax credit system), with Nirupama Rao, Do Tax Credits Stimulate R\&D Spending? The Effect of the R\&D Tax Credit in Its First Decade, 140 J. PUB. ECON. 1, 1 (2016) (finding strong empirical evidence that U.S. federal R\&D tax credit increased firm R\&D activity in both the short- and long-run). 
negative externality of carbon pollution and make climate-change mitigation cheaper. Patents, in contrast, concentrate the costs of cleantech innovation on a small subset of beneficiaries, namely: large energy users and future cleantech innovators. A cleantech $R \& D$ tax credit, on the other hand, could be funded through a general tax on the population that spreads the costs of cleantech innovation broadly.

This is not to say, of course, that policymakers cannot or should not promote cleantech innovation through modifications to the patent system. Lisa Larrimore Ouellette has argued, for example, that the Bayh-Dole $\mathrm{Act}^{171}$ impedes green innovation by allowing scientists and universities to patent technologies developed with federal research grants. ${ }^{172}$ While supporters of the Act claim that public patents are needed to incentivize commercialization of federally funded technologies, Ouellette and others counter that these commercialization hurdles are small for green technologies. ${ }^{173}$ If these critics of the Bayh-Dole Act are correct, then policymakers could increase the cleantech knowledge stock by making nonexclusive licensing the default or prohibiting patents for publicly funded cleantech innovations.

Similarly, if one believes that overpatenting is a problem in the context of cleantech, several other legal options suggested by Mark Lemley could be adopted. ${ }^{174}$ First, there could be a stricter "utility" requirement in the case of cleantech, like the one that exists in chemistry and biotechnology. ${ }^{175}$ That is, those seeking patents in cleantech would have to show a higher threshold of usefulness in order to achieve the patent. ${ }^{176}$ Second, courts or Congress could limit injunctive relief in cleantech patent infringement cases, instead limiting remedies to a reasonable royalty. ${ }^{177}$ They could particularly do so where a patent infringes upon only a small part of a product. ${ }^{178}$ Doing so would make it more difficult for

171. 35 U.S.C. $\$ 203$ (a) (2012).

172. See Ouellette, supra note 150 , at $1737-38$.

173. Id. at 174 .

174. Mark Lemley, Patenting Nanotechnology, 58 STAN. L. REV. 601, 628-30 (2005)

175. See, e.g., In re Kirk, 376 F.2d 936, 961 (C.C.P.A. 1967) (Rich, J., dissenting) (arguing that such a utility requirement would not be applied elsewhere); David S. Almeling, Note, Patenting Nanotechnology: Problems with the Utility Requirement, 2004 STAN. TECH. L. REV. N1 (2004) (making the descriptive argument that courts have applied the utility requirement "with more force" in the context of chemistry and biotechnology patents).

176. Cf. 35 U.S.C. \& 101 (2012) (making patentability contingent on the invention being "useful"). See also Dmitry Karshtedt, The Completeness Requirement in Patent Law, 56 B.C. L. REV. 949, 972-74 (2015) (describing the current threshold of usefulness for patentability).

177. See Mark A. Lemley \& Carl Shapiro, Patent Holdup and Royalty Stacking, 85 Tex. L. REv. 1991, 1993 (2007) (explaining how patent holders can use the threat of an injunction to "negotiate royalties far in excess of the patent holder's true economic contribution.").

178. See, e.g., Lemley \& Shapiro, supra note 177 , at 1993 (showing that the problem is especially 
patentholders to "hold up" those who wish to build upon existing patents. ${ }^{179}$ Third, the law could further limit holdup by curtailing the ability of patent-holders to seek treble damages against infringers in the context of cleantech. ${ }^{180}$ Fourth, limiting the ability to keep some patent applications secret could also promote shoulder-standing in cleantech. ${ }^{181}$ Finally, disallowing patents on upstream "enabling technologies" might help catalyze innovation snowballs. As discussed above, the profitability of innovating on a particular innovation stock increases with the size of the stock. Thus, for nascent technologies with small knowledge stocks, even small costs to innovation can stop an innovation snowball in its tracks, so the costs of patents might be sufficient to strangle a young innovation snowball before it has time to grow and gain momentum. ${ }^{182}$ In contrast, as the technology matures, its knowledge stock grows, and its profitability increases, the innovation snowball gains "mass" and "momentum" and can therefore more easily overcome costs to innovation. These dynamics argue against allowing inventors to patent the initial, foundational building blocks of a technology stock, thereby increasing the transaction costs for future inventors.

Of course, any of the above patent proposals could have ambiguous impacts on innovation: encouraging the use of existing cleantech technology, but also discouraging its production in the first place by reducing the amount that patent-holders can recover in court. Moreover, pushing cleantech over the technology tipping point will require major increases in the incentives for cleantech innovation-and, especially given the ambiguous impacts of these changes, we are skeptical that these marginal changes to the patent system alone can provide the necessary stimulus. Instead, if policymakers are looking to address innovation snowballing while minimizing government's role in dispersing innovation subsidies, they may want to simultaneously create a cleantech R\&D tax

acute where "the injunction is based on a patent covering one small component of a complex, profitable, and popular product.").

179. See Lemley \& Shapiro, supra note 177, at 2009.

180. See Mark A. Lemley \& Ragesh K. Tangri, Ending Patent Law's Willfulness Game, 18 Berkeley TeCH. L.J. 1085, 1109-13 (2003); Mark A. Lemley, Ten Things to Do About Patent Holdup of Standards (And One Not to Do), 48 B.C. L. REV. 149, 164 (2007) (proposing modifications to the willfulness standard in patent law to reduce the risk of liability for treble damages and thereby mitigate some of the holdup problems).

181. Cf. 35 U.S.C. $\$ 122(\mathrm{~b})(1)(\mathrm{B})$ (in general, "[n]o information concerning published patent applications shall be made available to the public").

182. Indeed, it is suggestive that, for many of the breakthrough technology fields of the past century, such as computers and the Internet, early inventors did not patent their initial inventions and discoveries. See Lemley, supra note 174 , at 606. 
credit and weaken existing patent protections for cleantech. In theory, any loss of innovation incentives resulting from less patent protection could be offset by more generous tax credits. However, weaker patent protections will make it unambiguously cheaper for future innovators to build on the existing cleantech knowledge stock.

\section{B. Non-Innovation Policy}

While a first-best climate innovation policy would partner a carbon tax with increases in financial support for cleantech R\&D, optimal policymaking is rarely an option in a world with political constraints. Thus, it is also worth considering the implications of innovation snowballing for second-best approaches to cleantech innovation. This subsection examines four general policies: (1) performance standards; (2) deployment subsidies; (3) government procurement; and (4) infrastructure choices. Since governments already deploy these tools in the energy space, they provide opportunities to align climate policy with the implications of innovation snowballing.

\section{Performance Standards}

To reduce pollution levels, U.S. policymakers have often relied on performance standards that specify the environmental performance of a regulated entity. As discussed in Part $I$, performance standards have a recognized secondary objective of promoting innovation in abatement technologies. ${ }^{183}$ While scholars have debated whether performance standards or market-based approaches are more effective at inducing innovation, ${ }^{184}$ there is strong evidence that at least some performance standards have incentivized technological advancements in the past. ${ }^{185}$ Even so, few economists believe that even successful performance

183. Stewart, supra note 9, at 1296 (describing how existing command-and-control regulatory programs "have fallen far short of ambitious technology-forcing goals."); La Pierre, supra note 51, at 771 (characterizing "spurring the technological changes necessary to reduce pollution levels" as one of the main tasks that Congress attempted to accomplish through environmental legislation during the 1970s).

184. Compare Ayres \& Kapczynski, supra note 21, at 1817 (arguing that performance standards can serve as "innovation sticks" and pointing to CAFE standards as a successful example of a technology-forcing standard), with Sunstein, supra note 9, at 420 (arguing that best adequate technology standards under the Clean Air Act perversely discourage innovation). See also Popp, supra note 43 , at $283-84$ (reviewing recent research that has complicated the perceived comparative effectiveness of market-based policies and command-and-control regimes at incentivizing innovation in pollution mitigation technologies).

185. See Ayres \& Kapczynski, supra note 21, at 1815-17 (reviewing the literature on the effects of CAFE standards on vehicular innovation). 
standards are part of the optimal solution to pollution; instead, a pollution tax is the preferred tool. Nevertheless, these standards persist, making it worthwhile to consider how innovation snowballing affects their desirability and specifically how these spillovers raise concerns about dirtytech lock-in.

Some technology-forcing performance standards have driven environmentally beneficial technological development. For example, the Corporate Average Fuel Economy (CAFE) Standard is arguably a climate success story for its impact on greenhouse gas emissions. ${ }^{186}$ This performance standard substantially raised the fuel efficiency of American vehicles since its inception in $1975,{ }^{187}$ and stricter standards for 2025 promise to reduce carbon output from the transportation sector by six billion metric tons. ${ }^{188}$

Innovation snowballing, however, raises concerns about the use of performance standards like CAFE. To date, CAFE has worked to build up the knowledge stock of fossil-fuel vehicles. But many argue that climate stability requires a major shift away from the internal combustion engine and towards zero-emission cars like electric plug-in and fuel cell vehicles. ${ }^{189}$ If so, then CAFE standards may perversely undermine climate efforts to the extent that they direct innovation away from zero-emission cars and toward improving the fuel efficiency of fossil-fuel vehicles. In particular, if automakers believe they can more cost-effectively meet federal fuel-economy requirements by improving the efficiency of their

186. See id.; Virginia McConnell, The New CAFE Standards: Are They Enough on Their Own? 1 (Res. for the Future, Discussion Paper No. 13-14, 2013) (observing that "the early CAFE requirements are considered a success by many"); COMM. ON THE EFFECTIVENESS \& IMPACT OF CORP. AVERAGE FUEL ECON. (CAFE) STANDARDS, EFFECTIVENESS AND IMPACT OF CORPORATE AVERAGE FuEL ECONOMY (CAFE) STANDARDS 3 (2002) (concluding that " $[\mathrm{t}]$ he CAFE program has clearly contributed to increased fuel economy of the nation's light-duty vehicle fleet during the past 22 years.").

187. Fairly ambitious fuel economy standards in the 1970 s and $1980 \mathrm{~s}$, for example, helped double the mileage of passenger cars and increase the fuel economy of light trucks by fifty percent. Id. at 14 While some of these efficiency gains came from reducing vehicle size, others have been attributed to technological advancements in fuel efficiency. $I d$.

188. For a review of the effects of earlier CAFE standards on emission levels, see id. at 20 (calculating that "improvements in light-duty vehicle fuel economy have reduced overall U.S. emissions by about 7 percent").

189. See, e.g., James H. Williams et Al., ENERGy \& ENVTL. ECON. (E3), PATHWays to DeEP DECARBONIZATION IN THE UNITED STATES (2015), http://deepdecarbonization.org/wpcontent/uploads/2015/11/US_Deep_Decarbonization_Technical_Report_Exec_Summary.pdf (concluding that meeting 2050 climate-stabilization targets requires a massive shift to electric vehicles); James H. Williams et al., The Technology Path to Deep Greenhouse Gas Emissions Cuts by 2050: The Pivotal Role of Electricity, 335 SCI. 53, 53 (2012) (finding that "widespread electrification of transportation and other sectors is required" to "meet California's goal of an $80 \%$ reduction below 1990 levels" by 2050). 
gasoline-powered vehicles rather than by increasing the share of zeroemission vehicles in their fleet, the innovation gap between zero-emission vehicles and fossil-fuel cars will increase. ${ }^{190}$

Similarly, innovation snowballing raises some concerns about the design of the Clean Power Plan, President Obama's signature climate change initiative. ${ }^{191}$ According to projections made by the U.S. Energy Information Agency, this performance standard for the electricity grid would not only boost wind and solar production, but also lead to sizeable increases in electricity produced by natural gas. ${ }^{192}$ Given path dependency, this expansion in natural gas could be problematic, as natural gas proponents and opponents alike view the resource as a temporary "bridge" to the zero-emission energy system of the future. ${ }^{193}$ Regulations that induce natural gas production, however, may unintentionally widen the knowledge gap between natural gas and cleantech, making it ultimately harder to later transition to wind and solar. ${ }^{194}$

This analysis suggests that the design of the performance standard is

190. Notably, concerns about path dependency in automotive innovation are not merely theoretical in nature. As discussed earlier, careful empirical work has shown that dirty (clean) automotive innovations are strongly linked to a firm's past innovations in dirty (clean) car technologies. See Aghion et al., supra note 15, at 1.

191. Carbon Pollution Emission Guidelines for Existing Stationary Sources: Electric Utility Generating Units, 80 Fed. Reg. 64,662 (Oct. 23, 2015) (to be codified at 40 C.F.R. pt. 60).

192. Laura Martin \& JeFFrey JONES, ENERGY INFO. ADMIN., ReP. No. DOE/EIA-0383, ANNUAL ENERGY OUTLOOK 2016 WITH PROJECTIONS TO 2040 (2016), https://cepl.gatech.edu/sites/default/files/attachments/AEO2016.

193. Compare StePhen P.A. Brown, Alan J. KRUPNick \& Margaret A. Walls, Res. for ThE Future, NATURAl Gas: Is IT A BRIDGE to a Low-CARbon Future? 2 (2009) (expressing optimism that natural gas can play a useful role as "a bridge fuel to a low-carbon future"), with Parenteau \& Barnes, supra note 13, at 328 (recognizing natural gas' environmental advantages over coal, but warning of the risks of natural gas' long-term entrenchment in the U.S. energy system).

194. Importantly, although the Clean Power Plan would likely benefit natural gas, regulators took a number of steps to protect against the risk of natural gas lock-in. First, EPA closed a loophole in the proposed rule that would have allowed states to replace coal-fired power plants with newly constructed natural gas plants that would not be covered by the Clean Power Plan. Second, the rule limits the extent to which shifts from existing coal to existing natural gas can count for compliance purposes. And third, the Clean Power Plan created the Clean Energy Incentive Program, a voluntary mechanism that incentivizes states to invest in wind, solar, and energy efficiency resources in the near term. See generally Rachel Cleetus, Four Ways the Final Clean Power Plan Limits the Rush to Natural Gas, UNION OF CONCERNED SCIENTISTS (Aug. 7, 2015, 3:46 PM), http://blog.ucsusa.org/rachelcleetus/four-ways-the-final-clean-power-plan-limits-the-rush-to-natural-gas. Specifically, renewable energy projects developed prior to the official roll-out of the Clean Power Plan receive extra emission credits, which they can then sell when the regulation's carbon markets come online. Thus, while the first two modifications to the Clean Power Plan work to prevent a "dash to gas" and a subsequent widening of the gas-renewable knowledge gap, the Clean Energy Incentive Program proactively closes the knowledge gap by directing investors and innovators towards specified emission-free technologies. See id.; Dallas BURTRAw ET AL., RES. FOR THE FutURE, APPROACHES TO AdDRESS POTENTIAL CO2 EMISSIONS LEAKAGE tO NEW SOURCES UNDER THE ClEAN POWER PLAN (2016), http://www.rff.org/files/document/file/RFF-Rpt-CPPCommentstoEPA160121_1.pdf. 
important to its effectiveness at building the cleantech knowledge stock. Not all performance standards that reduce emissions close the cleantechdirtytech innovation gap. It also suggests that other tools may be worthy of consideration, like state renewable portfolio standards that specifically require cleantech energy sources, which evidence suggests have increased innovation in wind and solar technologies. ${ }^{195}$ In short, policymakers should not automatically equate emissions reductions with the closing of the cleantech-dirtytech knowledge gap. While policymakers can design performance standards to simultaneously lower pollution levels and redirect innovation towards cleantech, a myopic focus on near-term emissions reductions may unintentionally hinder the growth of cleantech innovation - and ultimately hinder emissions reductions - in the long term. In this way, too little attention to the long-term dynamics of innovation can produce counter-productive results.

\section{Deployment Subsidies}

Broadly speaking, deployment subsidies directly reward the adoption of, rather than research into, a particular technology. Prominent examples include the Production Tax Credit for wind and the Investment Tax Credit for solar. ${ }^{196}$ Green finance models-such as Property Assessed Clean Energy programs, loan guarantees from state Green Banks, and on-bill energy efficiency financing mechanisms - also fall under the heading of deployment subsidies, as these programs reduce the costs of building or adopting cleantech. ${ }^{197}$ According to the conventional policy analysis view, such subsidies are poor uses of taxpayer dollars, since the externalities (either positive for innovation or negative for pollution) should instead be targeted directly. ${ }^{198}$ If the positive spillovers come from R\&D, not

195. See Nathaniel Homer et al., Effects of Government Incentives on Wind Innovation in the United States, 8 ENVTL. RES. LETTERS 1, 1 (2013) (finding that renewable portfolio standards had a positive effect on U.S. wind innovation, as measured by patenting activity).

196. 26 U.S.C. $\S 48$ (2012) (investment tax credit); 26 U.S.C. $\S 45$ (2012) (production tax credit). See Dan Reicher, Setting the Climate Agenda for the Next President: Toward a More Effective Federal Clean Energy Toolkit 6 (Stan. Climate Implementation Project, Discussion Paper, 2016) (describing how federal tax credits have functioned as "key federal tools in incentivizing large-scale deployment of clean energy technologies" in the United States).

197. See Richard L. Ottinger \& John Bowie, Innovative Financing for Renewable Energy, 32 PACE ENVTL. L. REV. 701, 701 (2015) (discussing successful new finance mechanisms for renewable energy sources). See also generally Michael B. Gerrard, Introduction and Overview, in THE LAW OF CLEAN ENERGY: ENERGY EFFICIENCY AND RENEWABLES (Michael B. Gerrard ed., 2011) (reviewing innovative finance mechanisms for renewables and energy efficiency resources)

198. See e.g., COMM. ON THE EFFECTS OF PRovisions IN THE INTERNAL REVENuE Code ON Greenhouse Gas Emissions et al, EfFects of U.S. TAX POLICy ON GREenhouse Gas Emissions 
deployment, then the most efficient way of encouraging the spillovers is directly targeting the $R \& D$, since the impact of deployment subsidies is split between inducing R\&D and encouraging the adoption of existing technology. We do not take a stand on whether they are good or bad policy, but we offer a qualified defense that they are better policy than generally believed in light of innovation snowballing.

Innovation spillovers alone might justify government use of deployment subsidies. The existence of learning-by-using externalities would lead to suboptimal adoption rates and diffusion rates of emergent clean technologies, such as wind and solar, if the externalities are particularly large for these technologies. ${ }^{199}$ Innovation snowballing, however, further strengthens the case for deployment subsidies, as these policy instruments increase the knowledge stock of cleantech. Specifically, because deployment subsidies make cleantech more profitable, they have the indirect effect of making cleantech $R \& D$ more profitable. As a result, deployment subsidies can help direct innovation flows (including scientists and capital) away from dirtytech and towards cleantech. And, indeed, emerging empirical work suggests that cleantech deployment subsidies, including investment incentives and feed-in tariffs (in which governments guarantee a certain payment to energy producers), have significantly increased cleantech innovation, although innovation-inducing effects appear to vary across subsidy policies and types of clean energy technology. ${ }^{200}$ These findings make intuitive sense: just like a price shock to oil prices or a carbon tax induces cleantech innovation by changing the relative prices of producing cleantech and dirtytech, a deployment subsidy similarly alters relative prices by bringing down the price of cleantech. ${ }^{201}$ In this way, cleantech deployment subsidies do more than reducing

10 (William D. Nordhaus et al., eds. 2013) (concluding that "current tax expenditures and subsidies are a poor tool for reducing greenhouse gases and achieving climate-change objectives").

199. See Gillingham \& Sweeney, supra note 30, at 86-87 (discussing how government might intervene to addressing learning-by-doing, learning-by-using, and network externalities).

200. See, e.g., Nick Johnstone, Ivan Hascic \& David Popp, Renewable Energy Policies and Technological Innovation: Evidence Based on Patent Counts, 45 ENVTL. \& RES. ECON. 133, 133 (2010). It should also be stressed that this empirical literature is still in its infancy. For example, extant research has produced mixed conclusions about the innovation effects of the U.S. wind tax credits. Compare ElleEN HLAVka, POLICY IMPACTS ON WIND AND SOlaR INNOVATION (RAND 2013) (finding tax credits had positive impact on number of relevant academic journal articles published per month), with Horner et al., supra note 195, at 1 (finding that tax credits have not increased patenting activity among wind technologies).

201. Newell, Jaffe \& Stavins, supra note 71 , at 971 (showing that oil price spikes biased innovation in air conditioning toward producing more energy efficient units); Popp, supra note 19, at 160 (demonstrating that higher energy prices directed innovation toward energy-saving inventions); Aghion et al., supra note 15, at 3 (finding that higher fuel prices direct innovation toward cleaner forms of automobile innovation). 
greenhouse gas emissions in the near term; they also promise to build up the cleantech innovation stock over the long term.

In addition to highlighting the underappreciated benefits of cleantech deployment subsidies, innovation snowballing also exacerbates the irrationality of existing fossil fuel subsidies. Globally, fossil fuels receive hundreds of billions of dollars in government subsidization each year. ${ }^{202}$ Factoring in the "subsidy" that fossil fuel producers receive from not having a price on carbon raises this annual total into the trillions. ${ }^{203}$ Subsidization of fossil fuels far outstrips support for clean energy: indeed, global consumption subsidies alone are more than four times greater for fossil fuels than for renewable energy resources. ${ }^{204}$ This allocation of subsidies not only leads to increased greenhouse gas emissions in the short run but also widens the cleantech-dirtytech knowledge gap, with longlasting effects on innovation. ${ }^{205}$

\section{Government Procurement}

As with deployment subsidies, innovation snowballing increases the attractiveness of government procurement of cleantech. Those expenditures function like cleantech deployment subsidies in that they increase demand for cleantech, and therefore the profitability of cleantech R\&D. ${ }^{206}$ Moreover, governments wield substantial purchasing power that could shift market outcomes in favor of cleantech. In the United States, for example, the federal government is the single largest consumer of energy and vehicles, ${ }^{207}$ and federal agencies manage a little less than a third of all

202. Comparison of Fossil-Fuel Subsidy and Support Estimates, INT'L INST. FOR SUSTAINABLE DEV, https:/www.iisd.org/gsi/sites/default/files/ffs_methods_estimationcomparison.pdf (last visited July 28,2017 ) (summarizing estimates from various studies).

203. David Coady et al., How Large Are Global Energy Subsidies? 29 (Int'l Monetary Fund, Working Paper No. WP/15/105, 2015) (estimating that post-tax subsidies for petroleum alone to be about $\$ 1.6$ trillion in 2013).

204. Energy Subsidies, WORLD ENERGY OUTLOOK, http://www.worldenergyoutlook.org/reso urces/energysubsidies/ (last visited July 28, 2016).

205. In 2009, members of the G20 pledged to phase out inefficient fossil fuel subsidies. They have yet, however, to fulfill this promise. Alison Kirsch \& Timmons Roberts, Ghosts of Resolutions Past: The G20 Agreement on Phasing out Inefficient Fossil Fuel Subsidies, BROOKINGS: PlANETPOLICY (Nov. 14, 2014), https://www.brookings.edu/blog/planetpolicy/2014/11/14/ghosts-ofresolutions-past-the-g20-agreement-on-phasing-out-inefficient-fossil-fuel-subsidies/.

206. See Amy L. Stein, Renewable Energy Through Agency Action, 84 U. CoLo. L. REv, 651, 688-92 (2013).

207. U.S. GOV'T ACCOUNTABILITY OfFICE, GAO 17-43, INDIAN ENERGY DEVELOPMENT: AdDitional actions by Federal Agencies ARE NeEded To OVERCome Factors Hindering DEVELOPMENT (2016) (observing that "the federal government [is] the largest single consumer of energy in the nation"); COMM. ON OVERCOMING BARRIERS TO ELECTRIC VEHICLE DEPLOYMENT ET 
U.S. land. ${ }^{208}$ The Department of Defense alone owns more than 200,000 buildings, operates about 200,000 non-tactical vehicles, and has an annual electricity bill of roughly $\$ 4$ billion. ${ }^{209}$ And there are many ways in which the government could expand its procurement for cleantech. For instance, electric vehicles currently constitute about one percent of the U.S. federal government's fleet. ${ }^{210}$ Electrifying the entire fleet, however, would more than double the number of zero-emission vehicles currently on the roads. ${ }^{211}$ The government could similarly expand demand for clean electricity technologies by increasing its share of electricity from renewable power sources, which currently stands at about eight percent, ${ }^{212}$ or by making it easier for wind and solar developers to build on the roughly 640 million acres of federal lands. ${ }^{213}$

To be sure, there are tradeoffs and constraints to redirecting government procurement towards cleantech. Governments have a duty to spend taxpayer dollars wisely, and agencies may balk at having to pay a premium for cleantech. ${ }^{214}$ Moreover, "going green" can, in some cases, result in unacceptable losses of government functionality. For instance, with the current state of technology, electrifying certain types of military vehicles may not be feasible. ${ }^{215}$ In making these calculations, however, innovation snowballing should be considered, as the government's vast consumer purchasing power makes it uniquely situated to subsidize cleantech innovation and help close the cleantech-dirtytech innovation gap.

Al., OVERCOMING BARRIERS TO DEPLOYMENT OF PLUG-IN ElECTRIC VEHICLES 59 (2015).

208. Carol hardy VINCENT ET AL., CONG. Res. SERV., R42346, Federal LAND OWNERShip: OVERVIEW AND DATA 3 (2014) (estimating that the government owns about twenty-eight percent of the 2.27 billion acres of land in the United States).

209. See Stein, supra note 206 , at 697.

210. See COMm. ON OVERCOMing BARRIERs to Electric VehICle DePloyment ET AL., supra note 207, at 60 (noting that even the Department of Energy's vehicle fleet is only 0.73 percent electric).

211. The size of the federal government's non-tactical fleet has been estimated at about 400,000 vehicles. See Reicher, supra note 196, at 21. In 2014, cumulative sales of electric vehicles in the United States came in under 300,000 vehicles. See generally DAVID BLOCK ET AL., ELEC. VeHICLE Transp. CTR., EleCtric Vehicle SAles For 2014 AND FutURE Projections (2015).

212. In 2015 , approximately 8.3 percent of electricity used by the federal government came from renewables. Comprehensive Annual Energy Data and Sustainability Performance, U.S. DEP'T OF ENERGY, http://ctsedwweb.ee.doe.gov/Annual/Report/FederalAgencyUseRenewableElectricAsPerce ntageOfElectricityUse.aspx (last visited on July 28, 2017).

213. VINCENT ET AL., supra note 208.

214. See Stein, supra note 206 , at 655 (raising these same concerns).

215. For a discussion of the Department of Defense's efforts to integrate renewables into their energy supply, see generally PeW ChartTable Trs., POWER Surge: How the DePartment of

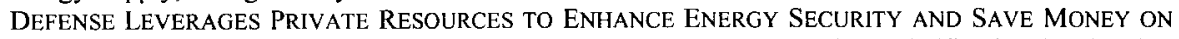
U.S. MLITARY BASES (2014), http://www.pewtrusts.org/ /media/legacy/uploadedfiles/peg/publication s/report/pewdodreport2013ks10020314pdf.pdf. 


\section{Infrastructure}

Finally, government infrastructure spending can also significantly influence the direction of technological change. For instance, the interstate highway system - the largest public works project undertaken by the U.S. government to date-has played a pivotal role in orienting the transportation sector away from mass transit and towards the personal automobile. ${ }^{216}$ More recently, environmentalists have raised concerns about permitting the construction of new oil and natural gas pipelines, such as Keystone XL and the Dakota Access pipelines. ${ }^{217}$ Although these projects would be built using private, rather than taxpayer, dollars, environmentalists and others have argued that approving such infrastructure entrenches and encourages fossil fuel growth. ${ }^{218}$ Given that pipelines last for decades, ${ }^{219}$ these fears of capital lock-in are not unfounded.

Innovation snowballing adds a new dimension to these infrastructure decisions by raising the specter of not only physical capital lock-in but also innovation lock-in. ${ }^{220}$ As with the transportation sector, innovation in energy technologies are often shaped by the physical infrastructure of the energy system. ${ }^{21}$ For example, Thomas Edison wired his original electric

216. Transp. Research Bd, CONSEquences of the Interstate Highway System for TRANSIT: SUMMARY OF FINDINGS 5 (1998), http://onlinepubs.trb.org/onlinepubs/tcrp/tcrp_rpt_42.pdf (finding that interstate highway funding biased transportation investments in favor of automobiles and against public transit); COMM. ON OVERCOMING BARRIERS TO ELECTRIC VEHICLE DEPLOYMENT ET AL., supra note 207, at 1 (observing that, in 1900, nearly a third of passenger cars sold in the United States were electric and attributing the decline of the electric vehicle partly to the "development of the national highway system, which allowed long-distance travel").

217. See, e.g., Merrit Kennedy, Judge Rules that Construction Can Proceed on Dakota Access Pipeline, NPR (Sept. 9, 2016, 3:38 PM), http://www.npr.org/sections/thetwo-way/2016/09/09/493 280504/judge-rules-that-construction-can-proceed-on-dakota-access-pipeline (describing how the Dakota access pipeline has "galvanized Native American tribes and environmentalists across the U.S."); Coral Davenport, Citing Climate Change, Obama Rejects Construction of Keystone XL Oil Pipeline, N.Y. TIMES (Nov. 6, 2015), http://www.nytimes.com/2015/11/07/us/obama-expected-toreject-construction-of-keystone-xl-oil-pipeline.html (describing how the Keystone XL pipeline "gained an outsize profile after environmental activists spent four years marching and rallying against it").

218. Parenteau \& Barnes, supra note 13 , at 328.

219. Notably, only about a third of existing U.S. gas pipeline infrastructure was built after 1980 . See James Conca, It Really Is Our Aging Energy Infrastructure, ForBEs (May 21, 2015, 6:35 AM) http://www.forbes.com/sites/jamesconca/2015/05/21/its-our-aging-energy-infrastructure-stupid/ $9 \mathrm{a} 730 \mathrm{~b} 47 \mathrm{~cd} 38$ (citing Department of Energy data for this statistic).

220. See REVESZ \& LIENKE, supra note 13 (describing capital lock-in).

221. Keith Smith, Economic Infrastructures and Innovation Systems, in SYSTEMS OF INNOVATION: TECHNOLOGIES, INSTITUTIONS AND ORGANIZATIONS 86, 88 (Charles Edquist ed., 1997) (arguing that most complex technologies-including consumer electric, information and communication, and aeronautic- have evolved around and been shaped by physical infrastructure). 
lighting systems using existing networks of gas transmission pipelines, the dominant technology at the time. ${ }^{222}$ More recently, many have argued that the physical infrastructure of today's electricity grid - which was designed for connecting large, centralized power sources to faraway population centers-has impeded the growth of emergent distributed generation technologies. ${ }^{223}$ Decisions that expand the physical infrastructure that undergirds fossil fuel innovation may perversely perpetuate and exacerbate the cleantech-dirtytech innovation gap. Thus, in permitting new cleantech or dirtytech infrastructure, policymakers should account for the dynamic and path-dependent nature of innovation.

Government can do more than simply limit the extent to which infrastructure choices widen the clean-dirty knowledge gap. It can also affirmatively promote cleantech innovation through infrastructure spending. A prominent example of this proactive approach is former President Obama's initiative to expand and enhance electric vehicle fueling infrastructure. In addition to providing $\$ 4.5$ billion in loan guarantees to electric vehicle charging facilities, the Obama Administration established forty-eight national electric-vehicle charging corridors that span more than thirty states. ${ }^{224}$ With the help of states, utilities, and manufacturers, President Obama established plans to develop sufficient charging infrastructure along these corridors to enable coast-tocoast travel by electric vehicles. ${ }^{225}$ These efforts will not only spur current demand for electric vehicles, but also lay the foundations for future innovations in zero-emission transportation technologies.

222. Unruh, supra note 68 , at $318-19$

223. Broadly speaking, distributed generation technologies are smaller-scale energy resources owned by electricity consumers, including rooftop solar, combined heat and power, micro turbines, energy storage, and demand-side management products. See N.Y. INDEP. SYS. OPERATOR, A REVIEW OF Distributed Energy Resources 1 (2014). See also Elec. Power Research Inst., The INTEGRATED GRID: REALIZING THE FULl VALUE OF CENTRAL AND DISTRIBUTED ENERGy RESOURCES 3 (2014) (observing that the current grid "was not designed to accommodate a high penetration of [distributed energy resources] while sustaining high levels of electric quality and reliability"); Eric Gimon, Is the Transmission Grid Ready for Aggregated Distributed Energy Resources?, GREENTECH MEDIA (Apr. 6, 2016), https://www.greentechmedia.com/articles/read/is-the-transmission-grid-readyfor-aggregated-distributed-resources (noting that "[d]istribution utilities must overcome considerable physical challenges to enable the participation of distributed resources in the transmission grid").

224. Press Release, White House, Obama Administration Announces New Actions To Accelerate the Deployment of Electrical Vehicles and Charging Infrastructure (Nov. 3, 2016), available at https://www.whitehouse.gov/the-press-office/2016/1 1/03/obama-administration-announces-newactions-accelerate-deployment.

225. Id. 


\section{INTERNATIONAL POLICY}

\section{A. Innovation in the International Regime}

The challenges of addressing innovation snowballing are daunting for a single government. But the task becomes significantly more complicated when trying to coordinate across the globe. Innovations spread across the globe for many reasons, including international trade, ${ }^{226}$ foreign direct investment, ${ }^{227}$ the international migration of scientists ${ }^{228}$, and international scientific research collaborations. ${ }^{22}$ Though empirical work shows that technology diffusion "decays" with geographical distance, ${ }^{230}$ estimates suggest there is indeed a great deal of technology diffusion across borders. ${ }^{231}$

Thus, how one nation innovates affects the direction of innovation for the rest of the world; countries' directions of technological progress are interdependent. For example, if the United States produces more cleantech innovation, not only domestic but also global innovation will be redirected toward cleantech, further reducing the risk of climate change. Innovation snowballing is, in short, a global issue: individual countries can adopt cleantech innovation policies, but the total global response to climate change largely determines the direction of innovation. And, as noted earlier, experts believe that current global cleantech R\&D spending levels are far below what is needed to transition to clean energy sources. ${ }^{232}$

226. Wolfgang Keller, International Technology Diffusion, 42 J. ECON. LITERATURE 752, 752 (2004) (identifying imports as a "significant channel of technology diffusion.").

227. Wolfgang Keller, International Trade, Foreign Direct Investment, and Technology Spillovers, in HANDBOOK OF THE ECONOMICS OF INNOVATION 796 (Bronwyn H. Hall \& Nathan Rosenberg eds., 2010) (identifying foreign direct investment a key potential channel for international technology spillovers).

228. William R. Kerr, Ethnic Scientific Communities and International Technology Diffusion, 90 REV. ECON. \& STAT. 518, 518 (2008) (finding strong empirical evidence that U.S. ethnic scientific communities transfer technology and information to their home countries); Petra Moser et al., German Jewish Emigrés and US Invention, 104 AM. ECON. REV. 3222, 3222 (2014) (finding that German Jewish emigres to the United States during World War II substantially increased patenting by US inventors).

229. Valentina Bosetti et al., International Energy $R \& D$ Spillovers and the Economics of Greenhouse Gas Atmospheric Stabilization, 30 ENERGY ECON. 2912, 2913 (2008) (discussing how knowledge flows "circulate among world research laboratories, the so-called disembodied knowledge flows").

230. Wolfgang Keller, Geographic Localization of International Technology Diffusion, 92 AM. ECON. REV. 120, 120 (2002) (finding that the "distance at which the amount of spillovers is halved is about 1,200 kilometers").

231. See Keller, supra note 226, at 776 (underscoring the "significance of international technology diffusion," based on a detailed survey of the economics literature).

232. See KERR \& CHIAVARI, supra note 86 (describing these estimates). It is not obvious that 
Furthermore, not only does each new "imported" cleantech innovation increase the productivity of other countries' innovations in cleantech; it also increases their cleantech absorptive capacity, making it easier to appropriate future cleantech inventions. ${ }^{233}$ Research suggests that firms with more developed $R \& D$ programs tend to also be better at identifying and appropriating technological inventions produced by other firms. ${ }^{234} \mathrm{In}$ other words, appropriating external innovation requires a certain level of skill, investment, and knowledge. ${ }^{235}$ At the country level, these differences in absorptive capacity translate into the uneven dispersion of knowledge, with international innovation spillovers tending to be larger for countries that spend more on domestic R\&D and have more educated workforces. ${ }^{236}$

Innovations diffuse across borders, redirecting technological development and changing countries' abilities to absorb future developments. Countries' paths of technological development are interdependent; the needed cleantech innovation snowball is largely a global one. The next subsection works out policy implications.

\section{B. Implications}

An optimal response to climate change would involve a global carbon tax to address the negative externality of greenhouse gas emissions and a global cleantech innovation subsidy to address innovation snowballing. Since no global government exists to implement the optimal policy and these are not realistic goals in today's geopolitical climate, we instead examine how existing international frameworks could address innovation snowballing, as existing policies give the best guidance on what is feasible internationally. We concentrate our attention on three promising

standard spillovers lead to underinvestment, since countries have motivations to invest in knowledge production that the conventional account fails to capture, like the production of local agglomeration economies. See Daniel J. Hemel \& Lisa Larrimore Ouellette, Knowledge Goods and Nation-States, 101 MINN. L. REV. 167, 175-76 (2016) (making this argument). The same argument could in principle apply to innovation snowballing, but the low current spending level suggest that the argument does not apply in this context.

233. For one of the first discussions of absorptive capacity, see Wesley M. Cohen \& Daniel A. Levinthal, Innovation and Learning: The Two Faces of R\&D, 99 ECON. J. 569, 569 (1989).

234. Cohen \& Levinthal, supra note 233 , at 569 (arguing that conducting R\&D not only generates new information for the firm, but "also enhances the firm's ability to assimilate and exploit existing information").

235. Bronwyn H. Hall, The Financing of Research and Development, 18 OXFORD REV. ECON. POL'Y 35, 35 (2002) (citing literature suggesting that the costs of acquiring external R\&D can be quite high).

236. David T. Coe et al., International R\&D Spillovers and Institutions 4 (Nat'l Bureau of Econ. Research, Working Paper No. 14069, 2008) (finding with regression analysis that countries where the "quality of tertiary education systems are relatively high tend to benefit more" from international R\&D spillovers). 
international mechanisms: (1) the Paris Agreement, (2) knowledge-sharing platforms, and (3) international intellectual property rights.

\section{The Paris Agreement}

A historic accomplishment in climate negotiations, the Paris Agreement stands as the main international mechanism for addressing global warming in the near term. Innovation, however, does not feature prominently in the Agreement. Instead, the Agreement focuses primarily on emission reductions. ${ }^{237}$ Specifically, signatories submit Intended Nationally Determined Contributions (INDCs), which detail the emission reductions that a country pledges to take. ${ }^{238}$ The Agreement calls for the creation of reporting and monitoring mechanisms that will enable the public to track countries' progress towards their individual targets. ${ }^{239}$ Starting in 2020 , signatories will return to the negotiating table to revisit their climate contributions, the theory being that the publicizing of INDC progress will pressure (or shame) countries into achieving and strengthening their emission-reduction pledges.

Largely missing from Paris (and its predecessors) is the recognition that not all emission reductions are equal. The framework essentially equates an emission reduction due to closing a coal-fired power plant with an emission reduction resulting from innovation in solar technologies, even though the latter also helps build a cleantech innovation snowball. Indeed, the vast majority of submitted INDCs simply report climate targets as emission reductions relative to a baseline level - and most analysts have evaluated the ambitiousness of Paris by aggregating emission-reduction pledges. ${ }^{240}$ To be fair, the transparency framework for tracking Paris Agreement progress is still in the works, ${ }^{241}$ and there will likely be calls in the upcoming years for countries to add detail to and improve the quality

237. Suggestively, the word "emission" is used twenty-five times in the text of the main Paris Agreement; the word "innovation" is only used once. See Conference of the Parties, Adoption of the Paris Agreement, U.N. Doc. FCCC/CP/2015/L.9 Art. 10 (Dec. 12, 2015).

238. For an overview of the Paris Agreement, see Savaresi, supra note 25, at 16.

239. Gregory Briner \& Sara Moarif, Unpacking Provisions Related to Transparency of Mitigation and Support in the Paris Agreement 9 (Org. for Econ. Coop. and Dev., Climate Change Expert Grp., Paper No. 2016(2), 2016) (describing reporting and negotiation timeframes under the Paris Agreement).

240. See, e.g., Joeri Rogelj et al., Paris Agreement Climate Proposals Need a Boost to Keep Warming Well Below $2^{\circ}$ Celsius, 534 NATURE 631, 631 (2016) (modeling the potential effects of INDC emission-reduction pledges on global temperatures).

241. Eliza Northrop \& Melisa Krnjaic, After COP21: 7 Key Tasks to Implement the Paris Agreement, WORLD RESOURCES INST. (Mar. 4, 2016), http://www.wri.org/blog/2016/03/after-cop21-7key-tasks-implement-paris-agreement. 
of their INDCs. ${ }^{242}$ But, the Agreement provides little guidance as to what information should be reported on domestic mitigation measuresinformation that will be crucial to evaluating a country's contribution to addressing innovation spillovers. ${ }^{243}$ Thus, apart from a side agreement called Mission Innovation that appears to have little prospect of leading to substantial increases in innovation support, how emissions are reduced appears secondary to the reduction itself. ${ }^{244}$

Given the importance of innovation snowballing to optimal climate policy, two modifications could improve the Agreement's focus on cleantech innovation. First, the transparency framework could be augmented to include an array of cleantech innovation indicators. For example, countries could be encouraged to report government funding of cleantech R\&D, subsidization of cleantech adoption, and procurement of emergent cleantech-among other things. Other indicators might focus more on innovation outcomes, rather than inputs, such as numbers of cleantech patents filed per year or adoption rates of emergent technologies (appropriately normalized to, say, GDP). Since developed countries are required under the Paris Agreement to provide data on their climate finance to developing countries, ${ }^{245}$ the burdens of reporting additional data on cleantech innovation metrics (e.g., government R\&D spending) would likely be minimal. But data on other potential indicators of cleantech innovation (e.g., deployment subsidies to cleantech) might be more

242. See, e.g., Harv. Project on Climate Agreements, The Paris Agreement and Beyond: InTERnational Climate Change Policy Post-2020 13 (Robert N. Stavins \& Robert C. Stowe eds., 2016) ("It is essential to improve the quality of NDCs.").

243. Briner \& Moarif, supra note 239 , at 9 (noting that "it remains unclear what information is to be reported on domestic mitigation measures and what methodological consistency means in practice").

244. In Mission Innovation, an initiative announced during the final weeks of the Paris negotiations, twenty-one countries pledged to double their public investment in clean energy R\&D within five years. See MISSION INNOVATION SECRETARIAT, supra note 85, at 3 . However, countries' pledges are voluntary and nonbinding, and signatories can exit at any time. Id. at 4 . Perhaps partly for this reason, there was little indication that countries were following through on their commitments under Mission Innovation, even before the election of President Trump. See Umair Irfan, A Grim Prognosis for Mission Innovation under Trump, E\&E NEWS (Jan. 9, 2017), https:/www,eenews.net/stories/1 060048035/ (observing that "the United States is already behind schedule on its journey to double clean energy R\&D"). Another development was the creation of Breakthrough Energy Coalition, a $\$ 1$ billion venture capital fund committed to investing in climate solutions that may take many years to yield results. See Kirsten Korosec, Bill Gates Is Heading a \$1 Billion Clean Energy Venture Fund, FORTUNE (Dec. 11, 2016), http://fortune.com/2016/12/11/billgates-john-doerr-venture-fund/. While helpful, the sums involved are small relative to what is needed, especially since the effective subsidy is far smaller than the total funding, since the investors expect to not only recoup their investment but also make a profit-just with a tolerance for risk and slow returns.

245. See U.N. Conference of the Parties, Adoption of the Paris Agreement, U.N. Doc. FCCC/CP/2015/L.9 Art. 9.7 (Dec. 12, 2015). 
difficult to obtain, in which case qualitative descriptions of innovation policy may have to suffice. Ultimately, the goal of this proposal is to focus public and policy attention on the importance of cleantech innovation. If countries begin reporting on cleantech innovation metrics, then public pressure could - in line with the overall logic of the Paris model-induce countries to commit more resources toward cleantech innovation.

Second, and relatedly, future negotiations could explicitly account for cleantech innovation by asking countries to submit a separate cleantech innovation INDC. Given the importance of innovation snowballing, the Paris Agreement could be restructured to require two INDCs: one pledging reductions in emissions, the other pledging increases in cleantech innovation. In short: two INDCs for the two important components in mitigating global climate change. While there may be substantial overlap in how a country plans to achieve each INDC (e.g., tax credits for wind not only induce greater cleantech innovation but also reduce total emissions), doing so would account for the fact that reductions through innovation are more valuable globally than those through cut-backs or switches to existing technology.

At a minimum, a cleantech INDC could contain the following three features. First, comparable measurements of cleantech innovation investment would help promote a clearer understanding of countries' contributions to the global cleantech knowledge stock. This task, however, would be tricky, as different governments will likely want different definitions of what constitutes cleantech. Comparability of metrics would support the second recommendation for a cleantech INDC: verification. Built upon a set of agreed-upon definitions of what constitutes cleantech support, external verification would pressure countries into achieving their voluntary cleantech targets. While not easy, such a restructuring could bring clarity, attention, and urgency to the problem of cleantech innovation spillovers.

Third, private-sector innovation should be included in the cleantech INDCs. Snowballing comes from both public- and private-sector innovation. Indeed, the vast majority of cleantech innovation currently comes from the private sector. ${ }^{246}$ Countries may vary in a myriad of ways beyond public spending on cleantech that affect their contribution to cleantech innovation, including investments in K-12 and tertiary

246. Id. One example of a recent U.S. effort is the Breakthrough Energy Coalition, in which wealthy individuals committed funds for investment in cleantech with long-run financial payoffs. See Breakthrough Energy Coalition, BREAKTHROUGH ENERGY, http:/www.b-t.energy/coalition/.com (last visited July 28,2017 ) (describing group's mission). 
education, other human capital policies, tax policy (including not just R\&D tax credits but also incentives to invest generally), land use policy (affecting the ease of deploying new renewable energy technologies), cultural norms, and the quality of the patent system. It would be difficult to track how these public policies contribute to cleantech innovation directly, making the total private contribution perhaps the best measure of how well public policy, outside of government funding, is deployed to encourage cleantech innovation. It would be problematic if inclusion of the private sector in reporting and commitments discouraged public-sector spending commitments, but including private-sector reporting could encourage diverse government policies and private-sector initiatives to promote cleantech development and at least paint a more accurate picture of the state of affairs, thereby drawing attention to the importance of private- sector innovation in developing cleantech.

While the Paris Agreement can do more to support and encourage cleantech innovation, the Agreement does take some steps towards addressing innovation spillovers. As we discuss next, the Agreement's creation of a cleantech knowledge sharing platform will induce some clean innovation. We celebrate these actions, even as we call attention to possible improvements.

\section{Knowledge Sharing Platforms}

The Paris Agreement most directly addressed innovation by pledging to strengthen the Technology Mechanism, a knowledge sharing platform that provides technical assistance to developing countries to adopt new climate technologies, expands global access to climate technology knowledge, and spurs collaborations among climate technology experts. As a result, the Paris Agreement continues the international community's long tradition of promoting cleantech development and diffusion through voluntary crossborder collaborations. ${ }^{247}$ Since the 1970 s, for example, the International Energy Agency has administered a series of Technology Collaboration Programs: international research ventures in which member countries coordinate their R\&D efforts and share findings on various emergent energy technologies. ${ }^{248}$ More recently, the United States established the Asia Pacific Partnership on Clean Development and Climate: a voluntary

247. Heleen de Coninck et al., International Technology-Oriented Agreement to Address Climate Change, 36 ENERGY POL'Y 335, 336-37 (2008) (reviewing several prominent climate-related knowledge sharing platforms that pre-dated the Paris Agreement).

248. For a comprehensive overview of these programs, see generally INT'L ENERGY AGENCY, TeCHNOlogy COllaboration PROgRammes: Highlights and OUTCOMES (2016). 
multilateral agreement that funded various joint cleantech demonstration projects. $^{249}$

Innovation snowballing underscores the value of these knowledgesharing, research-coordinating platforms, and suggests value in devoting further resources to strengthen them. All other things equal, it is most efficient to make knowledge freely available, since knowledge is nonrival, meaning a person's use of knowledge does not interfere with another's use of the same knowledge. That said, the acquisition and processing of knowledge involve transaction costs-and there likely are economies of scale in collecting, organizing, and digesting cleantech research. In light of these economies of scale, a private-sector company could gather, process, and disseminate cleantech information. But the company would charge more than the roughly zero cost of providing existing information to the marginal party. (Once collected, organized, and digested, the cost of posting information on a website is roughly zero for the marginal user, making the optimal price zero.) This inefficiency creates space for government intervention in coordinating the collection and dissemination of cleantech information through the creation of international knowledge sharing platforms.

The reasoning laid out thus far applies to any knowledge. Two factors, however, make knowledge sharing platforms particularly valuable for cleantech. First, the absence of optimal global carbon taxes and research subsidies results in an insufficient transfer of cleantech know-how, and innovation snowballing makes the benefits of sharing cleantech knowledge even larger than they typically would be. Knowledge platforms help make up for some of that knowledge-transfer gap by reducing the costs of cleantech dissemination. That is, they function as a second-best policy in the absence of optimal innovation policy.

Second, knowledge sharing platforms help prevent the rise of pollution havens, and therefore mitigate some of the particular concerns raised by innovation snowballing. For the reasons just discussed, well-designed knowledge sharing platforms reduce the transaction costs associated with knowledge diffusion. At the same time, these collaborations likely enhance the absorptive capacity of developing countries, as their scientists expand their cleantech know-how through interactions with scientists from other countries. Both of these effects, in turn, help accelerate the diffusion of cleantech knowledge blocks to areas of the world that have low

249. For an overview of the Partnership, see generally Noriko Fujiwara, The Asia-Pacific Partnership on Clean Development and Climate: What It Is and What It Is Not (Ctr. for European Pol'y Studies, Brief No. 144, 2007). 
cleantech knowledge stocks and therefore are at greatest risk of becoming pollution havens. In other words, by making the cleantech knowledge stocks in the developing world more productive, knowledge sharing platforms mitigate some of the risk that ambitious cleantech policies enacted by innovation leaders (i.e., technology-exporting countries) might cause dirtytech to flee to innovation laggards (i.e., technology-importing countries). ${ }^{250}$

\section{International Intellectual Property Regime}

A number of international institutions seek to regulate or influence patent protection levels across the globe. The Trade-Related Aspects of Intellectual Property Rights Agreement (TRIPS), for instance, requires that all members of the World Trade Organization adopt a minimum set of intellectual property (IP) standards. Meanwhile, the United Nations created the World Intellectual Property Organization (WIPO) to develop international IP rules and, more generally, work to protect IP rights across borders. ${ }^{251}$ And increasingly, bilateral and multilateral trade agreementssuch as the now defunct Trans-Pacific Partnership - have included IP provisions that go beyond the TRIPS minimum. ${ }^{252}$

Much has been written on these efforts, and a comprehensive review of the literature on international IP policy lies beyond the scope of this Article. Nevertheless, as discussed in the domestic policy Part of this paper, innovation snowballing increases the costs of patents (since monopolization of knowledge becomes more problematic) and reduces the benefits of patents (since market valuation is less valuable and much of the benefit of cleantech does not directly accrue to its users). The same reasoning applies internationally.

250. Cross-border collaborations may amplify standard international innovation spillovers, thereby disincentivizing the production of domestic cleantech innovation. But these perverse effects will likely be small because governments do not require private firms to participate in knowledge sharing platforms. Indeed, many of these voluntary ventures do not even involve profit-maximizing companies, and instead involve researchers from government or university laboratories. (For example, the ITER project-an international collaboration that aims to prove the feasibility of fusion technologies-primarily involves publicly-funded scientists. See What is ITER, ITER, https://www.iter.org/proj/inafewlines (last visited July 28, 2017).) As a result, knowledge sharing platforms should have little to no impact on the private returns to R\&D-and therefore little to no impact on private-sector investment levels in cleantech R\&D.

251. Inside WIPO, WORLD INTELL. PROP. ORG., http://www.wipo.int/about-wipo/en/ (last visited Jun. 15, 2017).

252. For a concise review of these efforts, see Carlos A. Primo Braga, TPP: The New Gold Standard for Intellectual Property Protection in Trade Agreements?, HUFFINGTON POST: THE BLOG (Mar. 24, 2016, 10:35 PM), http://www.huffingtonpost.com/eastwest-center/tpp-the-new-goldstandard_b_9544428.html. 
As a result, innovation snowballing increases the value of using tools other than patents to encourage global cleantech innovation. One possibility is establishing a global fund to purchase cleantech IP and place it in the public domain, as some have suggested. ${ }^{253}$ Such a move would preserve the positive incentives to innovate while encouraging innovation snowballing. Alternatively, a global climate prize or research grant fund could be established. In any case, innovation snowballing strengthens the argument of using public funding rather than strengthening international IP rules in the context of cleantech.

\section{POLITICAL ECONOMY}

Before concluding, we pause to consider whether our recommendation of refocusing some of the political effort to reduce greenhouse gas emissions on innovation aligns with political economy considerations. Political economy factors largely reinforce the value of making innovation policy an integral part of climate policy. First, unlike carbon taxes, innovation commits future governments to long-term reductions in emissions that cannot easily be revoked: while a tax can be rolled back, it is difficult to "unlearn" innovation. Second, cleantech innovation policies can boost the chances that a carbon tax will be adopted, both because innovation lowers the costs of complying with a carbon tax and because innovation policies foster the growth of cleantech constituencies who will lobby for a carbon tax. Indeed, empirical research shows that subsidies for cleantech generally precede the adoption of carbon taxes. In addition to these political-economy benefits, there are good reasons to believe that increased cleantech spending would be popular and might be more politically feasible than carbon taxes. We discuss each of these points in turn.

One political-economy benefit of innovation is that it cannot be rolled back by future governments. If public R\&D spending, for example, leads to a technological breakthrough in battery storage, the breakthrough will remain even if federal funding is later discontinued. Similarly, the privatesector benefits of participating in publicly-funded R\&D ventures-

253. The proposal to create a global fund for climate-related IP is not new. See, e.g., Reichman et al., supra note 147 , at 24 (suggesting that UNFCCC and WIPO establish a joint fund to "buy out" key climate-focused IP and then "make the innovation available to others, especially developing countries"); Richard G. Newell, International Climate Technology Strategies, in POST-KYOTO International Climate Policy 403, 432 (Joseph E. Aldy \& Robert N. Stavins eds., 2010) (suggesting that the World Bank establishes a "Strategic Technology Fund" that, among other things, would purchase climate-related intellectual property rights and place them in the public domain). 
namely, new knowledge and new inventions-do not obviously depend on future public commitments to R\&D. True, private companies may decide not to engage in a research project that depends heavily on future public funding, especially if they believe that these promised taxpayer dollars will not ultimately materialize. However, governments cannot reclaim public dollars that have already been spent on clean energy $R \& D$, nor can they erase the new knowledge, discoveries, or inventions generated as a result of this funding. Thus, from the perspective of a private firm, the benefits of participating in an innovation subsidy program are durable and largely independent of government commitments to future action.

In contrast, carbon pricing faces a notable credibility problem, since the continuing existence of such a regime depends on the behavior of future governments and future voters. ${ }^{254}$ Today's pledges to reduce emissions can always be revoked by tomorrow's politicians. ${ }^{255}$ This concern factors into both international and domestic climate policy: policymakers wish to bind other countries (in the international case) and future political leaders (in the domestic case) to emission-reduction commitments made today. But companies investing in cleantech capital and $\mathrm{R} \& \mathrm{D}$ in response to a pollution tax run the risk that future politicians will renege on their climate promises, thereby saddling firms with sunk costs that they originally expected to recover through a non-zero price on carbon. ${ }^{256}$ Thus, while the benefits of an innovation subsidy are certain and secure, the benefits of investing in cleantech innovation under a carbon pricing scheme hinge on politicians' willpower to follow through on their policy commitments. ${ }^{257}$

Historical experience suggests that firms have good reason to be wary of political promises on energy policy. Australia, for example, reversed the nation's carbon tax following a transfer of power between political parties, ${ }^{258}$ thereby upending an earlier promise to price carbon until at least

254. For an extensive survey of this topic, see Steffen Brunner et al., Credible Commitment in Carbon Policy, 12 Climate POL'y 255 (2012).

255. Indeed, some have argued that it may be welfare maximizing for governments to renege on their carbon commitments after firms have sunk investments into emission-mitigating infrastructure and technologies. See, e.g., Lisandro Abrego \& Carlo Perroni, Investment Subsidies and TimeConsistent Environmental Policy, 54 OXFORD ECON. PAPERS 617, 617-18 (2002).

256. Dieter Helm et al, Credible Carbon Policy, 19 OXFORD REV. ECON. POL'Y 438, 439 (2003) (arguing that the "profitability of such carbon-reducing investments is highly sensitive to carbon policy").

257. Lion Hirth, Governance Under Time Inconsistency and Limited Credibility: What Can Be Learned from Monetary Policy for Climate Policy? (Univ. of Tübingen \& Potsdam-Inst. for Climate Impact Research, Working Paper, 2009) (arguing that policies that establish property rights, like research subsidies, are more credible than carbon prices).

258. Michelle Innis, Environmentalists Denounce Repeal of Australia's Carbon Tax, N.Y. TIMES (July 17, 2014), https://www.nytimes.com/2014/07/18/world/asia/environmentalists-decry-repeal-ofaustralias-carbon-tax.html. 
$2050 .{ }^{259}$ Likewise, several countries have reduced their gasoline taxes in response to rising energy costs, suggesting that carbon taxes might also be vulnerable to fluctuations in electricity prices. ${ }^{260}$ Case in point: British Columbia's carbon tax became a target for political opponents following a sudden rise in gasoline prices. ${ }^{261}$ The surprise election of President Donald Trump further highlights the perils of relying on government pricing schemes. Firms that began preparing for the rollout of President Obama's Clean Power Plan-a regulation that would have required the power sector to reduce carbon emissions by about a third below 2005 levels ${ }^{262}$-may now find themselves at a competitive disadvantage, as President Trump has promised to dismantle the Plan. ${ }^{263}$

In addition to commitment benefits, innovation boosts the chances of a carbon tax being adopted in two ways: by reducing its compliance costs and by building a constituency for the policy. In particular, innovation can lower the compliance costs of future carbon emission regulations by making clean energy cheaper. In the past, governments have balked at enforcing regulatory standards deemed too costly by industry. ${ }^{264}$ For example, in response to industry pushback during the 1990s, California progressively weakened a zero-emission vehicle mandate that required car manufacturers to sell a certain percentage of electric automobiles. ${ }^{265}$ Today's investments in innovation, however, promise to reduce tomorrow's clean energy costs, making future carbon prices less burdensome to industry and therefore more palatable to politicians.

Second, and relatedly, cleantech subsidies can help develop and expand

259. Int'l Ctr. for Trade and Sustainable Dev., Australia Repeals Carbon Tax, BrIDGES WKLY., July 17, 2014, at 7, available at https:/www.ictsd.org/sites/default/files/review/bridgesweeklyl826.pdf.

260. Hirth, supra note 257 (describing how government-induced increases in gasoline prices created huge political backlash in Venezuela and Germany).

261. For a fascinating analysis of the political economy underlying British Columbia's carbon tax, see Kathryn Harrison, The Political Economy of British Columbia's Carbon Tax, (Org. for Econ. Coop. and Dev., Env't Working Paper No. 63, 2013).

262. Envtl. Protection agency, The Clean Power Plan: Overview of the Clean Power PLAN (2015), available at https:/19january2017snapshot.epa.gov/sites/production/files/2015 08/documents/fs-cpp-overview.pdf.

263. For one perspective on the effects of the Supreme Court's stay of the Clean Power Plan on the business community, see Thomas Covert, The Clean Power Plan 'Stay' Could Slow Clean Energy Progress, FORBES (Apr. 25, 2016 9:30 AM), http://www.forbes.com/sites/ucenergy/2016/04/25/theclean-power-plan-stay-could-slow-clean-energy-progress/ - 133da33d18ea.

264. See, e.g., Stewart, supra note 9, at 1302-03 (describing the repeated postponement of 1970 air emission standards for new automobiles).

265. See Gary E. Marchant, Complexity and Anticipatory Socio-Behavioral Assessment of Government Attempts to Induce Clean Technologies, 61 UCLA L. REV 1858, 1863-69 (2014) (describing the history of the California Zero Emission Vehicle program). 
cleantech constituencies. It is in the interest of these cleantech groups to lobby for stronger climate change policies, including carbon pricing regulations. ${ }^{266}$ In this way, cleantech innovation policies can catalyze a positive feedback loop that leads to stricter and stricter climate regulations. Notably, some economists and political scientists argue that cleantech subsidies are more effective than carbon pricing at stimulating the growth of cleantech coalitions. ${ }^{267}$ This hypothesis builds on a long line of political economy research suggesting that interest groups are strongest when they consist of a small number of members who seek to either hold onto a large benefit or avoid a sizeable cost. ${ }^{268}$ When regulatory impacts are big and concentrated, the payoffs to political action are more likely to justify the high upfront costs of lobbying, while the potential for free-riding is minimized since smaller groups can more easily monitor their members. In contrast, when regulatory costs or benefits are small and diffuse, collective action problems loom large and the cost-benefit calculus for lobbying weighs in favor of political inaction.

As a result, a strong carbon tax is less likely to pass in the absence of a powerful cleantech coalition, since a carbon price imposes concentrated costs on an entrenched fossil fuel industry while generating diffuse benefits for the public at large. ${ }^{269}$ And many researchers agree that a robust cleantech coalition cannot be expected to form around a modest carbon tax, as such a policy will not meaningfully redirect innovation and capital towards emerging or established cleantech. ${ }^{270}$ In contrast, government innovation subsidies can confer concentrated benefits to cleantech firms, while imposing indirect and dispersed costs on fossil fuel companies and the public at large. The political economy calculus is therefore reversed: innovation subsidies give cleantech firms a strong incentive to organize politically, while mitigating the risks of a dirtytech political response. At the same time, cleantech subsidies help cleantech industries grow and, as a

266. For a concise overview of this argument, see Meckling et al., supra note 26.

267. Id. at 1170; Jonas Meckling \& Gernot Wagner, Policy Sequencing Toward Decarbonization (2016) (unpublished) (on file with author).

268. For the seminal work on this issue, see generally MANCUR OLSON, THE LOGIC OF COLlective ACTION (1965).

269. Meckling \& Wagner, supra note 267 (explaining that carbon pricing is often met with strong economic opposition because the benefits of such a policy are diffuse while the costs are concentrated).

270. Indeed, carbon pricing's potential to stimulate green innovation may be undermined by the credibility problems described above. See Newell, supra note 253, at 417-418 (stressing that the longterm credibility of a carbon tax is critical to its effectiveness at inducing cleantech innovation). Thus, in light of the uncertainty surrounding greenhouse gas emission regimes in general, even strong commitments to reduce emissions might not be enough to induce meaningful investments in cleantech and build strong green industry coalitions. 
result, become more politically powerful and more capable of persuading government to enact stricter climate policies, including a tax on carbon. ${ }^{271}$ In theory then, public R\&D spending, feed-in tariffs (in which governments guarantee a certain payment to energy producers), renewable portfolio standards, and other so-called cleantech "industrial" policies offer a politically feasible mechanism for mobilizing and expanding the cleantech coalition. ${ }^{272}$

And indeed, in practice, cleantech industrial policies predate the vast majority of today's existing carbon pricing regimes. According to a recent study by Jonas Meckling and Gernot Wagner, at least 132 countries and subnational jurisdictions installed either a feed-in tariff or a renewable portfolio standard for their power sector by $2014 .{ }^{273}$ During the same time period, however, only fifty-two carbon tax or cap-and-trade systems were implemented (or scheduled for enactment)-and most of these imposed relatively weak prices on carbon emissions. ${ }^{274}$ The authors calculate that nearly two-thirds of carbon pricing schemes in the power sector benefited from an earlier feed-in tariff or renewable portfolio standard. They find a similar policy progression in the transportation sector, where twelve governments have adopted a pricing system for transport emissions, as compared to ninety-nine jurisdictions that have adopted either a biofuel mandate or electric vehicle incentives. While this work documents correlation (not causation) and primarily focuses on deployment subsidies (rather than direct $\mathrm{R} \& \mathrm{D}$ subsidies), it suggests that innovation policies can serve as stepping stones to subsequent carbon taxes. ${ }^{275}$

In the U.S. context, the political advantages of innovation policies over carbon pricing seem particularly pronounced. While several states and localities have considered a tax on carbon, only a few have enacted one. ${ }^{276}$ At the national level, efforts to legislate a national price on carbon have repeatedly failed, the most notorious example being the Waxman-Markey cap-and-trade bill that died in the Senate after passing the House in

271. Meckling \& Wagner, supra note 267 (arguing that "[t]argeted industrial and innovation policies, such as direct renewable energy subsidies, more easily mobilize political support by providing benefits to economic winners").

272. Llewelyn Hughes \& Johannes Urpelainen, Interests, Institutions, and Climate Policy: Explaining the Choice of Policy Instruments for the Energy Sector, 54 ENVTL. SCI. \& POL'Y 52, 53-54 (2015) (explaining that, while carbon pricing may be more effective than industrial policies at greenhouse gas mitigation, it is also more politically expensive).

273. Meckling \& Wagner, supra note 267.

274. Id.

275. Id.

276. For a list of state and local carbon tax initiatives, see generally States, CARBON TAX CTR., http://www.carbontax.org/states/ (last visited July 28, 2017). 
$2009 .{ }^{277}$ Indeed, enacting any increase in federal taxes-much less one related to a politically charged issue like climate change-seems improbable in today's highly polarized Congress. ${ }^{278}$ Nor does it appear that Republicans, who have staunchly opposed carbon pricing in recent years, will change their tune in the near future. Case in point: the 2016 Republican Platform unequivocally opposes "any carbon tax."279 The election of President Donald Trump has therefore likely extinguished any hope of establishing a national carbon tax in the next four years. ${ }^{280}$

Cleantech innovation spending, in contrast, might offer an opportunity for bipartisan consensus. To begin, opinion polls consistently find broad public support for government spending on scientific research and development. ${ }^{281}$ And the polls that have asked specifically about energy R\&D find similarly positive responses. For example, in one 2011 national poll, sixty-eight percent of participants supported "increasing federal funding for research on wind, solar and hydrogen energy technology." 282 As well, a number of Republican lawmakers have recently expressed support for government energy R\&D. ${ }^{283}$ For example, the Advanced Research Project Agency-Energy (often called "ARPA-E")-which conducts research primarily in low-carbon energy technologies-has

277. Carl Hulse \& David M. Herszenhorn, Democrats Call off Effort for Climate Bill in Senate, N.Y. Times, July 23, 2010 (reporting on the failure of the Waxman-Markey bill).

278. Timothy Cama, GOP to Rule Out Carbon Tax, THE Hill (June 8, 2016, 6:00 AM), $\mathrm{http} / /$ thehill.com/policy/energy-environment/282574-gop-to-rule-out-carbon-tax (reporting that "House Republicans this week will vote to condemn taxes on carbon dioxide emissions, slamming the door on an idea that some members of their party have flirted with in the past").

279. William A. Galston, Democrats and Republicans Disagree: Carbon Taxes, BrookINGs: FiXGov (July. 24, 2016), https://www.brookings.edu/blog/fixgov/2016/07/24/democrats-andrepublicans-disagree-carbon-taxes/ (comparing the Democrats' and Republicans' platforms on climate change).

280. Interestingly, even Democratic Presidential nominee, Hillary Clinton, hesitated to endorse carbon pricing. Leaked internal memos showed that the Clinton campaign viewed carbon taxes as politically toxic. David Roberts, WikiLeaks Reveals that Clinton Considered a Carbon Tax-But Her Campaign Missed Something, Vox (Oct. 24, 2016, 8:00 AM), https:/www.vox.com/energy-andenvironment/2016/10/24/13356486/clinton-campaign-carbon-tax (quoting a leaked email from a Clinton staffer that stated, "We have done extensive polling on a carbon tax. It all sucks.").

281. Cary Funk \& Lee Rainie, Pew Research CTR., Public and ScIEntists' Views on SCIENCE AND SOCIETY 1 (2015) (noting that, "despite considerable dispute about the role of government in other realms, there is broad public support for government investment in scientific research"); Roberts, supra note 280 (noting that many polls show widespread support for R\&D spending).

282. Partisan Divide over Alternative Energy Widens, PEW RESEARCH CTR. (Nov. 18, 2011), http:/www.people-press.org/2011/11/10/partisan-divide-over-alternative-energy-widens/ (last visited June 26,2017 ) (reporting the results of a survey by Pew Research Center conducted November 3-6, 2011).

283. Jean Chemnick, Clean Energy Research Money Has a Bipartisan Following, but Not Paris Link, E\&E NEwS (Dec. 1, 2015), https://www.eenews.net/stories/1060028725 (last visited July 28, 2017) (observing that some GOP lawmakers have begun to "call for a response to warming that embraces entrepreneurship rather than regulation"). 
enjoyed strong bipartisan support. ${ }^{284}$ In fact, the Republican-controlled Congress has increased the project's budget by more than half over the past five years. ${ }^{285}$ None of this is to say that increased spending on cleantech R\&D would not face headwinds. But there are hopeful signs about its feasibility and about the long-term political-economy benefits of adopting such policies. ${ }^{286}$

\section{CONCLUSION}

The conventional thinking on innovation in environmental law is to impose a pollution tax-and then let the market and general innovation policy do the rest. The government, in other words, should not be in the business of directly encouraging cleantech innovation. This Article unsettles that conventional view, arguing that a policy of carbon taxation plus general innovation policy may be a far from optimal way of addressing the climate crisis. Rather, in light of innovation snowballing, the government should encourage cleantech over dirtytech and some forms of cleantech over other types of cleantech. This argument suggests that environmental policy should return to its early goal of directly encouraging environmentally friendly technology, though not through command-and-control regulations but rather through targeted innovation policies.

Innovation snowballing also has several important implications for the design of those innovation policies. For example, it increases the value of government-set innovation tools, like prizes and grants, while decreasing the usefulness of market-based instruments, like patents and R\&D tax credits. It also alters the cost-benefit analysis of other climate-related programs. For instance, deployment subsidies-such as tax credits for installing solar panels - look better in light of innovation snowballing, since these subsidies help close the cleantech-dirtytech innovation gap.

284. Rob Cowin, How To Push Climate and Energy Funding Through a Republican Congress, UNION OF CONCERNED SCIENTISTS (Feb. 12, 2016, 3:17 PM), http://blog.ucsusa.org/rob-cowin/howto-push-climate-and-energy-funding-through-a-republican-congress (describing relatively strong Republican support for the program).

285. Id.

286. And if national-level policies prove unavailable, then a consortium of states could step in. For example, California Governor Jerry Brown recently promised that his state would begin collecting climate science data if President Trump terminates NASA's global warming work, as he has threatened to do. States could display similar leadership in cleantech innovation. See John Myers, 'We're Ready to Fight.' Gov. Jerry Brown Unloads on Trump and Climate Issues, L.A. TIMES (Dec. 14, 2016, 10:29 AM), http://www.latimes.com/politics/essential/la-pol-ca-essential-politics-updateswe-re-ready-to-fight-says-gov-jerry-1481739836-htmlstory.html. 
Similar implications follow for the international climate regime. In particular, future climate accords should consider encouraging emissions reductions through innovation rather than the adoption of existing technology or cuts in production.

This Article underscores the importance of dynamics in making climate policy - that is, of thinking not only about how a given policy will lead to short- or medium-run changes in emissions, but also about how policies will lead to long-term changes in technology equilibria. While earlier emissions reductions are, all else equal, more desirable, this Article gives important reasons for focusing in the near term on pushing cleantech over the tipping point of being cheaper than dirtytech, after which cleantech innovation will take off without additional government subsidization. This lesson of heavily investing in cleantech R\&D now holds as a matter of politics as well: an innovation policy that specifically encourages cleantech has strong political economy benefits, since innovation cannot be repealed and since cleantech policies foster constituencies that will demand more robust climate policies, including stricter carbon taxes.

Finally, the Article shows how innovation snowballing can affect innovation policy beyond the environmental sphere. It articulates two criteria for when these spillovers justify government intervention, namely: (1) there is a policy reason to redirect innovation away from one technology and toward another, and (2) the competing technologies are sufficiently substitutable. For example, for those concerned about income inequality, it might be efficient to redirect innovation from capitalaugmenting technologies toward labor-augmenting technologies-e.g., from prescription drugs (which use a lot of capital and little low-income labor) to tools that make home healthcare aides more productive (thereby benefitting aides, who are predominately low-income workers). But additional research will be required to determine where innovation snowballing merits government intervention. For now, innovation snowballing gives scholars and policymakers good reason to make innovation policy a core part of climate policy. By deploying innovation policy tools alongside traditional pollution regulations and carbon taxes, local, state, national, and world leaders can build an efficient climate policy that reduces emissions at a low and politically feasible cost. 